\title{
Implementing incentive-based HIV interventions in Zambia: The COMPACT model
}

\author{
Sam Kalibala \\ Population Council \\ Waimar Tun \\ Population Council \\ Chabu Kangale \\ Population Council \\ Jill Keesbury \\ Ray Handema
}

See next page for additional authors

Follow this and additional works at: https://knowledgecommons.popcouncil.org/departments_sbsr-hiv

Part of the Health Policy Commons, Immune System Diseases Commons, International Public Health Commons, Medicine and Health Commons, Public Health Education and Promotion Commons, and the Virus Diseases Commons

How does access to this work benefit you? Let us know!

\section{Recommended Citation}

Kalibala, Sam, Waimar Tun, Chabu Kangale, Jill Keesbury, Ray Handema, and Mwaka Monze. 2013.

"Implementing incentive-based HIV interventions in Zambia: The COMPACT model," Baseline evaluation report. Lusaka: Population Council. 


\section{Authors}

Sam Kalibala, Waimar Tun, Chabu Kangale, Jill Keesbury, Ray Handema, and Mwaka Monze 


\section{IMPLEMENTING INCENTIVE-BASED HIV INTERVENTIONS IN ZAMBIA: \\ THE COMPACT MODEL}

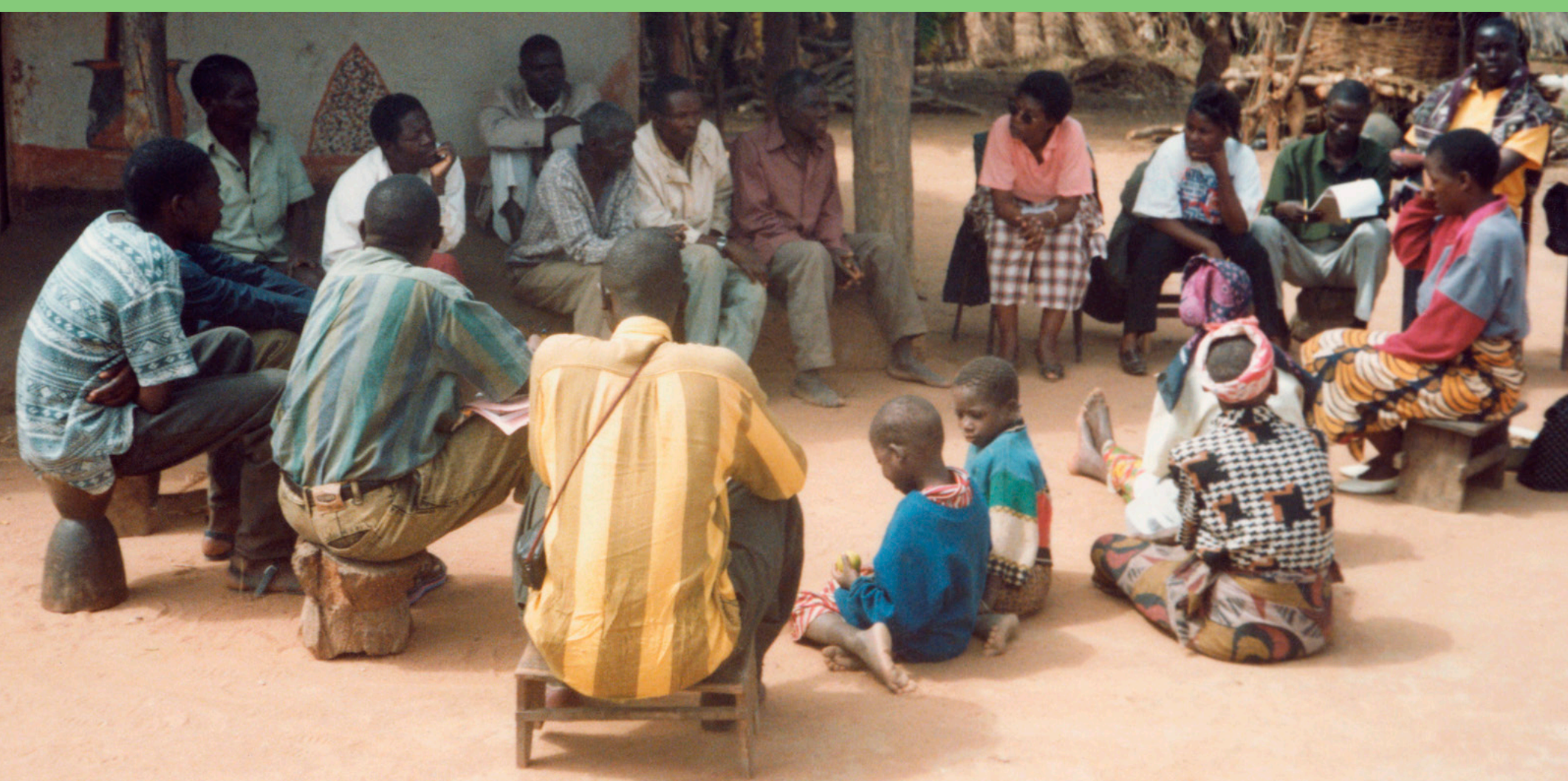





\section{IMPLEMENTING INCENTIVE-BASED HIV INTERVENTIONS IN ZAMBIA: THE COMPACT MODEL}

BASELINE EVALUATION REPORT

Principal Investigators

Samuel Kalibala ${ }^{1}$

Waimar Tun ${ }^{1}$

Co-Investigators

Chabu Kangale ${ }^{2}$

Jill Keesbury ${ }^{3}$

For Sero-survey only

Ray Handema ${ }^{4}$

Mwaka Monze ${ }^{5}$

${ }^{1}$ Population Council, Washington, DC, USA

${ }^{2}$ Population Council, Lusaka, Zambia

${ }^{3}$ Path International, Washington, DC, USA

${ }^{4}$ Tropical Diseases Research Center (TDRC), Ndola, Zambia

${ }^{5}$ Virology Laboratory, Lusaka, Zambia
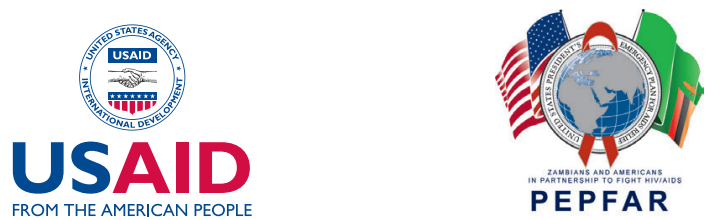

(P) Population Council 


\section{ACKNOWLEDGEMENTS}

The Community Mobilization for Preventive Action (COMPACT) acknowledges the efforts of all those who contributed to the successful conduct of the baseline survey and report. In particular, COMPACT appreciates the efforts of Principal Investigators Drs. Sam Kalibala and Jill Keesbury for initiating this evaluation, Dr. Waimar Tun for leading the analysis and writing of this report and Mr. Chabu Kangale, Chief of Party for managing the project.

Special thanks to Benjamin Kayungwa for programming the handheld computers for data collection, Kumbutso Dzekedzeke for his input regarding mapping activities and selection of sampling units, the Tropical Diseases Research Centre (TDRC) and the Virology Laboratory of the University Teaching Hospital, in particular Dr. Ray Handema and Dr. Mwaka Monze, respectively, for ensuring successful specimen collection, HIV testing, and storage of the samples.

COMPACT also acknowledges the efforts of Maurice Pengele for managing the mapping exercise, Meredith Sheehy for assisting with the writing of the report, Morris Kosamu and William Tembo for supervising data collection in the field and ensuring data transmission, and Dr. Jessica Price for her review and assistance with the interpretation of results.

The contributions of Patrick Chilumba and Mutale Mwaba of Crystal Consulting, the organization contracted to conduct the survey, and the data collectors are appreciated.

We are also grateful to Dr. Kakungu Simpungwe, District Health Officer for Ndola District, and Dr. Charles Msiska, District Health Officer for Chongwe District, for their support during the data collection process. We thank all the respondents who gave their time to participate in the study.

In addition, we gratefully acknowledge the United States Agency for International Development (USAID) for supporting the project.

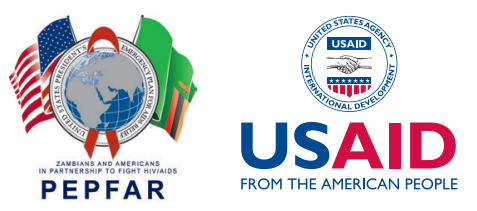

This report is made possible by the generous support of the American people through USAID. The contents of this are the sole responsibility of the COMPACT Project and Population Council and do not necessarily reflect the views of USAID or the United States Government.

\section{QP Population Council}

The Population Council confronts critical health and development issues-from stopping the spread of HIV to improving reproductive health and ensuring that young people lead full and productive lives. Through biomedical, social science and public health research in about 50 countries, the Council works with our partners to deliver solutions that lead to more effective policies, programs, and technologies to improve lives worldwide. Established in 1952 and headquartered in New York, the Council is a nongovernmental, nonprofit organization with an international board of trustees.

www.popcouncil.org

(C) 2013 The Population Council, Inc.

Front cover photo: (c) 2002 Elizabeth Serlemitsos/CCP, Courtesy of Photoshare

Suggested citation: Kalibala, Sam, Waimar Tun, Chabu Kangale, Jill Keesbury, Ray Handema, and Mwaka Monze. 2013. “Implementing incentive-based HIV interventions in Zambia: the COMPACT model," Baseline evaluation Report. Lusaka: Population Council.

Any part of this publication may be photocopied without permission from the publisher provided that copies are distributed without charge and that full source citation is provided. The Population Council would appreciate receiving a copy of any materials in which the text is used. 


\section{TABLE OF CONTENTS}

\section{Acronyms}

$\begin{array}{ll}\text { Executive Summary } & 1\end{array}$

Background and Rationale $\quad 5$

HIV/AIDS and the response in Zambia $r$

$\begin{array}{ll}\text { COMPACT overview } & 6\end{array}$

The intervention: community compacts and incentives for behavior change 6

Monitoring and evaluation: measuring progress toward benchmarks 8

Study Objectives and Research Questions $\quad 9$

\begin{tabular}{l} 
Overall objective \\
\hline Specific objectives
\end{tabular}

Specific objectives $r$

$\begin{array}{lr}\text { Baseline objectives } & 9\end{array}$

$\begin{array}{ll}\text { Methodology } & 10\end{array}$

$\begin{array}{lr}\text { Study design } & 10\end{array}$

$\begin{array}{lr}\text { Study population } & 10\end{array}$

Local consultations $r$

$\begin{array}{lr}\text { Ethical approvals } & 11\end{array}$

$\begin{array}{lr}\text { Survey questionnaires } & 11\end{array}$

$\begin{array}{lr}\text { Sample size and sampling } & 11\end{array}$

$\begin{array}{lr}\text { Hiv testing } & 12\end{array}$

$\begin{array}{lr}\text { Analysis } & 12\end{array}$

$\begin{array}{lr}\text { Limitations } & 13\end{array}$

$\begin{array}{ll}\text { Results } & 14\end{array}$

$\begin{array}{lr}\text { Socio-demographic characteristics } & 14\end{array}$

$\begin{array}{lr}\text { Knowledge about HIV and AIDS } & 14\end{array}$

$\begin{array}{lr}\text { Hiv testing } & 15\end{array}$

$\begin{array}{lr}\text { Sexual behaviors } & 20\end{array}$

$\begin{array}{lr}\text { Gender relations } & 23\end{array}$

Women experiencing physical and sexual violence $\quad 24$

Attitudes toward people living with AIDS $\quad 29$

$\begin{array}{lr}\text { Contraception and pregnancy } & 30\end{array}$

$\begin{array}{ll}\text { Antenatal care } & 35\end{array}$

$\begin{array}{lr}\text { Alcohol use } & 35\end{array}$

$\begin{array}{lr}\text { HIV seroprevalence } & 38\end{array}$

$\begin{array}{lr}\text { Focus on adolescent girls } & 42\end{array}$

$\begin{array}{ll}\text { Discussion } & 46\end{array}$

Appendix 1: Examples of Evidence-Based Interventions Utilized by COMPACT 51

Appendix 2: Illustrative Benchmarks for a Community Compact 52

Appendix 3: Socio-demographic Characteristics by Community and Sex 53

Appendix 4: Knowledge about HIV and AIDS $\quad 54$

Appendix 5: HIV Testing $\quad 55$

$\begin{array}{ll}\text { References } & 56\end{array}$ 


\section{ACRONYMS}

\begin{tabular}{|c|c|}
\hline $\mathrm{ABC}$ & Abstinence, Be Faithful, Condom Use \\
\hline ANC & Antenatal Care \\
\hline ARV & Antiretrovirals \\
\hline CAGE & Cut-down, Annoyed, Guilty, Eye-opener \\
\hline CBO & Community-Based Organization \\
\hline СОMPACT & Community Mobilization for $\underline{\text { Preventive Action }}$ \\
\hline CCDC & Community Compact Development Committee \\
\hline cso & Central Statistics Office \\
\hline DATF & District AIDS Task Force \\
\hline DHMT & District Health Management Team \\
\hline GBV & Gender-Based Violence \\
\hline GEM & Gender-Equitable Men \\
\hline GRZ & Government of the Republic of Zambia \\
\hline HCT & HIV Counseling and Testing \\
\hline HIV & Human Immunodeficiency Virus \\
\hline IMAGES & International Men and Gender Equality Survey \\
\hline KAP & Knowledge, Attitudes, and Practices \\
\hline MCP & Multiple Concurrent Partners \\
\hline $\mathrm{MOH}$ & Ministry of Health \\
\hline MOT & Modes of Transmission \\
\hline NAC & National HIV/AIDS/STI/TB Council \\
\hline $\mathrm{NHC}$ & Neighborhood Health Committee \\
\hline OVC & Orphans and Vulnerable Children \\
\hline $\mathrm{PCl}$ & Project Concern International \\
\hline PDA & Personal Digital Assistant \\
\hline PEPFAR & President's Emergency Plan for AIDS Relief \\
\hline PLHA & People Living with HIV/AIDS \\
\hline SEA & Standard Enumeration Area \\
\hline STI & Sexually Transmitted Infection \\
\hline USAID & United States Agency for International Development \\
\hline VCT & Voluntary Counseling and Testing \\
\hline WHO & World Health Organization \\
\hline ZDHS & Zambia Demographic and Health Survey \\
\hline
\end{tabular}




\section{EXECUTIVE SUMMARY}

In July 2010, the Population Council received a cooperative agreement from USAID to implement the Community Mobilization for Preventive Action (COMPACT) project. COMPACT aims to develop and determine the feasibility of "community compacts" as an innovative approach to prevent HIV in Zambian communities. Broadly, community compacts are agreements between service providers and recipient communities that are intended to increase the effectiveness of services by promoting community ownership. COMPACT is working directly with six communities: Chongwe, Nangwenya, and Chinyunyu in Chongwe District and Kawama, Kaniki, and Mushili in Ndola district to design and implement some of the first compacts in Zambia.

The aim is to mobilize the communities in efforts to prevent HIV through a capacity building process that enables communities to identify HIV prevention targets, develop interventions to achieve those targets, and measure the results. We are complementing the community compacts with a system of incentives designed to reward communities for reaching their targets. The rewards are not given to individuals; they are community goods that are intended to further the goals of each intervention and motivate the community. They are bestowed at public events to celebrate achievements and reinforce community ownership of and participation in the compact.

In four communities, Chongwe, Chinyunyu, Kawama, and Kaniki, the Population Council carried out a baseline study to establish levels of HIV prevalence and knowledge, attitudes, and practices (KAP) related to HIV before the roll-out of COMPACT in communities. The Population Council conducted a sero-behavioral survey between October and December of 2011. Data collected during the baseline will be used to compare with midline and endline data that will be collected in November to December of 2012 and November to December 2013, respectively.

The baseline study largely followed the methodology used for the 2007 Zambia Demographic and Health Survey (ZDHS). A set of KAP questions was administered to respondents, and from the same respondents a blood sample was drawn to test for HIV in order to establish baseline HIV prevalence. Just like in the ZDHS, HIV testing was anonymous since HIV testing took place at the central labs (Virology Laboratory at the University Teaching Hospital in Lusaka and the Tropical Diseases Research Centre in Ndola).

Participants were selected randomly from randomly selected households within randomly selected Standard Enumeration Areas within the four communities. A total of 3,293 participants, comprising 1,496 men age 15 to 59 and 1,797 women age 15 to 49, took part in the study.

\section{Key Findings}

\section{Knowledge about HIV and AIDS}

The majority of both male and female respondents had heard of HIV and AIDS (over 95 percent); there were no differences across communities. Overall, knowledge about how HIV can be prevented was also high, with approximately 80 percent of respondents knowing each of the three HIV prevention methods: abstaining, having only one uninfected partner, and using condoms consistently. However, comprehensive knowledge was low, at 50 percent in males and 52 percent in females, though the overall comprehensive knowledge results from this baseline survey appear to be better than the results from the 2007 ZDHS. Comprehensive knowledge was defined as i) 
knowing that both condom use and limiting sex partners to one uninfected partner are HIV prevention methods; ii) awareness that a healthy-looking person can have HIV; and iii) rejecting the two most common local misconceptions, that HIV and AIDS can be transmitted through supernatural means or through mosquito bites.

\section{HIV testing}

There were more women who tested for HIV than men (72 percent versus 43 percent). This is largely because women access HIV testing services through antenatal care. Approximately 23 percent of women that were tested for HIV were tested through antenatal care. Of women who attended antenatal care, 83 percent also received HIV testing services. This may explain the disparity between men and women that had tested for HIV in the four communities.

There is a need to increase actual HIV testing, particularly among men. For men, there is no equivalent to routine opt-out testing within ANC. As such, communities should consider conducting male-focused information and testing campaigns. Further, testing services should be evaluated to determine whether they are meeting the unique needs of men for HIV testing and sexual health. Male-centered/sensitive counseling and testing promotional campaigns should be considered.

\section{HIV seroprevalence}

The overall HIV seroprevalence was 14 percent. While the prevalence did not vary significantly across communities, there was a significant difference by sex. Women were significantly more likely to be HIV infected than men (17 percent versus 10 percent; $p<0.05$ ). The difference in HIV seroprevalence is particularly striking among 20-24 year olds; young women are six times more likely to be HIV infected than young men (12 percen versus 2 percent; $p<0.05)$. This may reflect earlier sexual debut by girls, often with partners who on average are at least five years older and may already have had multiple sexual partners.

Those who were married/cohabiting (17 percent) or divorced/separated (34 percent) were significantly more likely to be HIV infected compared to those never married (6 percent). There was no difference in HIV seroprevalence by education level.

\section{Sexual behaviors}

Approximately two-thirds of respondents were sexually active in the past 12 months. Among those who had sex in the last 12 months, men were more than twice as likely as women to have had sex with a non-regular partner (a non-marital, non-cohabiting partner) (43 percent versus 18 percent). The same pattern was found in all communities. Condom use with their last non-regular sex partner was low for both men and women, and it was significantly lower for men than for women (8 percent versus 22 percent; $p<0.05$ ).

Among those who had sex in the last 12 months, 25 percent of men and 8 percent of females had more than one sex partner. Prevalence of multiple sex partners was significantly lower among females than males in all communities. Males in Kawama had the highest prevalence of multiple partners (37 percent). The prevalence of multiple partnerships did not vary for females across communities. 
Programs must be designed to meet the sexual health needs of men, with messaging specifically tailored to high-risk men.

\section{Early sexual debut}

Among youth aged 15-24 years, 15 percent of males and 10 percent of females engaged in early sexual debut (before the age of 15) $(p<0.05)$.

\section{Gender relations}

The Gender-Equitable Men (GEM) Scale was used to measure traditional attitudes toward gender norms related to HIV and AIDS, pregnancy prevention, violence, sexual relationships, domestic chores and caregiving, and homosexuality (Pulerwitz and Barker 2008). Slightly over one-third of all respondents (37 percent) scored in the lowest tertile of the GEM scale, indicating that 37 percent supported inequitable gender norms. This varied greatly across the communities with Kaniki having the highest proportion of respondents supporting inequitable norms (50 percent) and Chongwe having the lowest proportion supporting inequitable norms $(25$ percent) $(p<0.05)$. In all communities except Kawama, men and women were equally likely to support inequitable norms.

Gender inequitable attitudes and risky behaviors are intertwined and must be addressed together in any HIV prevention program. Behavior change programs improving gender norms have been shown to improve HIV and STI risk outcomes (Pulerwitz et al. 2006; Pulerwitz et al. 2010).

\section{Gender violence}

Overall, a high proportion of women had experienced physical abuse in their lifetime (29 percent) with 5 percent having experienced abuse in the past 12 months. A small proportion of women sought help or services to stop the perpetrators of abuse. Among those abused, only 18 percent sought help; females in Kawama (18 percent) demonstrated more help-seeking behavior than those in other communities (8-10 percent). Of those who sought help, the vast majority sought help from their own family members (67 percent) or from their husband's family (54 percent). This suggests that there is a need to strengthen health and psychosocial services for survivors of gender-based violence. Providers at health facilities must be sensitized and doctors and nurses need to be trained to provide services for survivors. In addition to support for victims, programs need to also focus on the prevention of GBV. Programs need to work with men to change social norms and perceptions related to GBV.

\section{Alcohol use}

In all communities, males were significantly more likely than females to have used alcohol in the past four weeks (35 percent versus 11 percent; $p<0.05$ ). About one-quarter of all males were found to have a clinically significant alcohol problem, versus11 percent of females $(p<0.05)$. As part of a comprehensive risk reduction strategy during HIV counseling and testing, counselors should be given the appropriate tools to evaluate alcohol use, such as the CAGE tool (Ewing 1984), and to recommend strategies for reducing risk related to alcohol abuse. 


\section{Adolescent girls}

Overall, 17percent of adolescent girls were married or cohabiting. Approximately one-half of adolescent girls have had sex in their lifetime. There were no variations by community. Of those who had ever had sex, nearly one out of five (19 percent) indicated they had sex before the age of 15 . This is a significantly higher proportion than the older cohort, in which only 10 percent indicated they had sex before the age of 15 . Hence, girls today have a younger sexual debut than previous generations. Overall, only 63 percent used condoms at first sex. Because early sexual debut is significantly associated with risky sex, pregnancy, and increased HIV and STI risk (Duncan et al. 1990; Greenberg et al. 1992; Laga et al. 2001; Pettifor et al. 2004, Kaestle et al. 2005), interventions should include life skills and HIV prevention programs in schools and out of school. Programs should also promote positive communication with children on sexuality and HIV, and improve/provide youth-friendly sexual health services.

\section{Conclusion}

This study determined baseline levels of key indicators related to HIV, sexual behaviors, gender-based violence, alcohol abuse, and reproductive health. These baseline levels will be used as part of the evaluation in measuring the effect of the COMPACT program. These baseline measures will be compared with midline and endline levels to assess COMPACT's programmatic success. Additionally, the baseline findings provided critical insights into key areas for interventions in these four communities and highlighted variability in the populations across the communities and between males and females that provide valuable guidance for programming. 


\section{HIV/AIDS and the Response in Zambia}

As estimated by the 2007 Zambia Demographic and Health Survey (ZDHS), 14.3 percent of the country's population is infected with HIV (Central Statistical Office 2007). The epidemic disproportionately affects women and those in urban areas (16.1 and 19.7 percent, respectively), although all segments of society have been impacted. Recent data suggest some progress in combating the disease; the 2007 ZDHS found that national prevalence decreased from 15.6 percent in the 2001 ZDHS, although such a decline was not statistically significant (Central Statistical Office 2007). Data from the antenatal clinic sentinel surveillance surveys also confirm that HIV prevalence among young women aged 15-24 years decreased in both urban (27.4 percent to 15.5 percent) and rural (11.4 percent to 6.4 percent) sites from 1994 to2008.(Kayeyi et al. 2012) While overall prevalence appears to be decreasing, modeled incidence rates from the Modes of Transmission (MOT) study suggest that 1.6 percent of the population is newly infected each year (National AIDS Council 2009). In 2009, this number was estimated to be a total of 82,681 adults, 49,144 (59 percent) of which were women.

The Zambia National HIV/AIDS/STI/TB Council (NAC) identifies six core drivers of the epidemic in Zambia: (1) multiple and concurrent sexual partnerships; (2) low and inconsistent condom use; (3) low levels of male circumcision; (4) mobility and labor migration; (5) high risk behaviors among sex workers and in male-to-male relationships; (6) vertical transmission from mother to child. These drivers are addressed in the National Strategy for the Prevention of HIV and STIs. In addition to these individual-level drivers, NAC also identifies a set of structural, community-level drivers that have largely remained unaddressed by HIV programs and under-analyzed by researchers. These include alcohol use, gender inequality, harmful gender norms, sexual and intimate partner violence, transactional sex, and taboos and social barriers regarding communication among couples. To adequately address the epidemic, NAC urges programs to prioritize prevention and address the structural issues that underpin continued incidence.

The Government of the Republic Zambia (GRZ), in conjunction with international and local partners, has actively undertaken efforts to address these drivers. With support from the United States President's Emergency Plan for AIDS Relief (PEPFAR), the Ministry of Health (MOH) has improved access to clinical services by strengthening its antiretroviral (ARV) drug and HIV test kit supply chain systems, as well as counseling and testing in the public sector. Care and support services, especially for orphans and vulnerable children (OVC), have been expanded nationally with many national and international partners. While HIV prevention activities have not been as widely implemented, apart from the social marketing of condoms, the GRZ has recently embraced male circumcision as a central element of its prevention strategy.

The GRZ and partners have developed an array of informational materials to encourage prevention at the community level, as well as prevention with positives through post-test clubs and other individual-level interventions. The GRZ has shown commitment to reducing the country's high rates of gender-based violence (GBV) through service strengthening and policy development activities.

The Population Council and its partner, Project Concern International (PCl), are implementing a three-year "community compact" intervention in four communities in Zambia. The project, Community Mobilization for Preventive Action (COMPACT), is building upon the existing interventions, structures, and partnerships to further promote HIV prevention at the community-level. COMPACT 
is using the innovative mechanism of "community compacts," with the aim of creating social cohesion and mobilization, and providing incentives to help the mobilized community achieve its goals.

\section{COMPACT Overview}

The purpose of the COMPACT project is to develop, implement, and scale-up community-based agreements, and to demonstrate the feasibility and effectiveness of community compacts as an HIV prevention strategy. Broadly, community compacts are agreements between service providers and recipient communities that are intended to increase the effectiveness of services by promoting community ownership. COMPACT is working directly with six communities to design and implement some of the first compacts in Zambia.

Its specific objectives are to: (1) identify target communities and work collaboratively to develop community compacts for HIV prevention interventions; (2) transfer skills to communities through Zambian partners to sustain HIV prevention activities; and (3) develop and implement measurement frameworks to track progress of community prevention activities.

COMPACT partners directly with communities, developing compacts through a participatory, community-led process, and assisting them in working toward agreed-upon targets related to HIV. Key elements of this support are incentives and skills transfer.

\section{The Intervention: Community Compacts and Incentives for Behavior Change}

To encourage community engagement in the process, the COMPACT approach is complemented by a system of incentives designed to reward communities for reaching the benchmarks defined in their compacts. In addition to acting as reinforcers, incentives bring the rewards of HIV risk reduction closer to the present, rather than just avoiding AIDS many years in the future. Together, the interlinked intervention of compacts and incentives are desgined to improve sexual behaviors of individuals and to contribute over time to the reduction of HIV incidence through a community-driven process of social norms and behavior change. The hypothesized causal relationship is provided in Figure 1. 


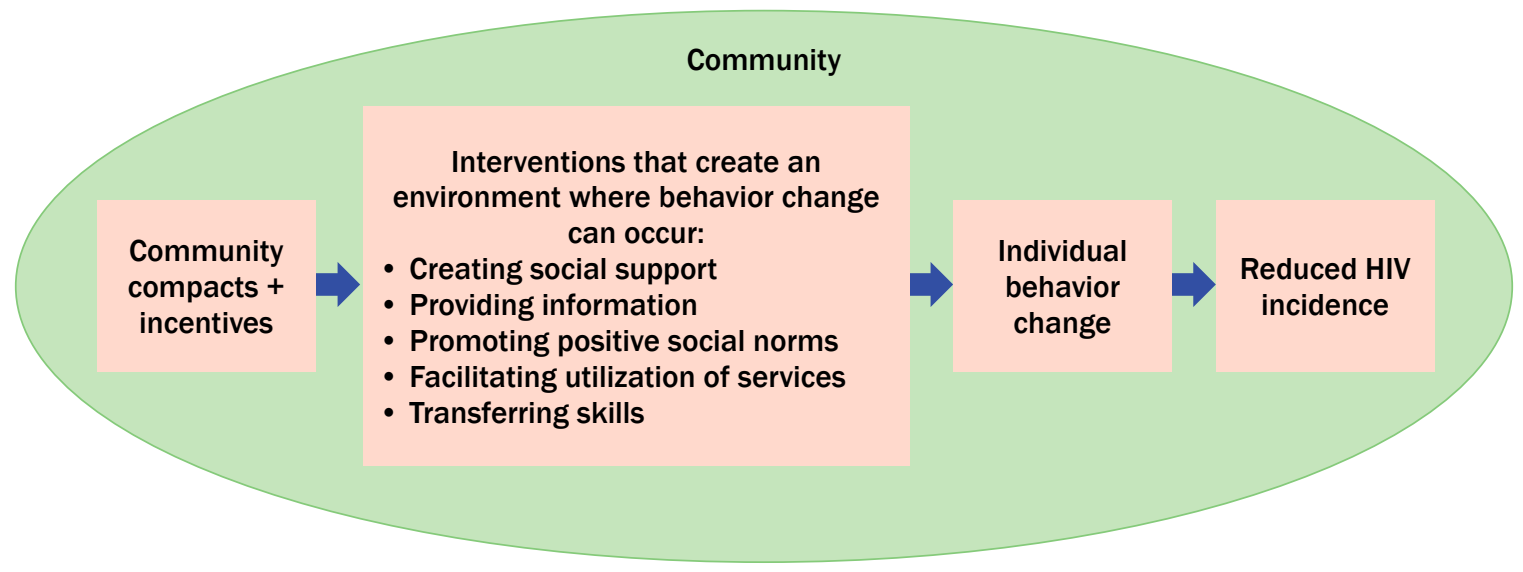

A cornerstone of the compact approach is to work with existing community structures to form a Community Compact Development Committee (CCDC), comprising community leaders and other stakeholders, to manage the compact. COMPACT supports the CCDC by conducting participatory assessments that determines existing $\mathrm{CBO}$ capacity and the key drivers of the HIV epidemic in the community. The CCDC selects evidence-based HIV prevention interventions relevant to the community, sets targets, identifies CBOs to implement the interventions, and develops the compact. It then monitors and evaluates progress at the community level and rewards the achievement of results. COMPACT continuously builds the capacity of the CCDC and CBOs through structured training, ongoing mentoring support, and community-to-community skills transfer.

\section{Project compacts have four components:}

1. Interventions: COMPACT staff, in collaboration with the communities, works to ensure that interventions are evidence-based; community-specific; address the primary drivers of the epidemic such as alcohol use, GBV, and harmful male norms; and contribute substantially to the overall project results. See Appendix 1 for examples of evidence-based interventions COMPACT uses.

2. Benchmarks: Benchmarks comprise a set of activity-specific targets that must be met or exceeded to qualify for a reward. Five benchmarks have been established to ensure that incentives are provided with necessary frequency to encourage excitement and engagement. The first four are linked to the process, intermediate measures, and final results of project implementation. The benchmarks are progressively more ambitious and follow a cycle of behavior change, from community mobilization to ultimate outcomes. The final benchmark is a community-wide indicator into which all program activities feed that serves as the ultimate measure of program success. Appendix 2 presents an illustrative example of benchmarks.

3. Implementing CBOs: The CCDC identifies $\mathrm{CBO}$ s to implement the interventions. These are existing, indigenous groups that are currently implementing relevant programs.

4. Incentives: Upon achieving each benchmark, CBOs are awarded incentives in a transparent and highly visible manner. Incentives represent community goods that are intended to further the goals of each intervention and motivate the community; they do not benefit individuals or private interests. While incentives are defined based on identified needs, COMPACT ensures 
that they are conceptualized as project inputs aimed at further improving access, availability, and quality of interventions.

\section{Monitoring and Evaluation: Measuring Progress toward Benchmarks}

Process and service utilization indicators are used to measure progress toward the first four benchmark categories (see Appendix 2). These indicators help to operationalize the benchmarks and are well-defined and realistic to ensure that the CCDC can report on them in order to award the incentives. Table 1 illustrates how the indicators are tied to each benchmark and data source.

\begin{tabular}{|c|c|c|}
\hline Illustrative benchmark & Illustrative indicators & Data source \\
\hline $\begin{array}{l}95 \% \text { of girls enrolled in IGA } \\
\text { participating in at least } 3 \\
\text { health education sessions }\end{array}$ & $\begin{array}{l}\text { - \# of girls enrolled in IGA activity } \\
\text { - \# of girls who participated in } 3 \text { health } \\
\text { education sessions }\end{array}$ & $\begin{array}{l}\text { - Program enrollment logs } \\
\text { - Health education session } \\
\text { attendance sheets } \\
\text { - CBO reports, verified by } \\
\text { COMPACT staff }\end{array}$ \\
\hline $\begin{array}{l}95 \% \text { of girls report avoiding } \\
\text { risky sexual behaviors }\end{array}$ & $\begin{array}{l}\text { - } \% \text { of girls } \geq 15 \text { who are not sexually active } \\
\text { - } \% \text { of sexually active girls with } 0 \text { or } 1 \text { part- } \\
\text { ner in last } 6 \text { months } \\
\text { - } \% \text { of sexually active girls who used a } \\
\text { condom at last intercourse }\end{array}$ & - Behavioral survey \\
\hline
\end{tabular}

The final benchmark (benchmark 5), which reflects overall community performance, is measured by a reduction in high-risk behavior among community members. This is intended to reflect the cumulative impact of each individual intervention, as well as other country-wide efforts, on the community as a whole. In the long run, the COMPACT intervention, together with other interventions at the community and national levels, is intended to reduce HIV incidence. HIV incidence and changes in knowledge, attitudes, and practices in the four project communities will be measured through the annual population-based HIV sero-behavioral surveys. This report is based on the baseline sero-behavioral survey that was conducted in four communities (Chinyunyu, Chongwe, Kaniki, and Kawama). 


\section{STUDY OBJECTIVES AND RESEARCH QUESTIONS}

\section{Overall Objective}

- Measure the potential of community compacts in changing knowledge, attitudes, and practices (KAP) and HIV incidence.

\section{Specific Objectives}

- Assess the KAP regarding HIV in the communities at different points of time before and after the introduction of the COMPACT project.

- Establish a baseline of HIV incidence estimates that will provide a basis for measuring impact of the COMPACT intervention, together with other ongoing efforts.

\section{Baseline Objectives}

The specific objective of the baseline sero-behavioral survey is to establish levels of HIV prevalence and knowledge, attitudes, and practices related to HIV before the roll-out of COMPACT in communities. 


\section{METHODOLOGY}

\section{Study Design}

The baseline is a community-based household survey with linked anonymous HIV testing conducted in four communities of Chimunyu, Chongwe, Kawama and Kaniki where COMPACT interventions are to be rolled-out.

This study largely follows the methodology used for the 2007 Zambia DHS. The DHS used anonymous samples and offered brochures with VCT service sites for respondents wanting to know their HIV status.

To determine HIV incidence, participants will be tested in two follow-up rounds of data collection 12 months after each round. Because the sero-survey is an anonymous study, even those who test HIV positive at baseline and midterm will be re-tested at subsequent rounds. These will be reported after subsequent data collection rounds. This report focuses only on the baseline sero-survey.

\section{Study Population}

The eligibility criteria for the household survey included:

- Being female aged 15 to 49 years or male aged 15 to 59 years

- Being a permanent resident of a household or having spent the previous night in the household

- Having no plans to migrate from the current residence for the next three years

Since the legal age of consent for participation in research in Zambia is 16 years ${ }^{1}$ the study required parental consent for participants aged 15 years. These participants also gave their assent to participate in the study.

Study areas: The COMPACT project is being implemented in Chongwe District in Lusaka and Ndola District in Copperbelt provinces. Within each of the above districts, the COMPACT project is being implemented in both rural and urban/peri-urban wards. Table 2 shows the provinces, districts, and wards, andwhether they are rural or urban.

Table 2 Intervention sites for COMPACT

\begin{tabular}{|llll|}
\hline Province & District & Community & Location \\
\hline Lusaka & Chongwe & Chinyunyu & Rural \\
& Chongwe & Chongwe & Peri-urban \\
Copperbelt & Ndola & Kawama & Peri-urban \\
& Ndola & Kaniki & Rural \\
\hline
\end{tabular}

${ }^{1}$ http://www.unicef.org/wcaro/Status_on_legal_frameworks_CSEC_Final_2.pdf accessed on 14 Feb 2011 


\section{Local Consultations}

Letters of support from the National AIDS Council (NAC) and the Ministry of Health (MOH) were obtained. The following authorities and stakeholders were briefed about the study and their inputs and oral agreement were obtained:

- District level: District AIDS Task Force (DATF), District Health Management Team (DHMT), and District Development Committees.

- Village level: Neighborhood Health Committees (NHCs), Home-Based Care Committees, People Living with HIV/AIDS support groups, Traditional Birth Attendants, Ward Chairpersons, Village headmen and women, and Community AIDS Task Force.

Additionally, meetings were held with village headmen/women and Ward Chairpersons as well as with the community, which were segmented into smaller sections by age and gender.

\section{Ethical Approvals}

Ethical approvals were obtained from the University of Zambia and the Population Council Institutaional Review Board.

\section{Survey Questionnaires}

Three questionnaires were used: the household, men, and women. The household questionnaire was an enumeration instrument which listed all residents of the household and was used to identify men and women eligible for the interviews. The behavioral survey consisted of a KAP questionnaire adapted from the 2007 ZDHS and the International Men and Gender Equality Survey (IMAGES) of gender norms. The questionnaire covered the following areas: knowledge of HIV, GBV, family planning, attitudes towards PLHA, experience and views about sexual violence, couple communication, self-risk perception, male norms, multiple concurrent partners (MCP), VCT use, male circumcision use, disclosure of HIV status, alcohol use, sexual behaviors, gender norms, and exposure to selected HIV/AIDS interventions. Interviews were conducted in Bemba in the Copperbelt province and Nyanja in Lusaka province. The interviews were conducted with personal digital assistants (PDA). Participants were asked to provide informed consent separately for the survey and the anonymous HIV testing.

\section{Sample Size and Sampling}

The sample size of 1,750 was based on detecting a 0.4 percent reduction in HIV incidence from 1.6 percent per 100 person-years modeled by the UNAIDS MOT study of 2009 (National AIDS National AIDS Council 2009) for the general population to 0.96 percent. $^{2}$ To account for 20 percent loss to follow-up at each subsequent round of data collection and a HIV testing refusal rate of 10 percent, the target sample size of 3,581 was established for the baseline (equal numbers of women and men). This sample size is large enough to detect a one-tenth reduction in reported high-risk intercourse behavior (i.e., sex with a non-marital, non-cohabiting partner) from the data reported in the 2007 ZDHS (16.9 percent to 15.2 percent for women and 35.4 percent to 28.4 percent for men). The sample was allocated to the four communities in proportion to the population size of each community.

${ }^{2}$ The sample size was calculated to construct a 95 percent Wilson Score confidence interval as determined using SAS's Proc Power procedure. 
The household survey used a cluster sampling technique so that interviews could be carried out in a smaller number of geographical locations known as Standard Enumeration Areas (SEAs). ${ }^{3}$ Ten SEAs (primary sampling unit) were randomly selected from ward. Household residents (secondary sampling unit) were then randomly selected in each SEA. The allocated number of men and women per community was divided among the 10 randomly selected SEAs in that community. Maps of SEAs and the latest household lists were obtained from the Central Statistics Office (CSO). However, a team of enumerators made advance visits to the selected SEAs to update the household listings. The household listings were used to identify households that had eligible women and/or men for the study.

During the two-week training, the process was pilot tested. This included pilot testing the tools and the methodology of approaching selected households and seeking permission to talk to them, identifying the household head to answer the household questionnaire, identifying the selected respondents for the male and female questionnaires, and administering the informed consent and the questionnaire. The nurses also practiced collectingblood samples on participants, after obtaining consent.

Three attempts were made to visit households in cases where there were no persons in the selected household at the time of the study team visit. If all three attempts failed, the study manager randomly selected another household in that same SEA.

\section{HIV Testing}

A venous blood sample was taken from each respondent who gave consent for anonymous HIV testing (i.e., respondents do not receive their test results). Each specimen was screened with the Determine ${ }^{\circledR}$ HIV-1/2 Test. Specimens testing positive on this test were confirmed on the UniGold ${ }^{\mathrm{TM}}$ HIV Test. Specimens with discrepant results between the two tests were subjected to an SD BIOLINE HIV-1/2 3.0 Test which was used as the tie breaker.

\section{Analysis}

Data was analyzed in STATA version 9.0. Continuous variables were compared using Student's $t$-test and categorical variables with Pearson's chi-square test. Variables were considered significant at $p<0.05$ (two-tailed).

\section{Variables and definitions}

Gender Equitable Men (GEM) Scale: Attitudes toward gender relations were measured using 15 items adapted from the Gender Equitable Men scale (Pulerwitz and Barker 2008). The items had a Cronbach's alpha or 0.73 for men and 0.71 for women. A typical item in the scale is "A man should have the final word about decisions in his home." Each of the items was scored on a 3-point scale, where 1=agree, 2=partially agree, and 3=do not agree. A high score represents high support for gender equitable norms. Responses to each item were summed and the total was divided into tertiles (Low, Medium, High equity).

\footnotetext{
${ }^{3} \mathrm{~A}$ SEA is the lowest geographic cluster used by the Central Statistical Office (CSO) of the Government of Zambia in demographic surveys. An SEA is a convenient geographical area with an average size of 130 households or 600 people. For each SEA there is a map indicating its geographical limits using main landmarks in the community.
} 
Wealth Index: The wealth index was developed according to the ZDHS and it measures a household's long-term standard of living (Central Statistical Office 2007). The index is based on the household's ownership of consumer goods, dwelling characteristics, type of drinking water source, toilet facilities, and other characteristics related to a household's socio-economic status. A score was calculated for each household and individuals were ranked based on the total score of the household in which they reside. The score was divided into quintiles (Lowest, Second, Middle, Fourth, Highest).

Comprehensive HIV and AIDS Knowledge: An index was developed for HIV prevention knowledge according to the ZDHS. Respondents were considered to have comprehensive knowledge about HIV and AIDS if they: i) knew that both condom use and limiting sex partners to one uninfected partner are HIV prevention methods; ii) were aware that a healthy-looking person can have HIV; and iii) rejected the two most common local misconceptions, that HIV and AIDS can be transmitted through supernatural means or through mosquito bites.

Physical and Sexual Abuse: Female respondents were asked if they had experienced physical or sexual abuse by a current or former male partner; male respondents were asked if they perpetrated physical or sexual abuse (lifetime and in the last 12 months) to any current or former female partners. Physical abuse includes pushing, shoving, slapping, throwing an object, hitting, kicking, dragging, beating, choking, burning, or threatening use or actually using a weapon. These questions were taken from the WHO violence against women instrument which was developed for international use (WHO 2000).

Alcohol Problem: Alcohol abuse was assessed using the CAGE 4-item questionnaire (Ewing 1984). CAGE stands for Cut down, Annoyed, Guilty, and Eye-opener. The items include feeling the need to cut down on drinking (Cut down), being annoyed by people criticizing drinking (Annoyed), feeling guilty about drinking (Guilty), and needing an eye-opener first thing in the morning (Eye-opener). Item responses were scored 0 for "No" and 1 for "Yes", with a higher score indicating alcohol problem. A total score of two or greater was considered to be a clinically significant alcohol problem.

\section{Limitations}

Missing data: Due to the complexity of the questionnaire section related to the last three partners of the respondent in the last 12 months, data on certain key outcome variables were missing for many respondents. The missing data was a result of a technical malfunction in downloading the data from the PDAs. Among those who indicated having sex in the last 12 months, 64 percent were missing detailed information about their last three sex partners (i.e., type of partner and condom use). An examination of the characteristics of those with missing data seems to indicate that data are missing at random (i.e., proportion of missing data did not vary by gender, community, age, marital status, wealth, or urban/rural residency). Therefore, we report results from the 36 percent who did have information for the indicators having a non-regular partner in the last 12 months and condom use). The missing data affect the sample size for the results presented on page 20 related to non-regular partners. Since data are likely missing at random, the analyses on these indicators are likely to be unbiased, although they are based on a smaller subset of the original sample. 


\section{Socio-demographic Characteristics}

The median age of male respondents was 26 years and female respondents was 25 years (Appendix 3). The age structure is similar across the four communities, with the exception of males in Kawama who were slightly younger than males in the other communities. Overall, females were more likely to be married or cohabiting than males (55 percent versus 41 percent) and also more likely to be divorced, separated, or widowed (11 percent versus 5 percent). Males were more educated than females; 67 percent of males and 54 percent of females had secondary education or higher. Those in Kawama were the most educated and those in Chinyunyu were the least educated. Kawama had the highest wealth (56-57 percent of respondents in the higher wealth index) while Chinyunyu had the lowest wealth (22-29 percent of respondents in the highest wealth index). The majority or all of respondents from Chinyunyu (100 percent), Chongwe (86-91 percent), and Kaniki (85-86 percent) were rural residents, while the majority of respondents from Kawama (96-98 percent) were urban residents.

\section{Knowledge about HIV and AIDS}

The majority of both male and female respondents had ever heard of HIV and AIDS (over 95 percent); there were no differences across communities (Appendix 4). Overall, knowledge about how HIV can be prevented was also high, with approximately 80 percent of respondents knowing each of the three HIV prevention methods: abstaining, having only one uninfected partner, and using condoms consistently. Of note, however, was that Chinyunyu had the lowest proportion of both males and females who had correct knowledge for all three indicators (64-79 percent) compared to the other three communities, which had 80-94 percent who had correct knowledge. In all other provinces, males and females had equal knowledge of HIV prevention methods. Overall, 84 percent of males and 87 percent of females knew that a healthy-looking person can have HIV. Again, Chinyunyu had the lowest proportion (76-81 percent) who knew this compared to other communities $(85-90$ percent) $(p<0.05)$.

Approximately three-quarters of respondents did not subscribe to myths that people can get HIV from mosquito bites and witchcraft.

The majority of respondents had heard of ARVs; however, females were significantly more likely to have heard of ARVs than males (86 percent versus 80 percent; $p<0.05$ ). Chinyunyu had the lowest proportion of participants who had heard of ARVs (71 percent of males and 78 percent of females).

A composite index was developed to measure comprehensive knowledge of HIV similar to the ZDHS (2007). Respondents were considered to have comprehensive knowledge about HIV and AIDS if they: i) knew that both condom use and limiting sex partners to one uninfected partner are HIV prevention methods; ii) were aware that a healthy-looking person can have HIV; and iii) rejected the two most common local misconceptions, that HIV and AIDS can be transmitted through supernatural means or through mosquito bites. Overall, comprehensive knowledge was low (50 percent in males and 52 percent in females); however, it was the lowest in Chinyunyu (33 percent in males and 40 percent in females) (Figure 2). Significant difference in comprehensive knowledge between males and females was only seen in Chinyunyu, with males having 
less comprehensive knowledge than females (33 percent versus 40 percent; $p<0.05$ ). Figure 1 also shows the comprehensive knowledge results of the 2007 ZDHS. The overall comprehensive knowledge results from this baseline survey appear to be better than the results from the 2007 ZDHS.

Figure 2 Comprehensive knowledge of HIV and AIDS by community (Male = 1,436; Female $=1,756)$

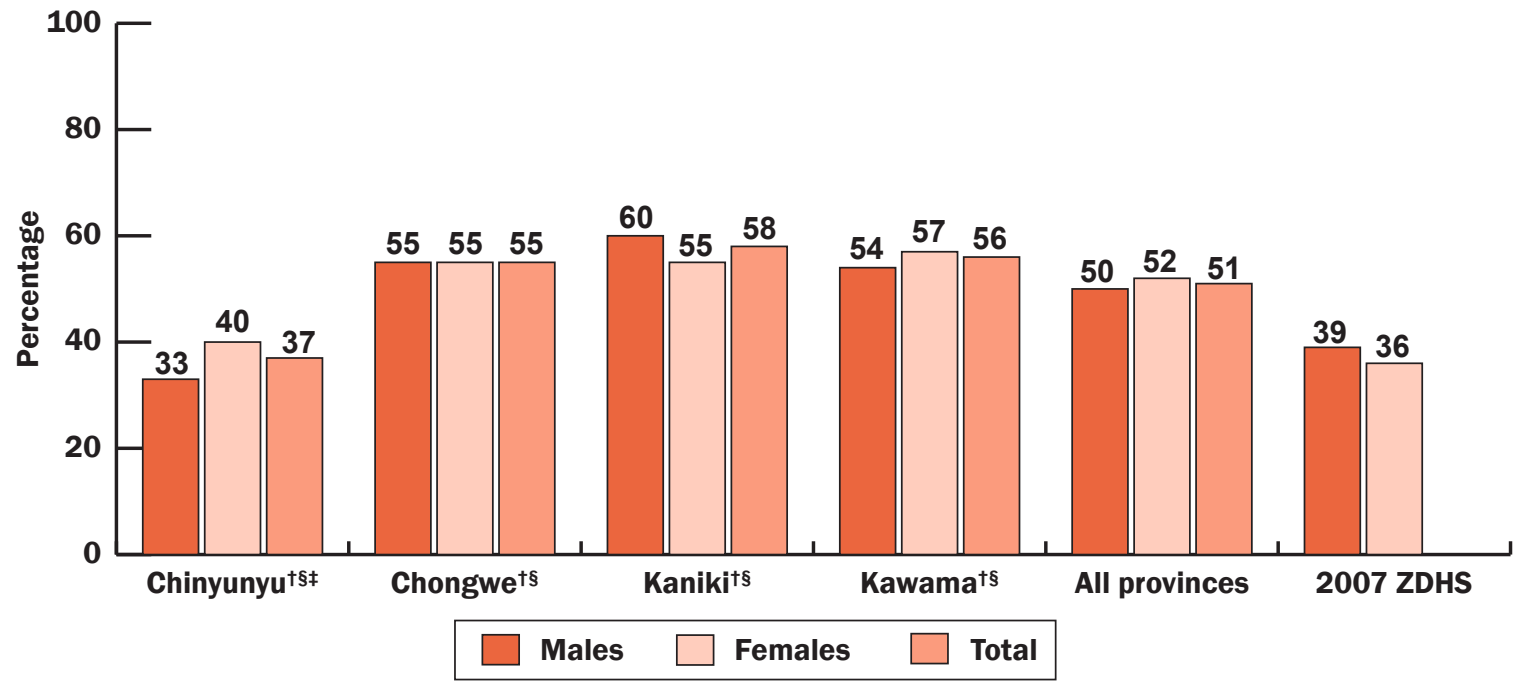

'Statistically different across provinces for males ( $p<0.05)$. sStatistically different across provinces for females $(p<0.05)$. ¥Statistically different between males and females $(p<0.05)$.

\section{HIV Testing}

Knowledge of where to get tested for HIV

Figure 3 shows that the majority of respondents (83 percent of males and 92 percent of females) knew where to test for HIV. Respondents in Chinyunyu were the least likely to know where they could test for HIV, particularly male respondents (76 percent). In all communities, males were significantly less likely to know where to test for HIV $(p<0.05)$. This is likely due to HIV testing being offered to women at ANC services. 
Figure 3 Percent who knows where to test for $\operatorname{HIV}($ Male = 1,436; Female $=1,756)$

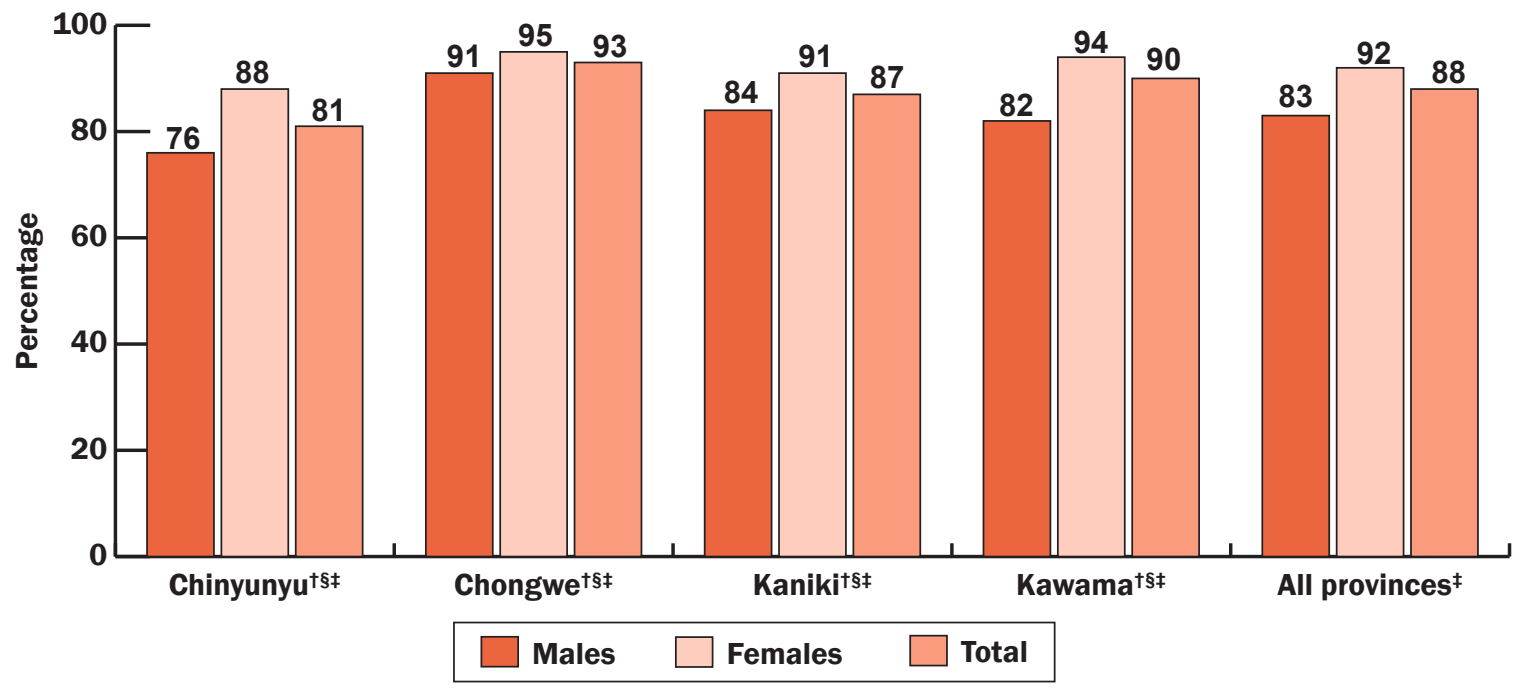

†Statistically different across provinces for males $(p<0.05)$.

sStatistically different across provinces for females $(p<0.05)$.

₹Statistically different between males and females $(p<0.05)$.

\section{HIV testing history}

Figure 4 shows an overall significantly greater proportion of females having ever tested for HIV and receiving results compared to males (72 percent versus 43 percent; $p<0.05$ ). For women, this includes those who were tested at ANC centers. This difference by sex is seen in each community. In particular, male respondents in Chinyunyu (34 percent) and Kawama (39 percent) were the least likely to have tested and gotten results.

These results are dramatically higher than the HIV testing rate found in the 2007 ZDHS, where; the overall rates for male and female were 20 percent and 35 percent, respectively. 


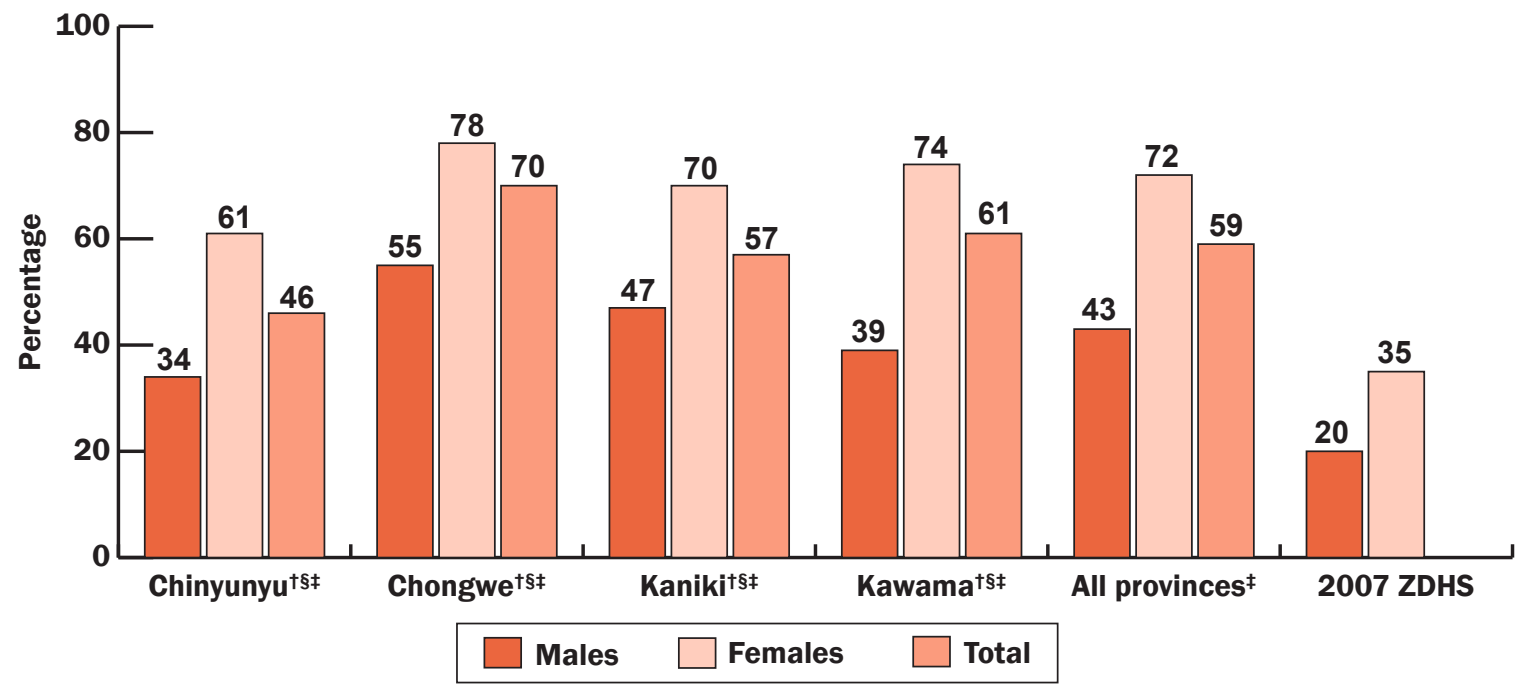

†Statistically different across provinces for males $(p<0.05)$.

sStatistically different across provinces for females $(p<0.05)$.

₹Statistically different between males and females $(p<0.05)$.

Almost all respondents who tested for HIV received the results of their test; less than 5 percent of all respondents did not receive their test results after testing for HIV (Appendix 5). Across all communities, among those who tested for HIV, about two-thirds had tested within the past 12 months. This did not vary by community or sex.

In all four communities, government health centers were the most common places where people received their last HIV test (Figure 5). Additionally, in all communities, females (70-85 percent) were more likely to receive their HIV test at the government health centers than males (approximately 50-75 percent). In all communities, stand alone government VCT centers and mobile clinics were places where males (10-31 percent) were last tested compared to females (6-14 percent). 
Figure 5 Place of last HIV test among those who have ever been tested for HIV (Male = 663; Female $=1,311)$

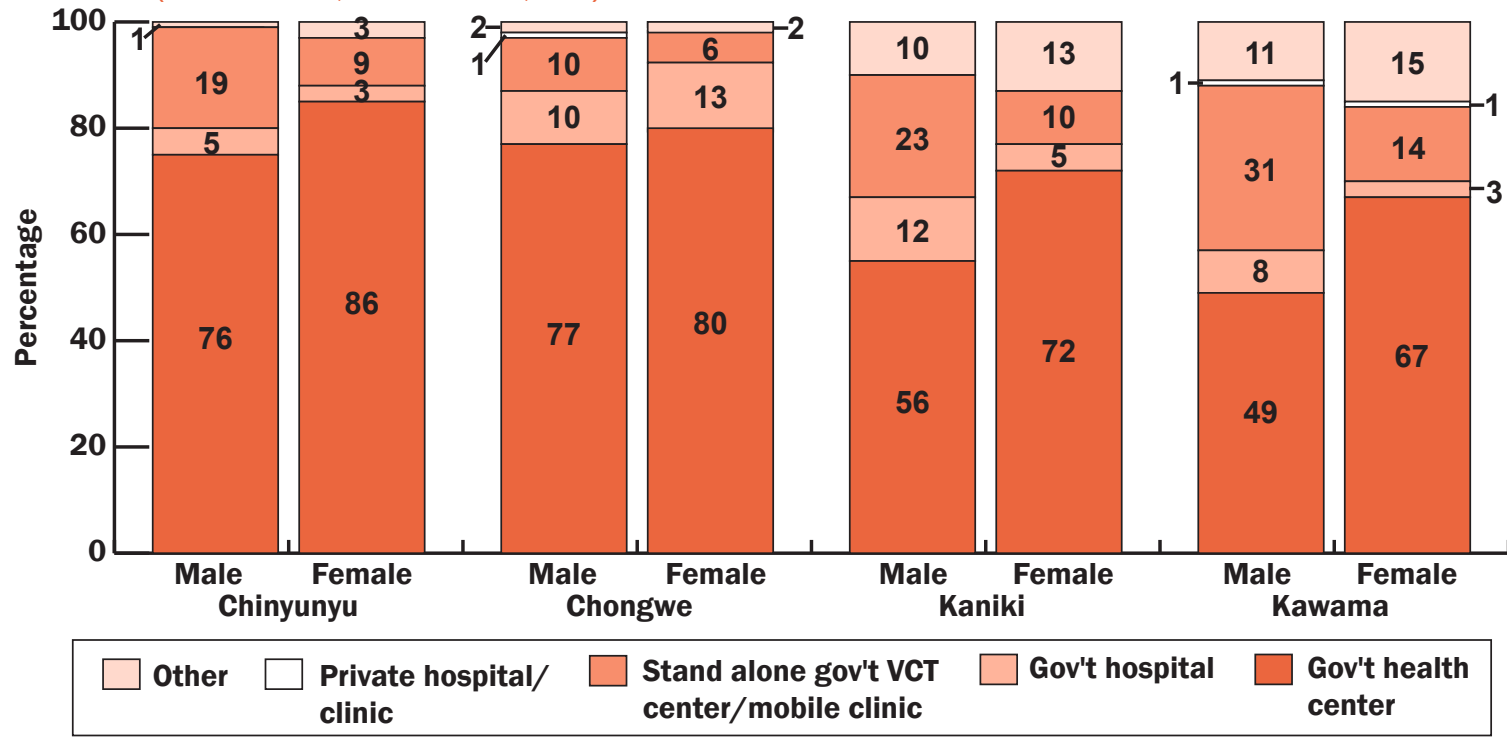

Table 3 shows the proportions who ever tested for HIV and received results by select characteristics. While HIV testing did not differ significantly by urban/rural residency and education, it did vary by age, wealth status, marital status, and sexual activity. HIV testing was significantly more common among those who were older than 25 years, had greater wealth, were married or co-habiting, and were sexually active.

Table 3 Correlates of HIV testing (including ANC testing) by key variables $(\mathrm{N}=3,188$ )

\begin{tabular}{|c|c|c|}
\hline & $\begin{array}{l}\text { HIV tested and received results } \\
\%\end{array}$ & p-value \\
\hline \multicolumn{3}{|l|}{ Age } \\
\hline $15-24$ & 46.7 & $<0.001$ \\
\hline $25+$ & 70.0 & \\
\hline \multicolumn{3}{|l|}{ Residency } \\
\hline Urban & 61.4 & 0.065 \\
\hline Rural & 57.9 & \\
\hline \multicolumn{3}{|l|}{ Education } \\
\hline No education/Primary & 59.5 & 0.663 \\
\hline Secondary or higher & 58.7 & \\
\hline \multicolumn{3}{|l|}{ Wealth index } \\
\hline Lower & 52.7 & $<0.001$ \\
\hline Middle & 61.3 & \\
\hline Higher & 64.3 & \\
\hline \multicolumn{3}{|l|}{ Marital status } \\
\hline Never married & 37.1 & $<0.001$ \\
\hline Married/Co-habiting & 76.9 & \\
\hline Divorced/Wid'd/Separated & 70.8 & \\
\hline \multicolumn{3}{|c|}{ Had sex in the last 12 months $(n=3,076)$} \\
\hline No & 40.4 & $<0.001$ \\
\hline Yes & 69.5 & \\
\hline
\end{tabular}




\section{HIV testing outside of ANC settings}

Figure 6 shows the proportion of women who were tested for HIV and received results outside of the ANC setting. Only one-half (49 percent) of all female respondents were ever tested for HIV outside of the ANC setting, compared to 72 percent who were tested anywhere (including through ANC). This indicates that a large proportion of women (23 percent) were captured through the ANC system for HIV testing and explains the higher HIV testing rates among women compared to men. HIV testing outside of the ANC setting was the lower in Chinyunyu (41 percent) and Kaniki (46 percent) compared to Chongwe (53 percent) and Kawama (52 percent), although not by much.

Figure 6 Percent of women ever tested for HIV (excluding testing at ANC) and received results by province

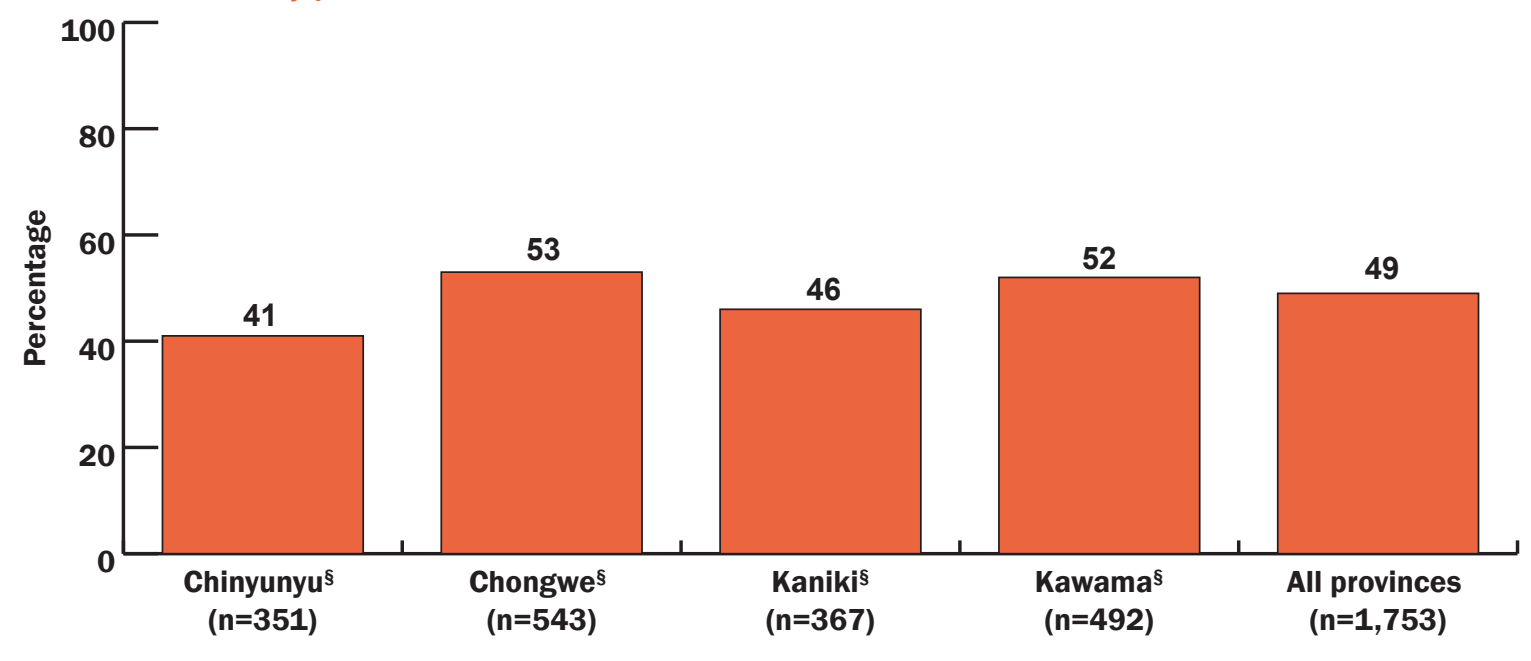

$\S$ Statistically different across provinces $(p<0.05)$.

\section{HIV testing in antenatal clinics}

Overall, 83 percent of women who received antenatal services for their last pregnancy also received testing and their HIV test result (Figure 7). This did not vary across the four communities. 
Figure 7 HIV testing at antenatal care during last pregnancy among females who sought antenatal services

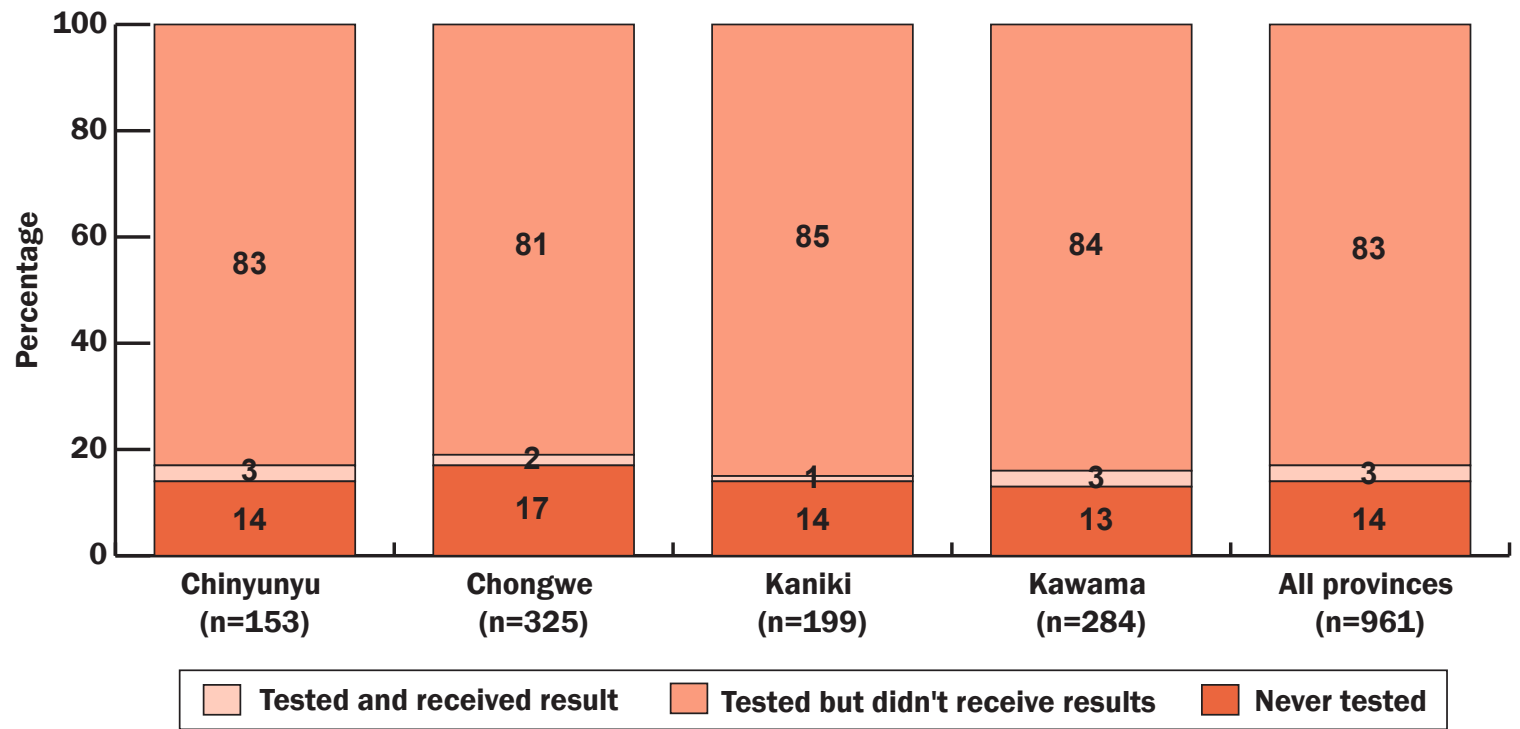

\section{Sexual Behaviors}

Over three-quarters of respondents engaged in sex at least once in their lifetime; females were significantly more likely to have ever had sex compared to males (84 percent versus 78 percent; $p$ $<0.05$ ) (Table 4).

\section{Early sexual debut}

Among youth aged 15-24 years of age, 15 percent of males and 10 percent of females engaged in early sexual debut (before the age of 15) $(p<0.05)$ (Table 4). There were no differences in sexual debut between males and females in each of the four communities except for Chongwe, where early sexual debut among males was more than twice as high as that among females (14 percent versus 6 percent; $p<0.05)$. There were no significant variations in early sexual debut across communities.

\section{Recent sexual activity}

Approximately two-thirds of respondents were sexually active in the past 12 months. This did not vary significantly between males and females except in Kawama, where males were less likely to have had sex in the last 12 months than females (54 percent versus 66 percent; $p<0.05$ ). Chongwe had the highest prevalence of sexually active males (72 percent) and females (74 percent).

\section{Non-regular partners}

Among those who had sex in the last 12 months, men were more than twice as likely as women to have had sex with a non-regular partner (a non-marital, non-cohabiting partner) (43 percent versus 18 percent). (Figure 8). The same pattern was found in all communities. Sex with non-regular partners among men was highest in Chinyunyu (48 percent) and Kawama (57 percent). There was 
no variation in prevalence of sex with non-regular partners across communities for both men and women. Condom use with their last non-regular sex partner was low for both men and women, and it was significantly lower for men than for women (8 percent versus 22 percent; $p<0.05$ ) (Data not shown). Condom use was not examined at the community level due to the small sample sizes.

Figure 8 Percentage who had sex with non-regular sex partners ${ }^{\mathrm{a}}$ in the last 12 months (among those who had sex in the last 12 months), (Males $=310$; Females $=387)^{\mathrm{b}}$

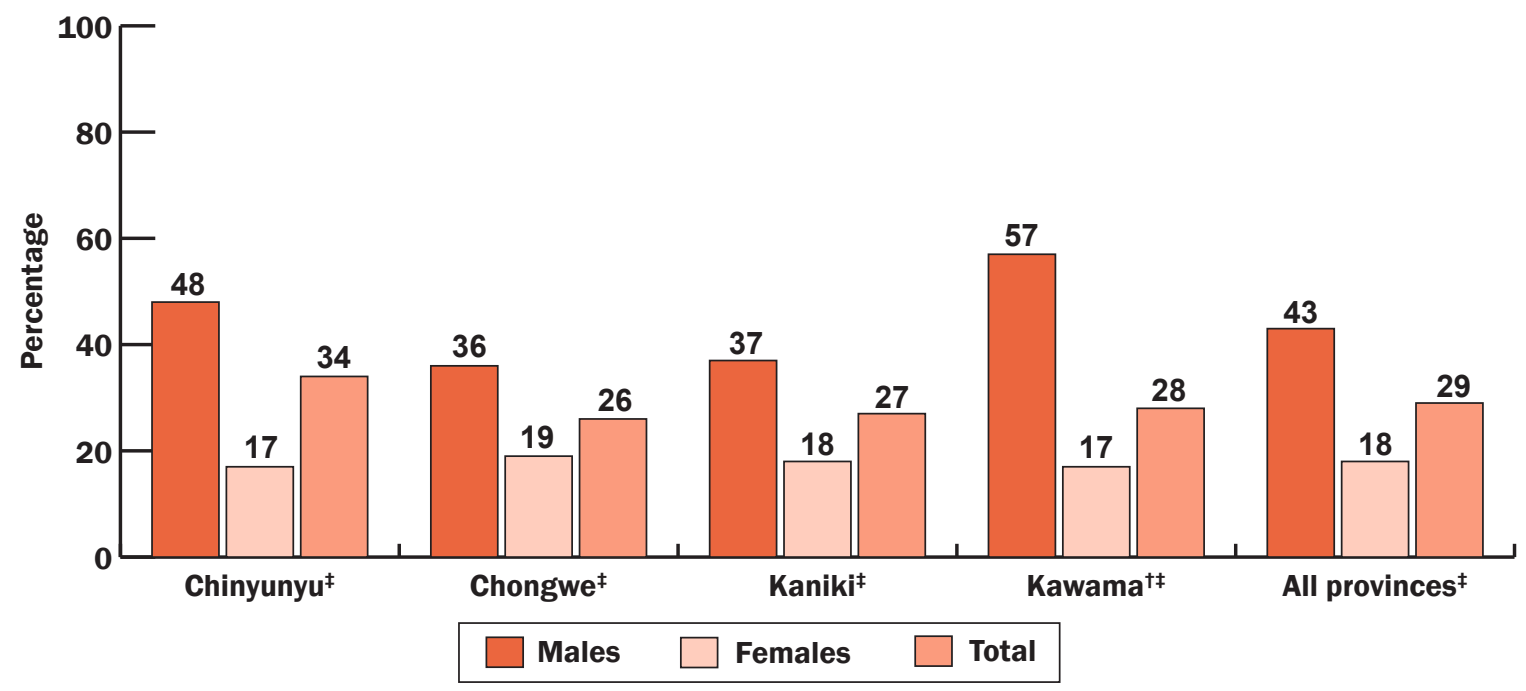

†Statistically different across provinces for males $(p<0.05)$.

§Statistically different across provinces for females $(p<0.05)$.

†Statistically different between males and females $(p<0.05)$.

${ }^{\mathrm{a} A}$ non-regular partner is defined as a non-marital and non-cohabiting partner.

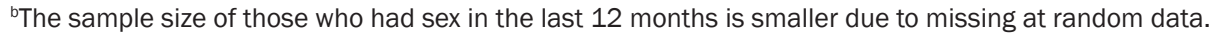




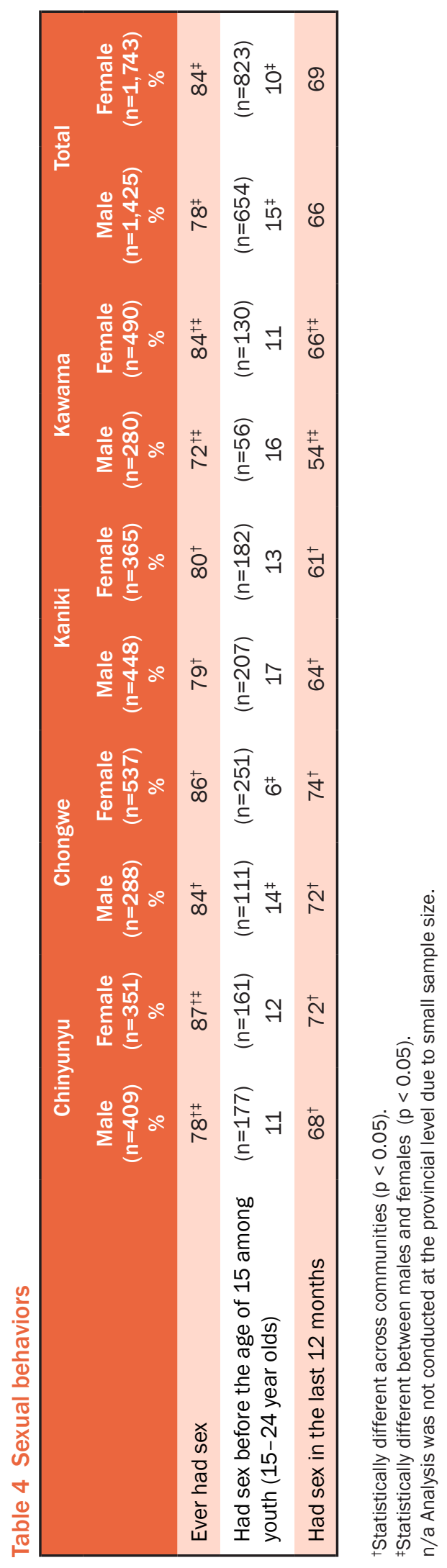




\section{Multiple sex partners}

Among those who had sex in the last 12 months, 25 percent of men and 8 percent of females had more than one sex partner (Figure 9). Prevalence of multiple sex partners was significantly lower among females than males in all communities. Males in Kawama had the highest prevalence of multiple partners (37 percent). The prevalence of multiple partnerships did not vary for females across communities.

Figure 9 Percentage who had 2 or more sex partners in the last 12 months (among those who had sex in the last 12 months), (Males = 868; Females = 1,121)

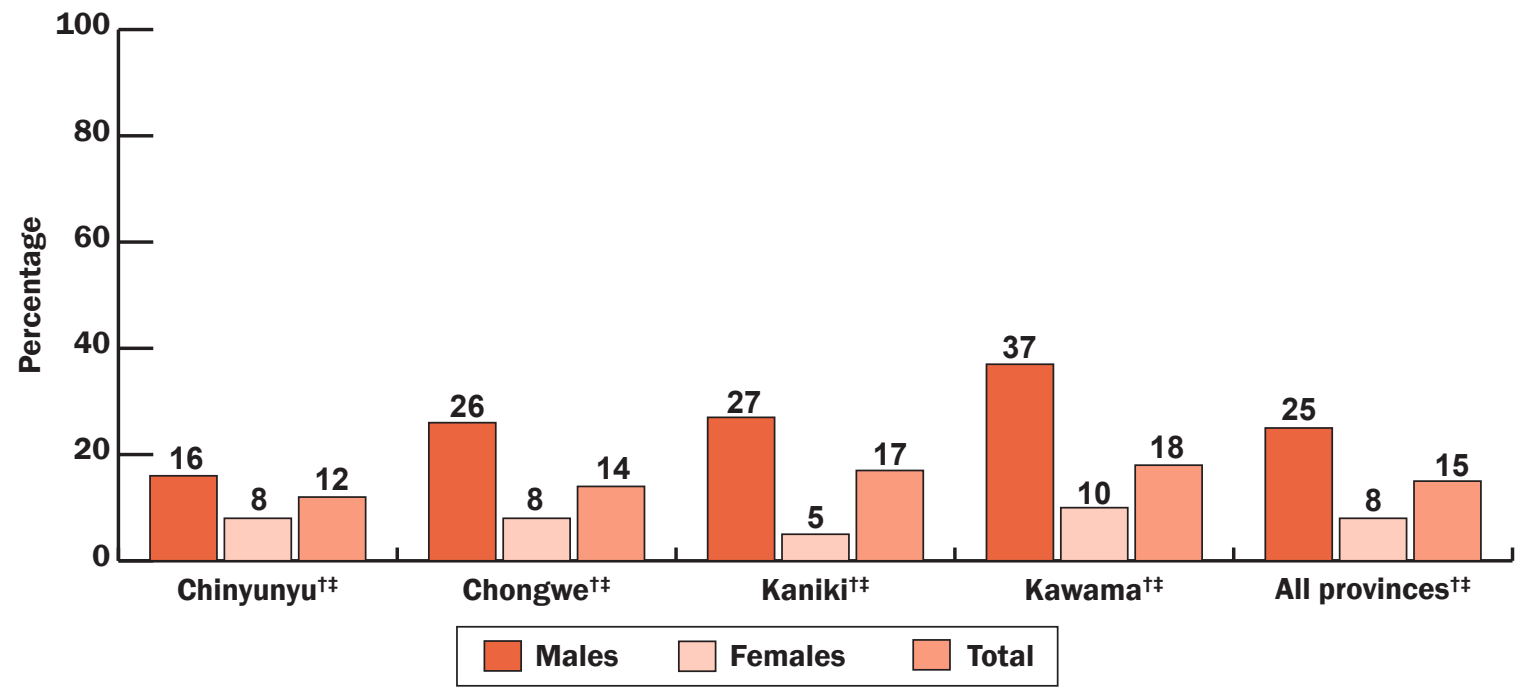

†Statistically different across provinces for males $(p<0.05)$. \$Statistically different across provinces for females $(p<0.05)$. †Statistically different between males and females $(p<0.05)$.

\section{Gender Relations}

\section{Gender equitable attitudes}

The Gender-Equitable Men (GEM) Scale was used to measure traditional attitudes toward gender norms related to HIV and AIDS and pregnancy prevention, violence, sexual relationships, domestic chores and caregiving, and homosexuality (Pulerwitz and Barker 2008). A typical item is "There are times when a woman deserves to be beaten" and "A man should have the final word about decisions in his home." A low equity score reflects having low gender equity (i.e., supporting inequitable gender norms). Figure 10 shows the proportion of respondents who had low gender equity attitudes by sex and community.

Slightly over one-third of all respondents (37 percent) scored in the lowest tertile of the GEM scale, indicating that 37 percent supported inequitable gender norms. This varied greatly across the communities, with Kaniki having the highest proportion of respondents supporting inequitable norms (50 percent) and Chongwe having the lowest proportion supporting inequitable norms (25 percent) $(p<0.05)$. In all communities except Kawama, men and women were equally likely to support inequitable norms. 
Figure 10 Percent who supported inequitable gender norms by community and sex $($ Male $=1,413 ;$ Female $=1,363)$

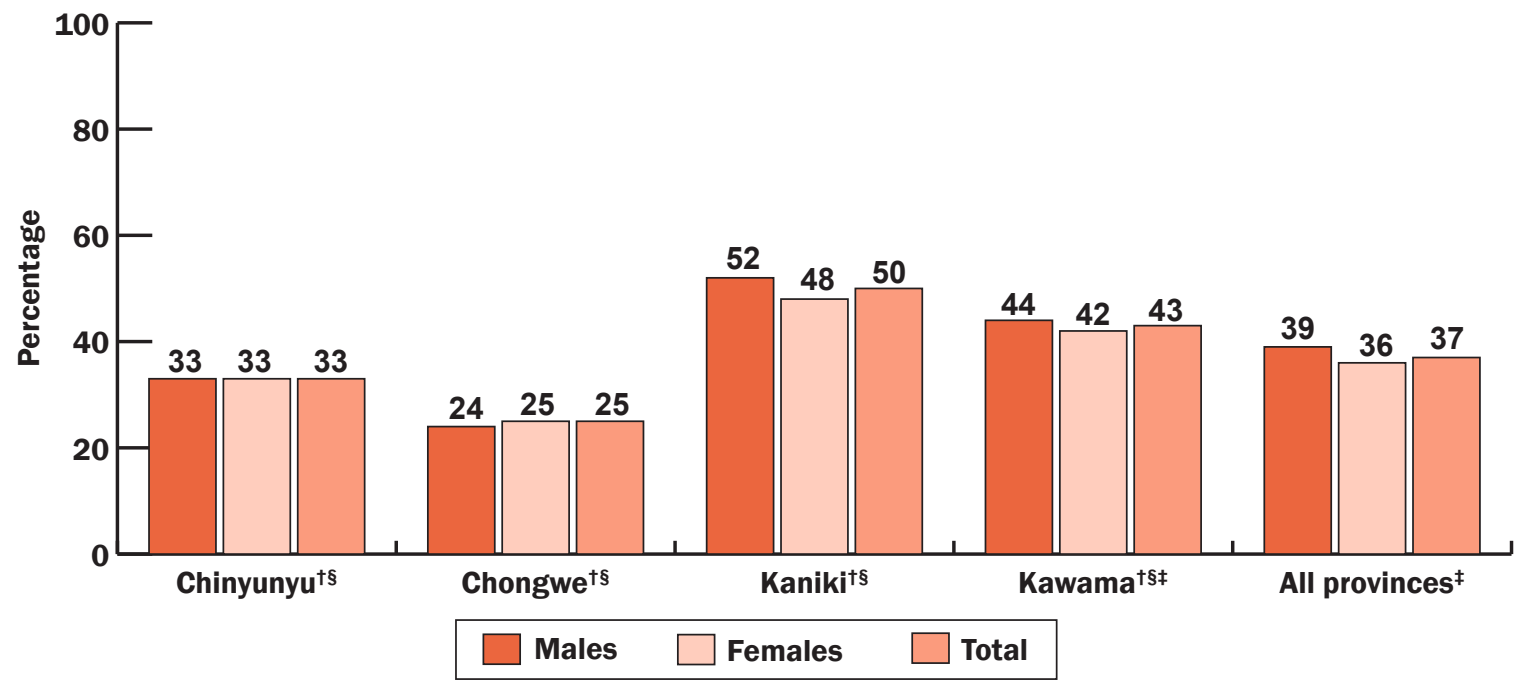

†Statistically different across communities for males $(p<0.05)$

sStatistically different across communities for females $(p<0.05)$.

₹Statistically different between males and females $(p<0.05)$

Figures 11 illustrates that higher risk sexual behavior was associated with support for inequitable gender norms. Those who had two or more sex partners in the last 12 months were significantly more likely to support inequitable gender norms.

Figure 11 Percent who supported inequitable gender norms by number of sex partners in the last 12 months $(n=2,678)$

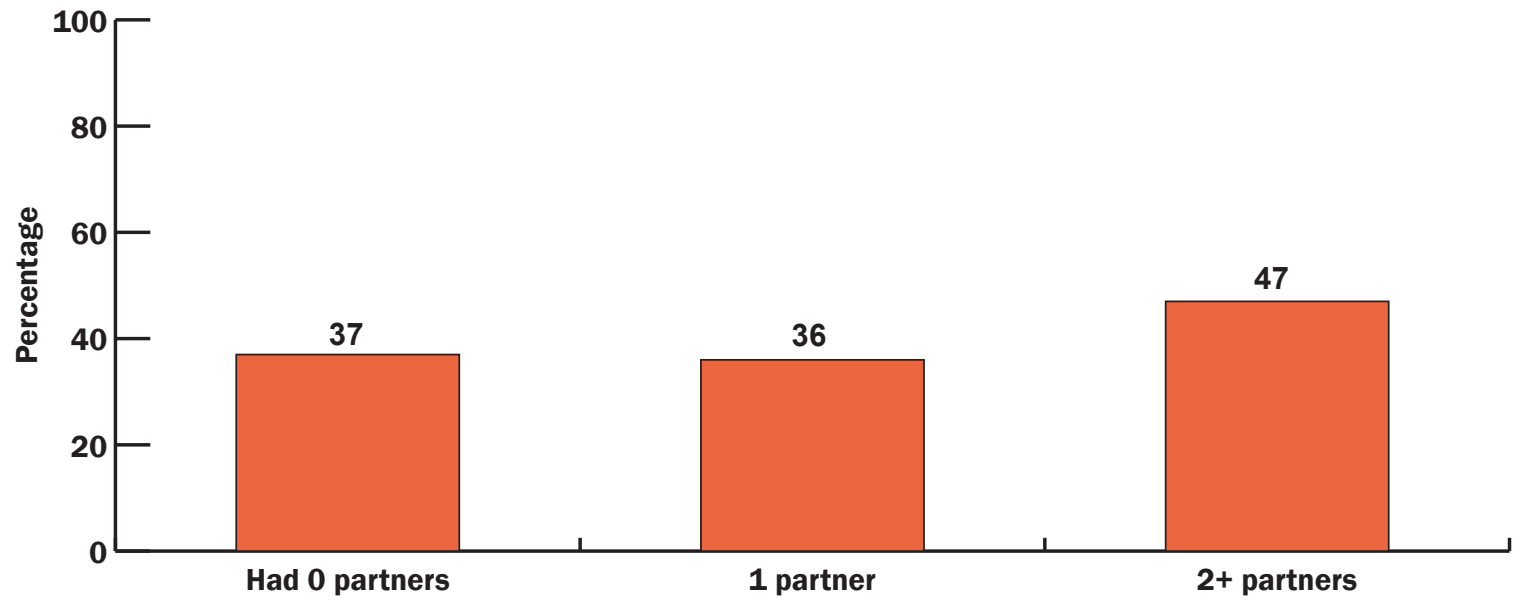

Statistically different $(p<0.05)$.

\section{Women Experiencing Physical and Sexual Violence}

Figure 12 shows the proportion of women who had experienced physical abuse (ever and in the past 12 months). Overall, a high proportion of women experienced physical abuse in their lifetime (29 percent) with 5 percent having experienced abuse in the past 12 months. These findings are 
slightly lower than that of the 2007 ZDHS, which reported a prevalence of lifetime experience of physical abuse of 47 percent. The highest proportion of woman who experienced physical abuse was in Kawama (40 percent ever and 7 percent in the last 12 months). Women in Chinyunyu were the least likely to have reported experiencing any physical abuse in their lifetime (13 percent).

Figure 12 Percent of women who experienced physical abuse in their lifetime and in the last 12 months

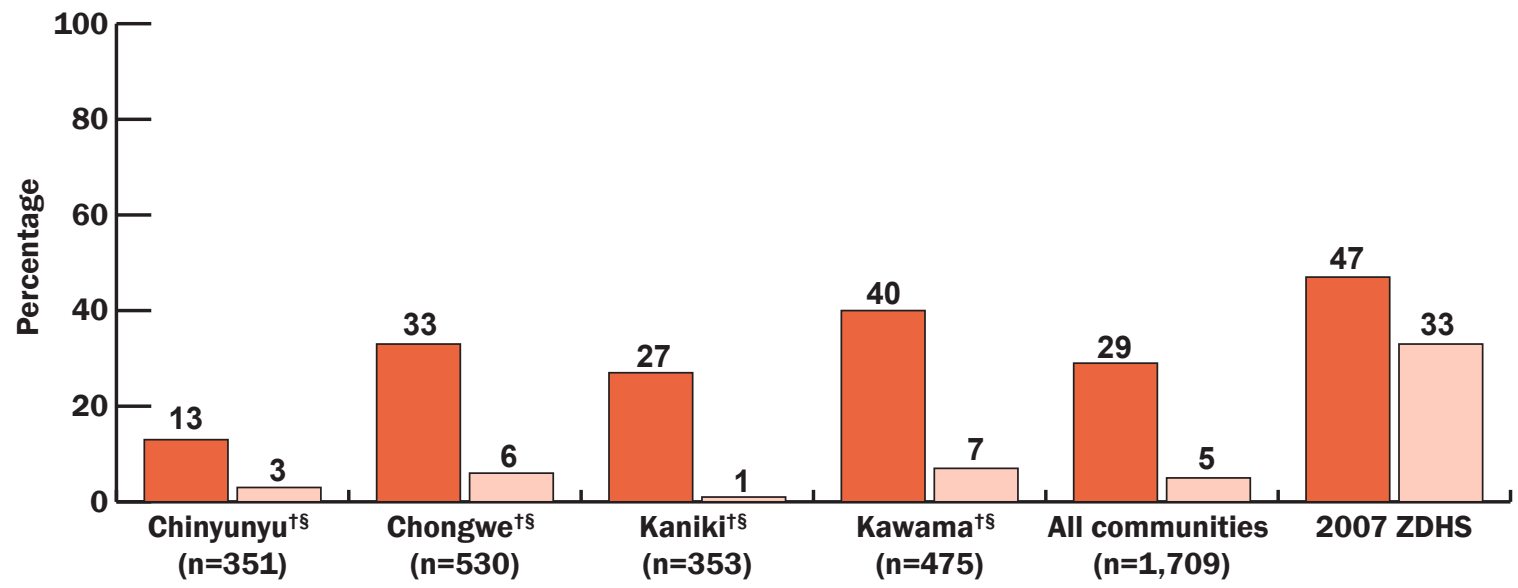

\section{$\square$ Ever physically abused $\square$ Physically abused in last 12 months}

†Statistically different across communities for ever physically abused ( $p<0.05$ ).

§Statistically different across communities for physically abused in the last 12 months $(p<0.05)$.

Figure 13 shows the proportion of women who experienced sexual abuse in their lifetime and in the past 12 months. Less than 5 percent reported having experienced sexual abuse in their lifetime and 1 percent experienced sexual abuse in the past month. Similar to physical abuse, the highest proportion of women experiencing sexual abuse was in Kawama (8 percent) and the lowest was in Chinyunyu (1 percent). These levels are much lower than the results from the 2007 ZDHS, which reported a lifetime experience of sexual abuse of 20 percent. 
Figure 13 Percent of women who experienced sexual abuse in their lifetime and in the last 12 months

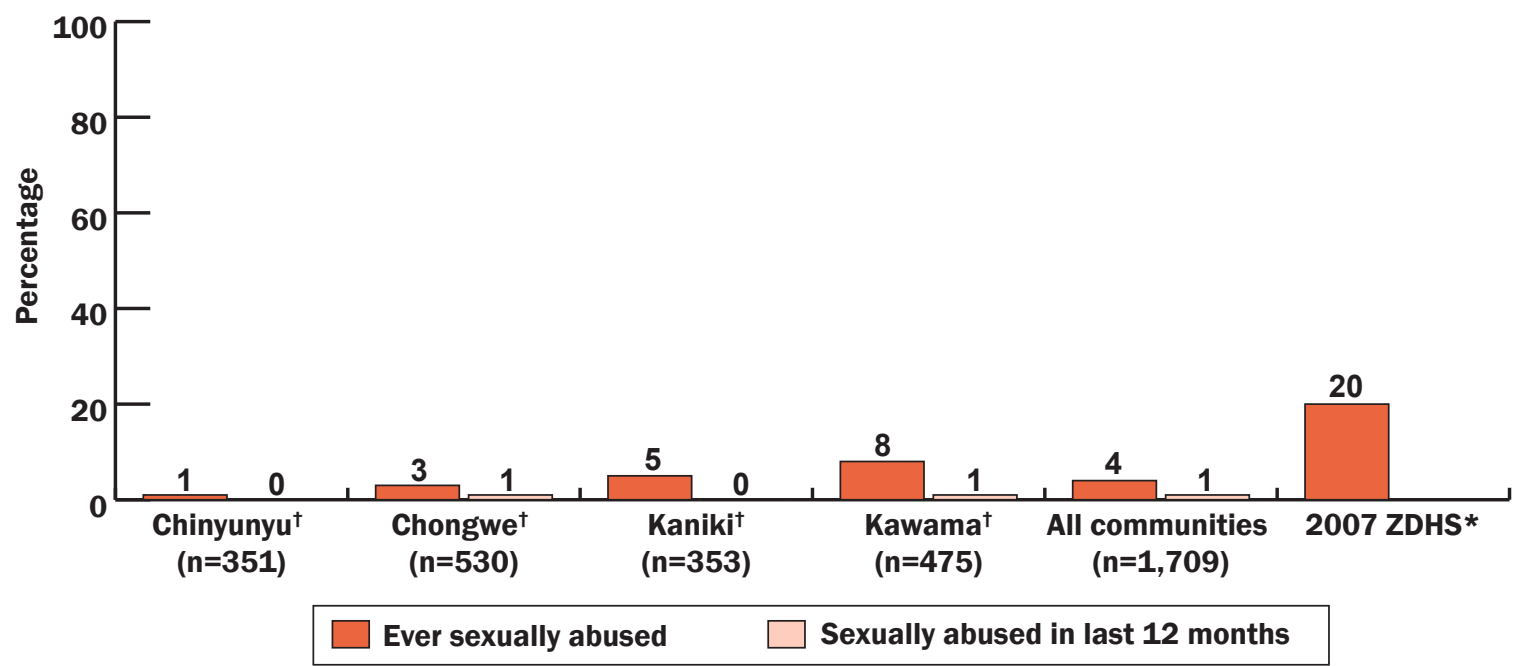

†Statistically different across communities for ever sexually abused $(p<0.05)$.

* Note: No data was reported for the past 12 months in the 2007 ZDHS.

Table 5 shows the proportion of women who were abused, either physically or sexually, and the proportion who sought services to stop the abuse. The prevalence levels varied greatly by community with Kawama having the highest level (41.5 percent) and Chinyunyu having the lowest (14.0 percent).

A small proportion of women sought help or services to stop the perpetrators of abuse. Among those abused, only 18 percent sought help; females in Kawama (18 percent) demonstrated more help-seeking behavior than those in other communities (8-10 percent). Of those who sought help, the vast majority sought help from their own family members (67 percent) or from their husband's family (54 percent) (Figure 14).

Table 5 Women's lifetime experience of physical or sexual abuse and help-seeking behavior by community

\begin{tabular}{|lccccc|}
\hline & $\begin{array}{c}\text { Chinyunyu } \\
(\mathrm{n}=351) \\
\%\end{array}$ & $\begin{array}{c}\text { Chongwe } \\
(\mathrm{n}=530)\end{array}$ & $\begin{array}{c}\text { Kaniki } \\
(\mathrm{n}=353)\end{array}$ & $\begin{array}{c}\text { Kawama } \\
(\mathrm{n}=477) \\
\%\end{array}$ & $\begin{array}{c}\text { All } \\
(\mathrm{n}=1,711) \\
\%\end{array}$ \\
$\begin{array}{l}\text { Ever physically or sexually } \\
\text { abused }\end{array}$ & $14.0^{\dagger}$ & $34.0^{\dagger}$ & $28.6^{\dagger}$ & $41.5^{\dagger}$ & 30.9 \\
$\begin{array}{l}\text { Sought help to stop } \\
\text { perpetrator(s) from abuse }\end{array}$ & $(\mathrm{n}=49)$ & $(\mathrm{n}=180)$ & $(\mathrm{n}=101)$ & $(\mathrm{n}=198)$ & $(\mathrm{n}=528)$ \\
& $10.2^{\dagger}$ & $10.0^{\dagger}$ & 7.9 & 18.2 & 12.7 \\
\hline
\end{tabular}

${ }^{\dagger}$ Statistically different across communities $(p<0.05)$. 
Figure 14 Percent of women who sought help from various sources among those who sought help after experiencing physical or sexual abuse $(n=67)$

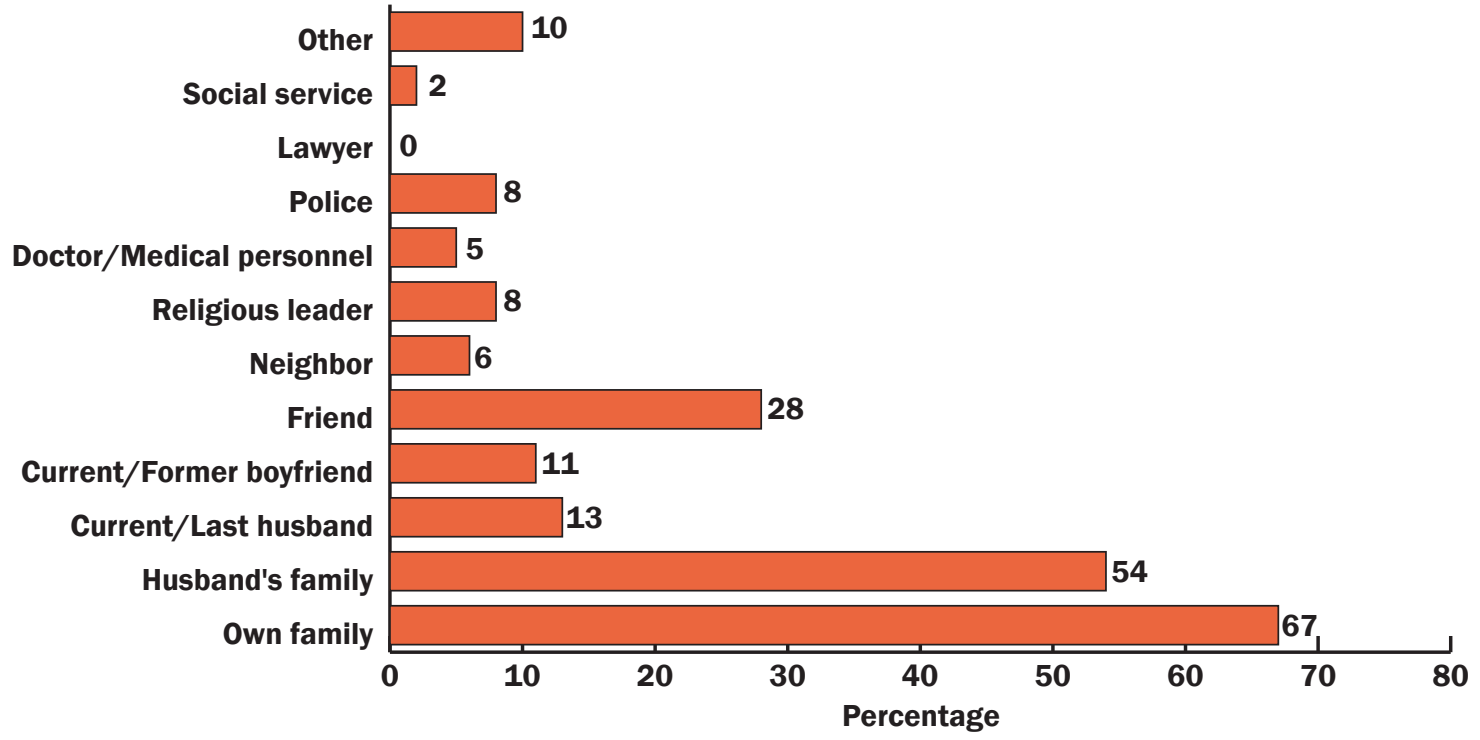

Urban women were significantly more likely than rural women to have ever experienced physical or sexual abuse (39 percent versus 27 percent; $p<0.05$ ). Wealth was not associated with abuse in the urban setting; however, in the rural setting increasing wealth was associated with higher prevalence of abuse (Figure 15).

Figure 15 Percent ever physically or sexually abused by wealth in urban and rural settings

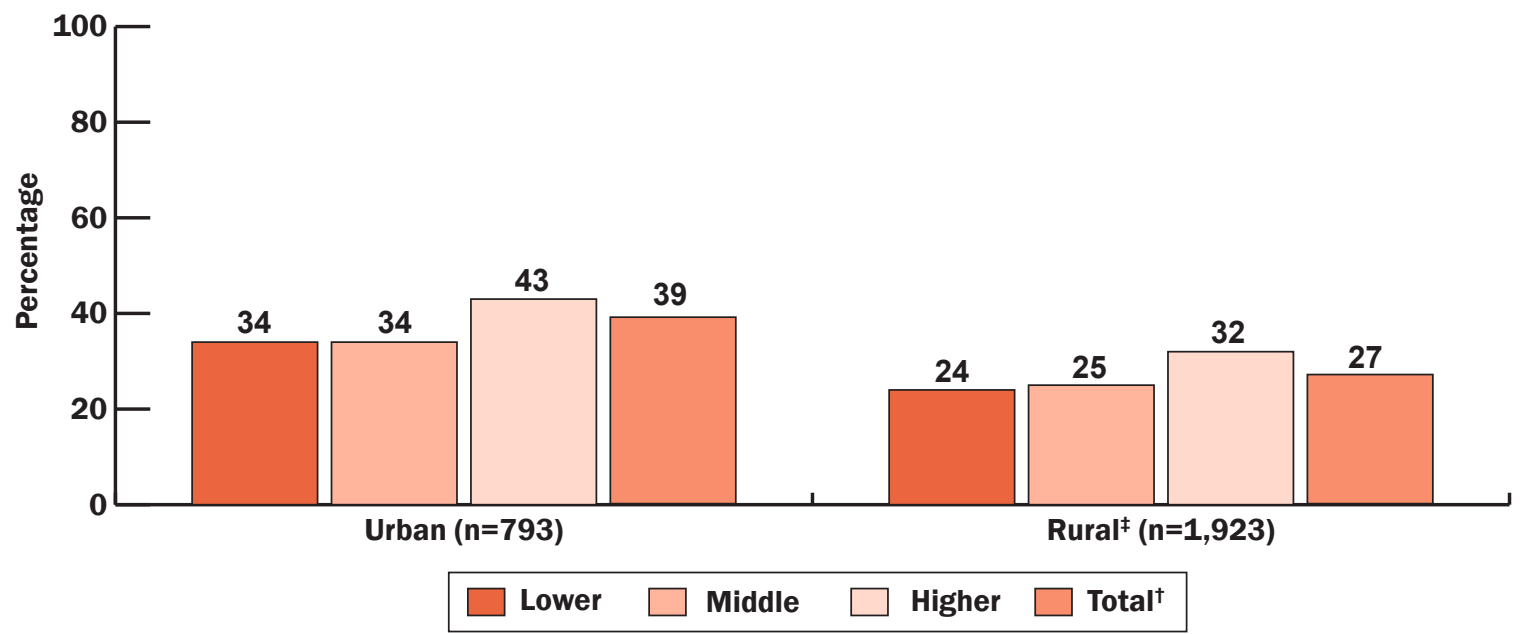

†Statistically significant by urban and rural area $(p<0.05)$.

‡Statistically significant by wealth index $(p<0.05)$.

The percentage of women who have ever experienced physical or sexual abuse was higher among older women than those under 25 years (38 percent versus 24 percent; $p<0.001$ ), and women with no or primary education compared to women with secondary education or higher (34 percent versus 28 percent; $p<0.05$ ). Lastly, married or co-habiting women as well as divorced or separated women had the highest prevalence of physical or sexual abuse compared to those never married (38 percent vs. 16 percent; $p<0.001$ ) (Table 6). 
Table 6 Prevalence of having been physically or sexually abused in their lifetime by select characteristics $(n=1,711)$

\begin{tabular}{|c|c|c|}
\hline & $\begin{array}{l}\text { Ever experienced physical or sexual abuse } \\
\qquad \%\end{array}$ & p-value \\
\hline \multicolumn{3}{|l|}{ Age } \\
\hline $15-24$ & 23.6 & $<0.001$ \\
\hline $25+$ & 37.5 & \\
\hline \multicolumn{3}{|l|}{ Education } \\
\hline None or primary & 33.7 & $<0.05$ \\
\hline Secondary or higher & 28.3 & \\
\hline \multicolumn{3}{|l|}{ Marital status } \\
\hline Never married & 15.8 & $<0.001$ \\
\hline Married/Co-habiting & 38.4 & \\
\hline Divorced/Wid'd/Separated & 38.8 & \\
\hline
\end{tabular}

Men were asked about whether they agreed to specific statements justifying wife beating, such as wife going out without telling him, wife neglecting him, or wife refusing to have sex with him. Approximately one-quarter of male respondents agreed to at least one of the reasons that wife beating is justified (Figure 16). This varied significantly across the communities (Figure 17), with 35 percent of men in Kawama believing that wife beating is justified for at least one of the five reasons and 19 percent of men in Chinyunyu believing so.

Figure 15 Percent of men who believe that wife beating is justified for various reasons ( $n=1,367)$

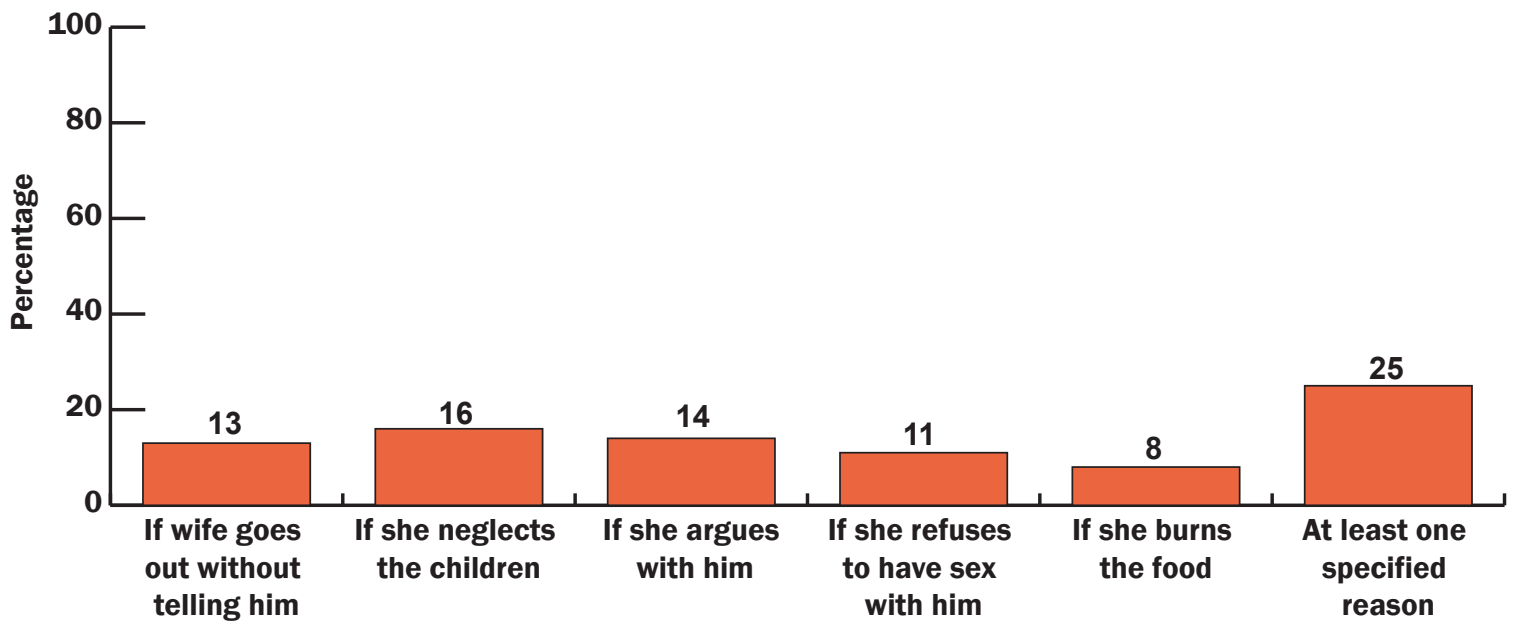


Figure 17 Percent of men who believe that wife beating is justified for at least one of the five reasons $(n=1,367)$

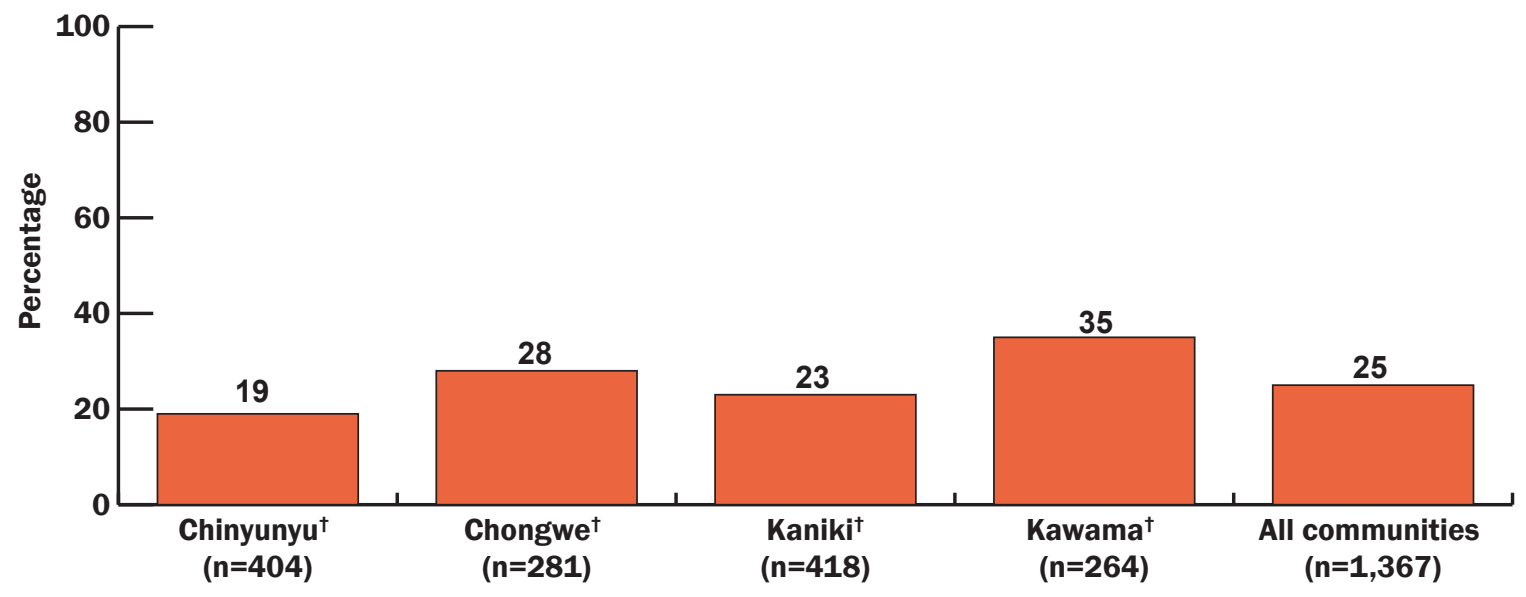

†Statistically different across communities $(p<0.05)$.

\section{Attitudes toward people living with AIDS}

Reducing stigma and discrimination associated with HIV is one of the objectives of COMPACT. The baseline questionnaire assessed people's attitudes toward people living with AIDS to assess the level of stigma associated with HIV and AIDS. Figure 18 shows that the majority of respondents were willing to care for a family member with HIV or AIDS in their own home (93 percent), would buy vegetables from a shopkeeper who has HIV (86 percent), and think that a female teacher with HIV who is not sick should be allowed to continue teaching (84 percent). However, a smaller percentage indicated they would not want to keep secret that a family member is HIV positive (41 percent). In all, only 31 percent of all respondents had accepting attitudes on all four indicators.

Figure 18 Percent of respondents with accepting attitudes toward people living with HIV and AIDS $(n=3,160)$

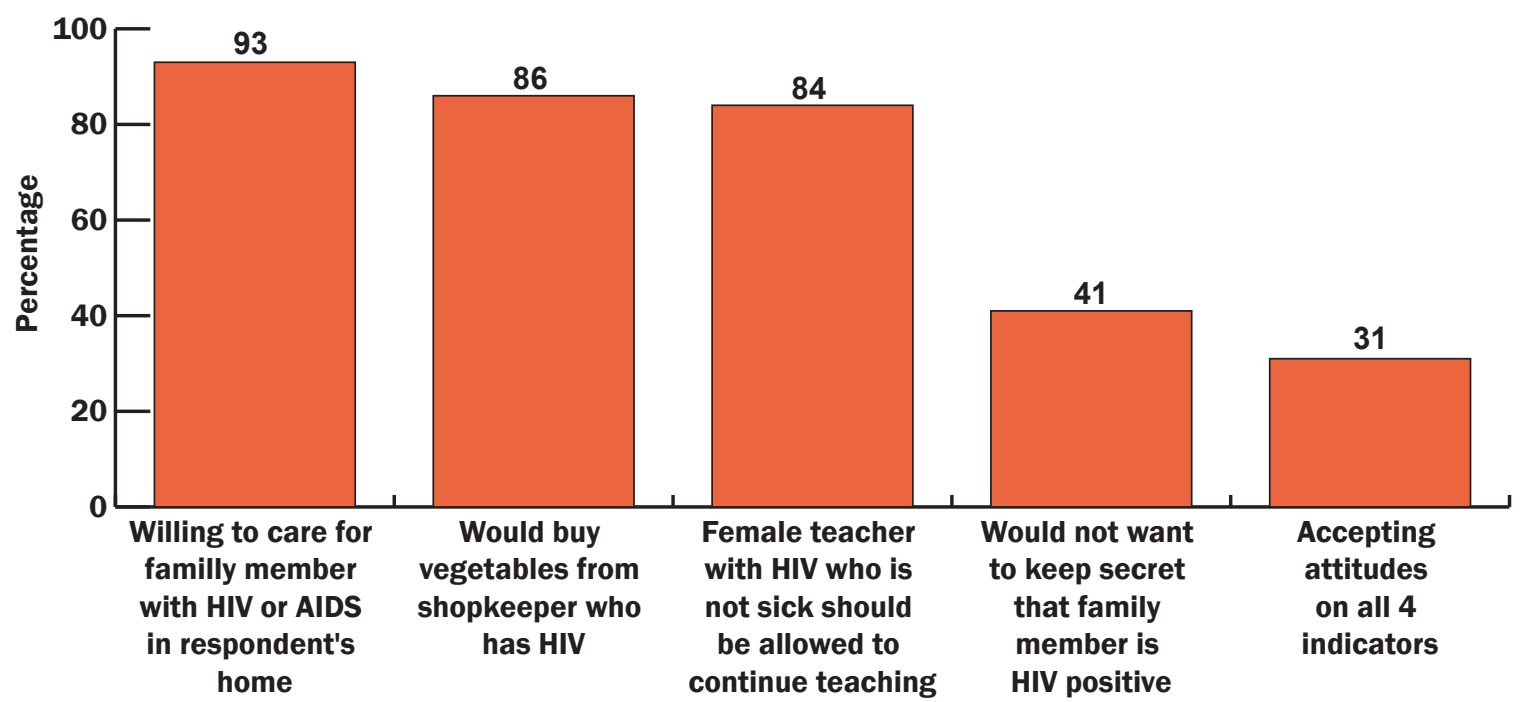


Accepting attitudes on all four indicators varied by community, with Chongwe reflecting the highest proportion of respondents with accepting attitudes (43-49 percent) (Figure 19). Kaniki and Kawama had the lowest proportion of respondents with accepting attitudes (24-27 percent). There were no significant differences in attitudes between males and females in any of the communities.

Figure 19 Percent of respondents with accepting attitudes toward people living with HIV and AIDS* $($ Male = 1,393; Female $=1,723)$

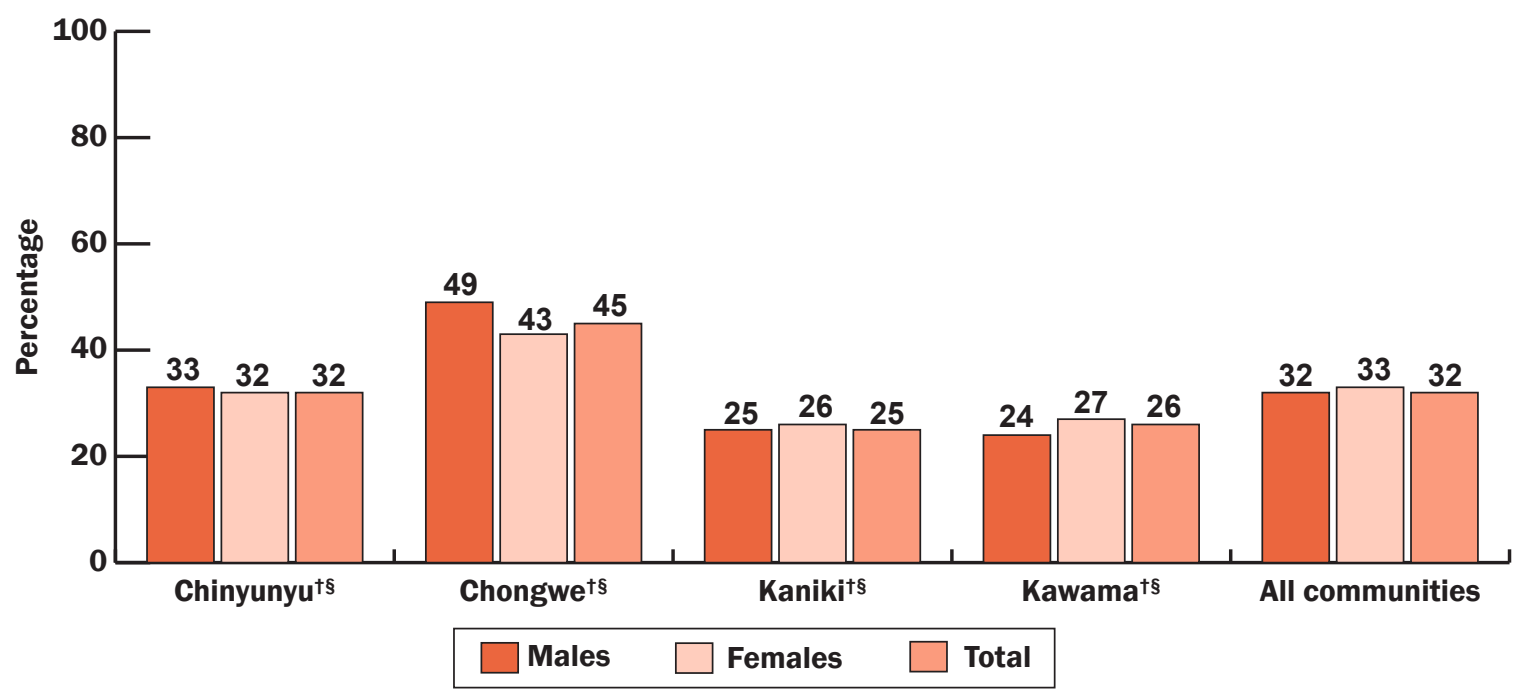

†Statistically different across communities for males $(p<0.05)$ sStatistically different across communities for females $(p<0.05)$.

*Accepting attitudes on all four indicators (i.e., willing to care for HIV-infected family member in respondent's home, would buy vegetables from shopkeeper with HIV, female teacher with HIV who is not sick should be allowed to continue teaching, and would not want to keep secret that family member is HIV positive).

\section{Contraception and Pregnancy}

The percentage of respondents who had heard of methods that men or women can use to avoid pregnancy was very low (57 percent overall) (Figure 20). Males were significantly less likely to have heard of such methods ( 45 percent versus 67 percent; $p<0.05$ ). For males in Chinyunyu, Kaniki, and Kawama, only about 40 percent had heard of ways to avoid pregnancy. Chinyunyu had the lowest percentage of females who had heard of ways to avoid pregnancy (54 percent) compared to other communities (66-72 percent). 
Figure 20 Percent who have heard of methods women or men can use to avoid pregnancy by community and sex $($ Male $=1,396$; Female $=1,746)$

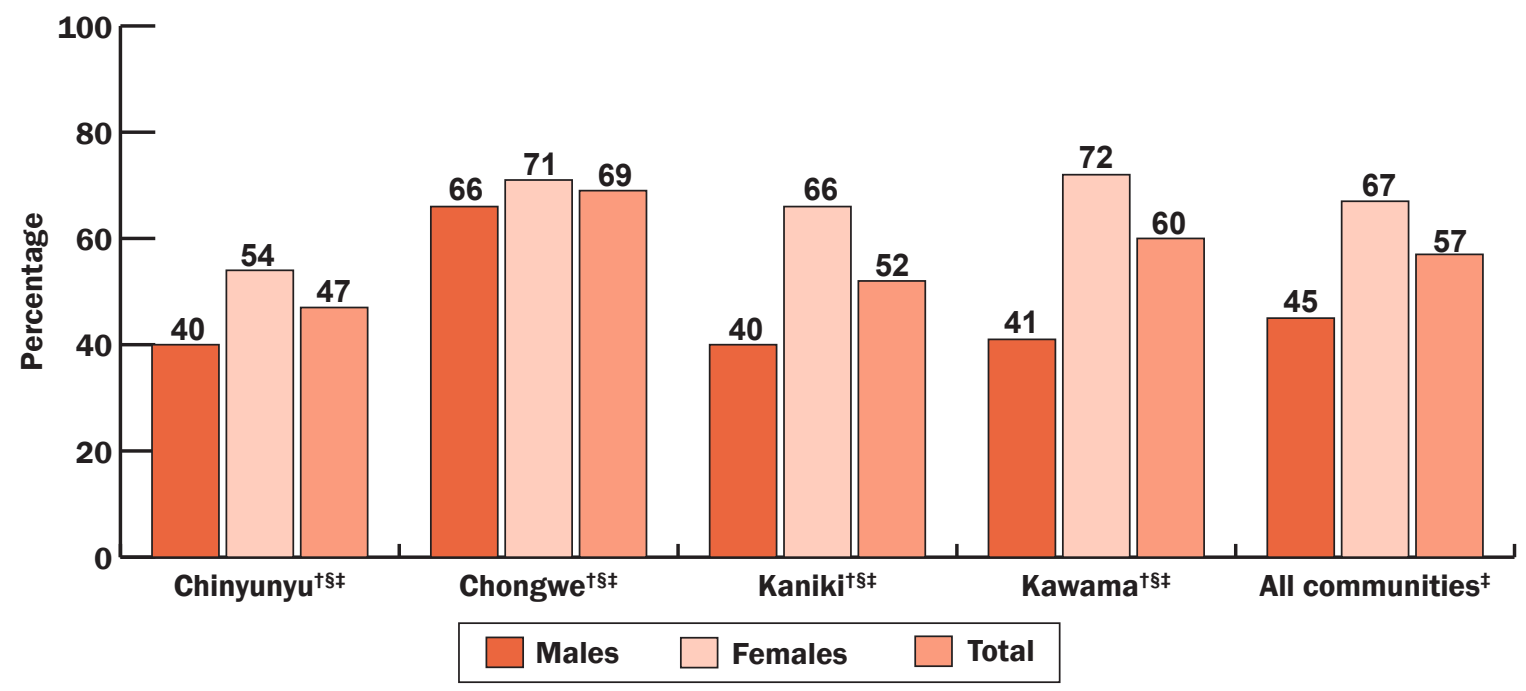

†Statistically different across communities for males $(p<0.05)$.

§Statistically different across communities for females $(p<0.05)$.

$\neq$ Statistically different between males and females $(p<0.05)$.

Figure 21 shows that even among sexually active males and females, the percentage of people who had heard of ways to prevent pregnancy was still low (51 percent among males and 75 percent among females).

Figure 21 Percent who have heard of methods women or men can use to avoid pregnancy among those who had sex in the last 12 months (Male = 845; Female = 1,132)

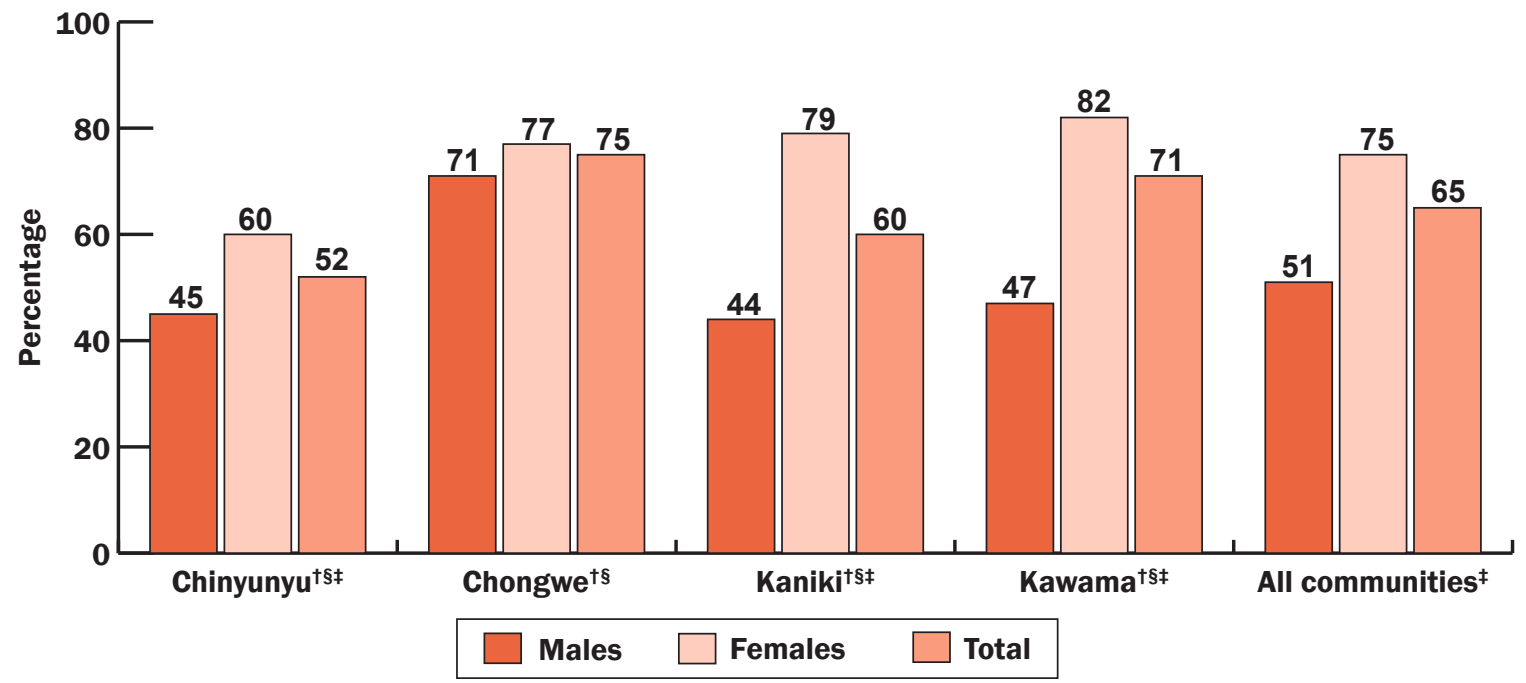

'Statistically different across communities for males $(p<0.05)$.

§Statistically different across communities for females $(p<0.05)$.

₹Statistically different between males and females $(p<0.05)$. 
Use of contraception is low in all four communities. Only one-third of sexually active women reported using some kind of method to avoid/delay pregnancy, with Chinyunyu having the lowest prevalence of family planning use (19.1 percent) (Table 7). Women did not report challenges in getting contraceptives in any of the communities. Only a few women had heard of Postinor 2 , the emergency contraceptive pill (2.8 percent).

Table 7 Contraception use and pregnancy intentions among women by community

\begin{tabular}{|c|c|c|c|c|c|}
\hline & $\begin{array}{c}\text { Chinyunyu } \\
(\mathrm{n}=351) \\
\%\end{array}$ & $\begin{array}{c}\text { Chongwe } \\
(\mathrm{n}=538) \\
\%\end{array}$ & $\begin{array}{c}\text { Kaniki } \\
(n=363) \\
\%\end{array}$ & $\begin{array}{c}\text { Kawama } \\
(\mathrm{n}=492) \\
\%\end{array}$ & $\begin{array}{c}\text { All } \\
\text { communities } \\
(n=1,744) \\
\%\end{array}$ \\
\hline $\begin{array}{l}\text { Ever used any method to avoid/ } \\
\text { delay pregnancy among those who } \\
\text { ever had sex }\end{array}$ & $32.6^{\dagger}$ & $46.4^{\dagger}$ & $45.9^{\dagger}$ & $52.2^{\dagger}$ & 45.1 \\
\hline $\begin{array}{l}\text { Currently using method to avoid/ } \\
\text { delay pregnancy among those who } \\
\text { had sex in last } 12 \text { months }\end{array}$ & $19.1^{\dagger}$ & $36.5^{\dagger}$ & $36.3^{\dagger}$ & $36.5^{\dagger}$ & 32.8 \\
\hline $\begin{array}{l}\text { Who decided type of family } \\
\text { planning/spacing method }\end{array}$ & $(n=55)$ & $(n=161)$ & $(n=90)$ & $(n=123)$ & $(n=429)$ \\
\hline Mainly self & 23.6 & 29.8 & 25.6 & 23.6 & 26.3 \\
\hline Mainly partner & 14.6 & 8.7 & 7.8 & 11.4 & 10.0 \\
\hline Jointly & 61.8 & 60.9 & 64.4 & 61.8 & 62.0 \\
\hline Other & 0.0 & 0.6 & 2.2 & 3.3 & 1.6 \\
\hline $\begin{array}{l}\text { Faced any challenges in getting } \\
\text { contraceptive method }\end{array}$ & 7.7 & 6.8 & 3.3 & 5.7 & 5.8 \\
\hline $\begin{array}{l}\text { Heard of emergency contraceptive } \\
\text { (Postinor2) }\end{array}$ & $1.4^{\dagger}$ & $3.9^{\dagger}$ & $1.7^{\dagger}$ & $3.3^{\dagger}$ & 2.8 \\
\hline Pregnancy intention (at last birth) & $(n=238)$ & $(n=391)$ & $(n=242)$ & $(n=342)$ & $(n=1,213)$ \\
\hline Wanted to be pregnant & 42.0 & 44.0 & 38.8 & 36.6 & 40.5 \\
\hline Wanted to wait until later & 33.2 & 36.6 & 38.4 & 36.3 & 36.2 \\
\hline $\begin{array}{l}\text { Did not want to get pregnant at } \\
\text { all }\end{array}$ & 24.8 & 19.4 & 22.7 & 26.9 & 23.3 \\
\hline
\end{tabular}

†Statistically different across communities $(p<0.05)$.

Despite lower family planning method use, Chinyunyu did not have higher prevalence of unintended pregnancy. In all communities, the prevalence of unintended pregnancy was high, ranging from 56-63 percent (Table 7). In further exploring unintended pregnancies by age and marital status, we found that among those who had ever given birth, unmarried younger females had the highest rate of unintended pregnancies; 90 percent of younger (15-24 years) unmarried females had unintended pregnancies compared to approximately 51-75 percent of all other females (Figure 22). Additionally, those in urban areas and in the lowest wealth index were the most likely to have unintended pregnancies (Figure 23). 
Figure 22 Percent of unintended pregnancy by age and marital status among women who have ever given birth

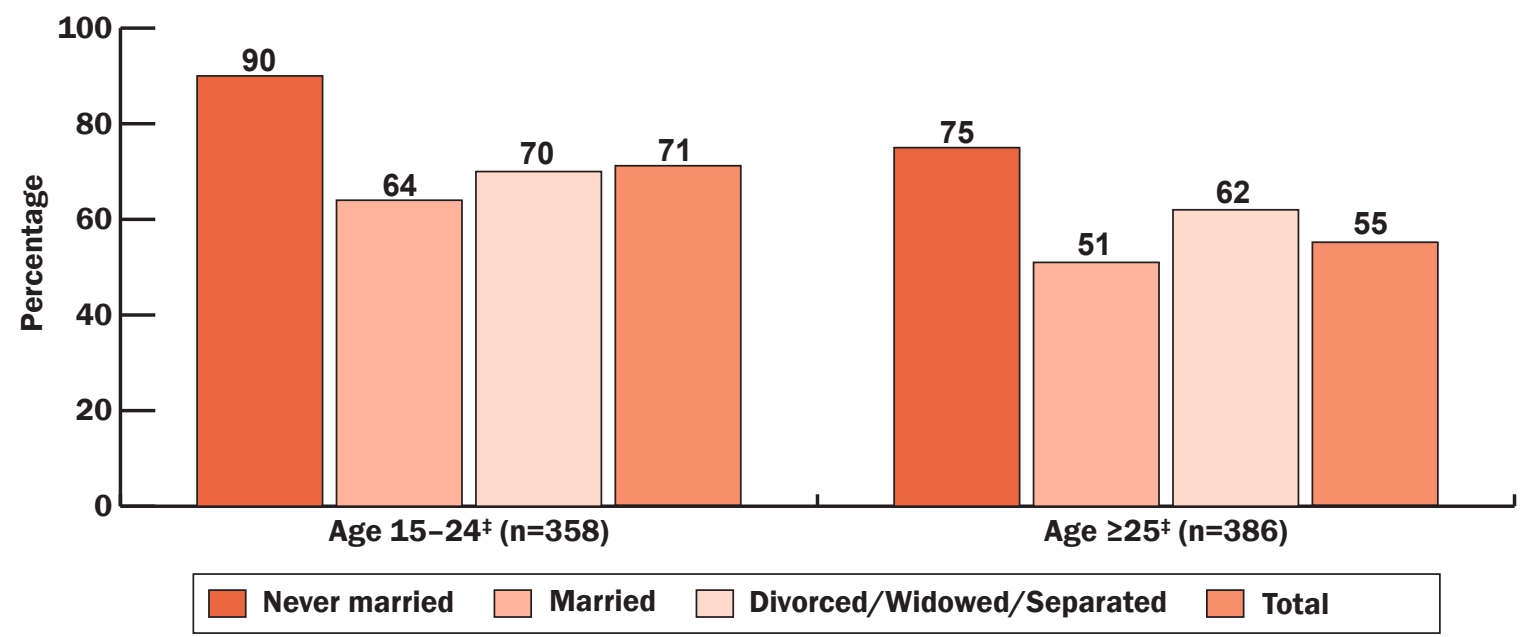

†Statistically significant by age $(p<0.05)$.

₹Statistically significant by marital status.

Figure 23 Percent of unintended pregnancy by wealth in urban and rural settings among women who have ever given birth

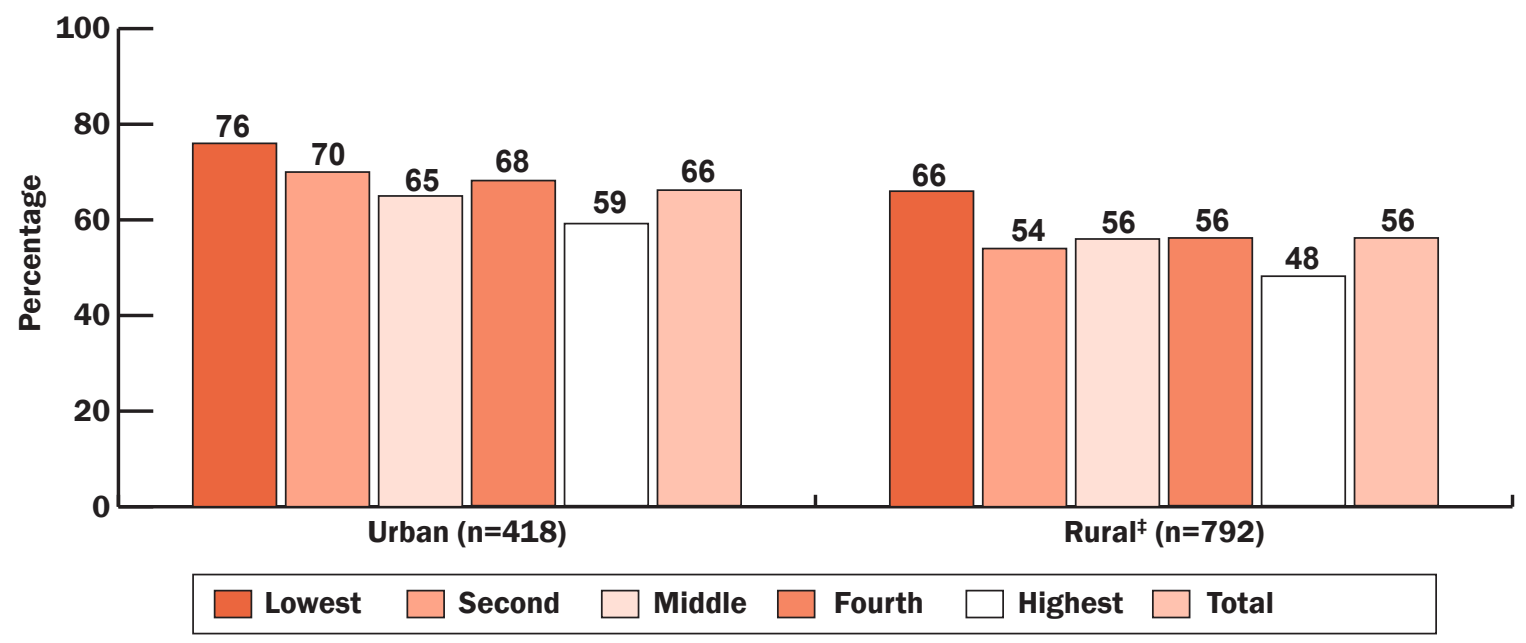

†Statistically significant by urban and rural area $(p<0.05)$.

‡Statistically significant by wealth quintile.

Women who reported some type of contraceptive use were most likely to report using the pill, injectable contraceptives, or male condoms. Other types of contraception not included in Figure 24 were mentioned by less than 5 percent of women using any contraceptives; these include male and female sterilization, diaphragm, foam/jelly, withdrawal, lactational amenorrhea method, and emergency contraception. 
Figure 24 Types of contraception currently used by women using some method to avoid or delay pregnancy

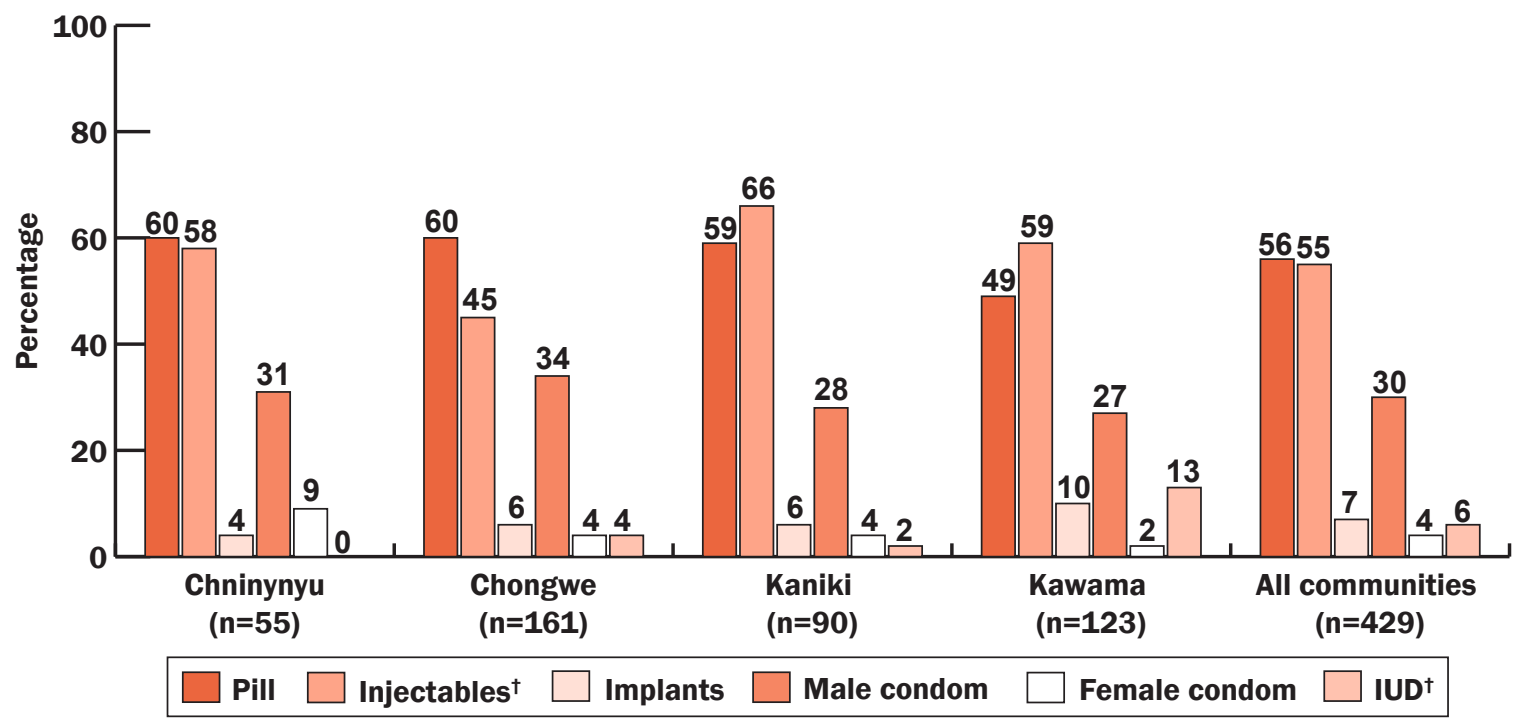

†Statistically different across communities $(p<0.05)$.

\section{Men's perspective on contraception}

We examined men's attitudes toward contraception as a potential barrier to contraceptive use. Figure 25 shows that indeed a fairly high proportion of men (16 percent) think that contraception is women's business and 27 percent think that women who use contraception may become promiscuous. Men in Kawama were more likely to hold these views compared to men in other communities. Fears about women becoming promiscuous due to contraceptive use was more common in all communities than belief that contraception is a woman's business, except for in Chinyunyu.

Figure 25 Men's views regarding contraception by province and sex*

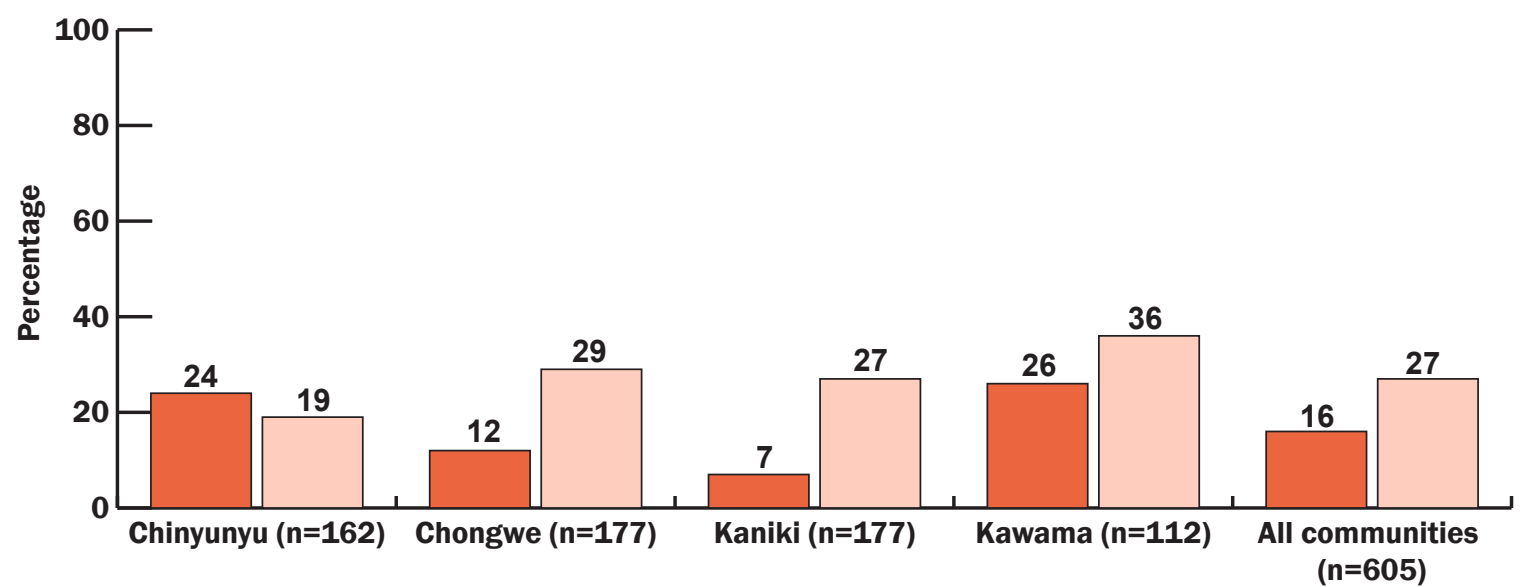

Contraception is women's business and a man should not have to worry about it ${ }^{\dagger}$ Women who use contraception may become promiscuous ${ }^{\dagger}$

*Among those who have ever heard of contraception.

${ }^{+}$Statistically different across communities $(p<0.05)$. 


\section{Antenatal Care}

Approximately three-quarters (77 percent) of women attended antenatal care for their last pregnancy (Table 8); however, this varied across communities, with Chinyunyu having the lowest prevalence of ANC attendance (63 percent). In all communities, however, the proportion who had fewer than the recommended four ANC visits was high (40 percent); this did not vary by community. The largest proportion of women who attended ANC saw nurse/midwives (68-88 percent). Although Chinyunyu had the lowest prevalence of women who attended ANC, Chinyunyu also had the lowest proportion of women who gave birth to a live child who later died ( 9 percent) compared to other communities (16-25 percent).

Table 8 Antenatal care among women by province

\begin{tabular}{|c|c|c|c|c|c|}
\hline & $\begin{array}{c}\text { Chinyunyu } \\
(\mathrm{n}=351) \\
\%\end{array}$ & $\begin{array}{c}\text { Chongwe } \\
(n=538) \\
\%\end{array}$ & $\begin{array}{c}\text { Kaniki } \\
(n=363) \\
\%\end{array}$ & $\begin{array}{c}\text { Kawama } \\
(n=492) \\
\%\end{array}$ & $\begin{array}{c}\text { All } \\
\text { communities } \\
(n=1,744) \\
\%\end{array}$ \\
\hline $\begin{array}{l}\text { Attended antenatal care for last } \\
\text { pregnancy }\end{array}$ & $63.2^{\dagger}$ & $79.8^{+}$ & $81.0^{\dagger}$ & $80.5^{\dagger}$ & 77.0 \\
\hline $\begin{array}{l}\text { Had }<4 \text { ANC visits (among } \\
\text { those who attended ANC for last } \\
\text { pregnancy) }\end{array}$ & 44.0 & 40.6 & 36.3 & 41.3 & 40.5 \\
\hline \multicolumn{6}{|l|}{$\begin{array}{l}\text { Whom seen for antenatal care at } \\
\text { last pregnancy }\end{array}$} \\
\hline Doctor & $19.5^{\dagger}$ & $7.7^{\dagger}$ & $19.6^{\dagger}$ & $9.9^{\dagger}$ & 12.7 \\
\hline Clinical officer & $40.3^{\dagger}$ & $30.8^{\dagger}$ & $49.8^{\dagger}$ & $38.4^{\dagger}$ & 38.5 \\
\hline Nurse/Midwife & $68.2^{\dagger}$ & $84.3^{\dagger}$ & $83.4^{\dagger}$ & $88.0^{\dagger}$ & 82.6 \\
\hline \multirow[t]{3}{*}{ Traditional birth attendant } & 0.7 & 1.2 & 1.0 & 1.4 & 1.1 \\
\hline & $(n=244)$ & $(n=396)$ & $(n=248)$ & $(n=354)$ & $(n=1,242)$ \\
\hline & $8.6^{\dagger}$ & $16.4^{\dagger}$ & $25.0^{\dagger}$ & $21.5^{\dagger}$ & 18.0 \\
\hline
\end{tabular}

${ }^{\dagger}$ Statistically different across communities $(p<0.05)$.

\section{Alcohol Use}

In all communities, males were significantly more likely than females to have been drunk in the past four weeks (35 percent versus 11 percent; $p<0.05$ ) (Figure 26). Prevalence of being drunk varied across communities for both males and females. Kawama (42 percent) had the highest prevalence of drunkenness compared to the other three communities, although all communities had high prevalence of drunkenness for males. 
Figure 26 Percentage of males and females who reported being drunk in the past 4 weeks $($ Male $=1,434 ;$ Female $=1,750)$

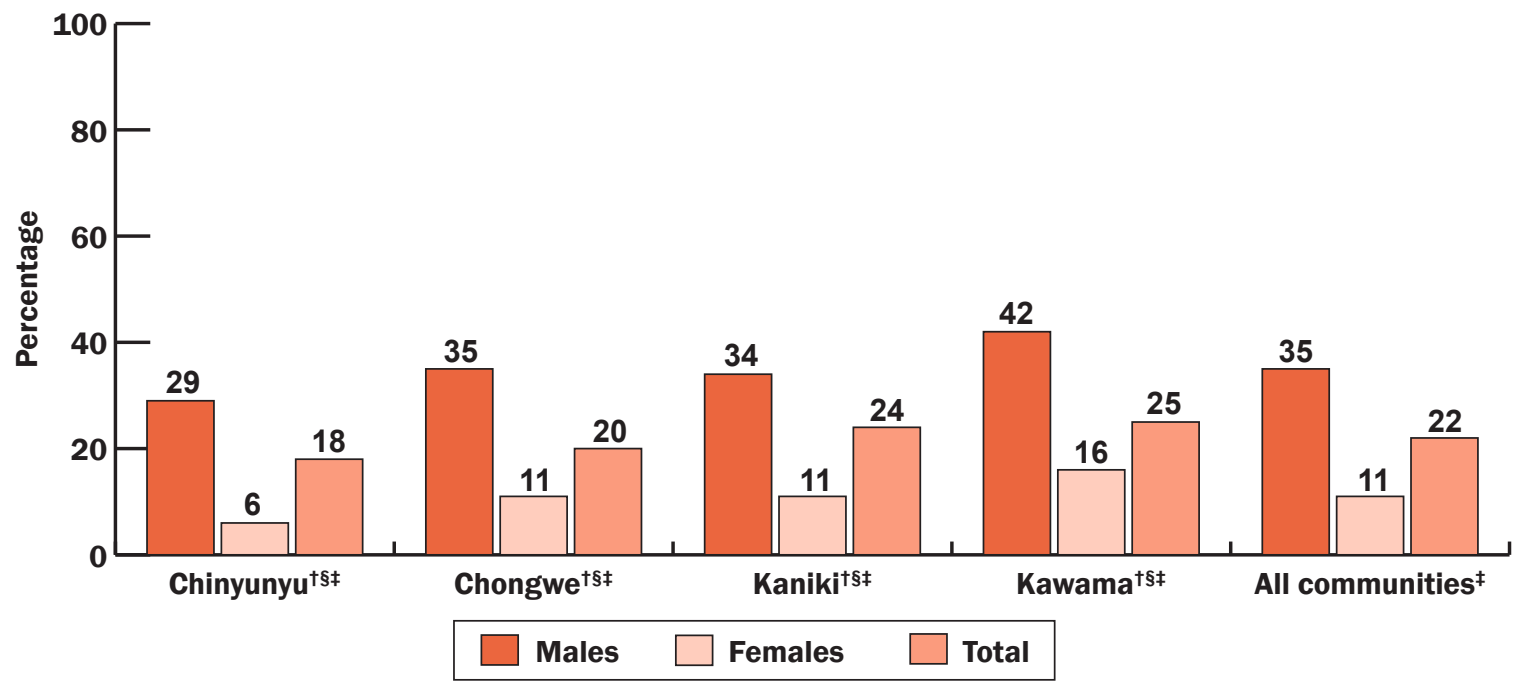

'Statistically different across communities for males $(p<0.05)$

sStatistically different across communities for females $(p<0.05)$.

₹Statistically different between males and females $(p<0.05)$

Alcohol abuse is best measured using the CAGE 4-item questionnaire (Ewing 1984). CAGE stands for Cut down, Annoyed, Guilty, and Eye-opener. The items include feeling the need to cut down on drinking (Cut down), being annoyed by people criticizing drinking (Annoyed), feeling guilty about drinking (Guilty), and needing an eye-opener first thing in the morning (Eye-opener). A high score on the questionnaire represents a clinically significant alcohol problem.

The findings are similar to findings for drunkenness. About one-quarter of all males were found to have a clinically significant alcohol problem, compared to 11 percent of females $(p<0.05)$ (Figure 27). 
Figure 27 Percentage of males and females who are considered to have a clinically significant alcohol problema $($ Male $=1,434 ;$ Female $=1,750)$

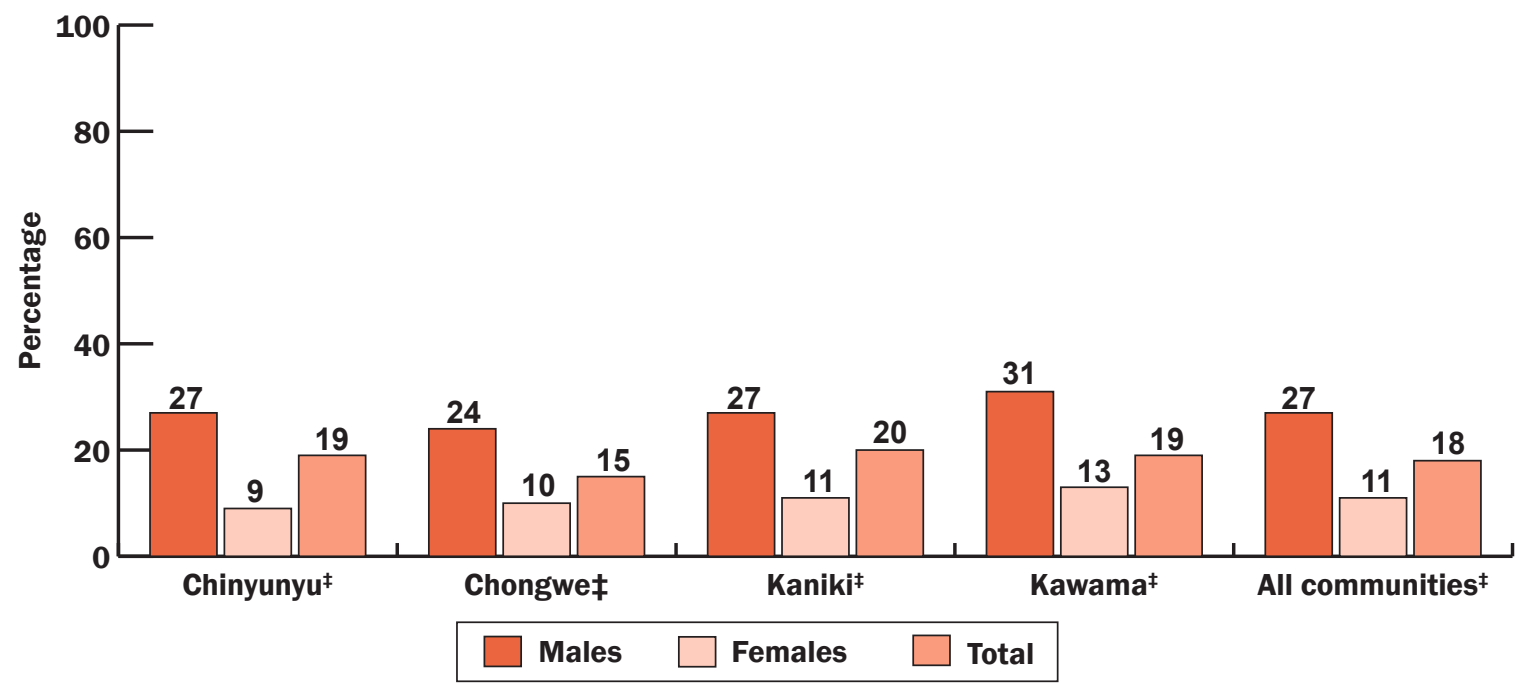

${ }^{\mathrm{a} A}$ person is considered to have a clinically significant alcohol problem based on the CAGE questionnaire (Ewing 1984). †Statistically different across communities for males $(p<0.05)$.

§Statistically different across communities for females $(p<0.05)$.

†Statistically different between males and females $(p<0.05)$.

When stratified by age, we found that men aged 20 years or older were more likely to have a clinically significant alcohol problem (approximately 28-39 percent) compared to 15-19 year old males (11 percent). Among females, clinical alcohol problem was highest among 30-34 year olds (20 percent) (Figure 28).

Figure 28 Percentage of males and females who are considered to have a clinically significant alcohol problem ${ }^{\mathrm{a}}$ by age $($ Male $=1,434 ;$ Female $=1,750)$

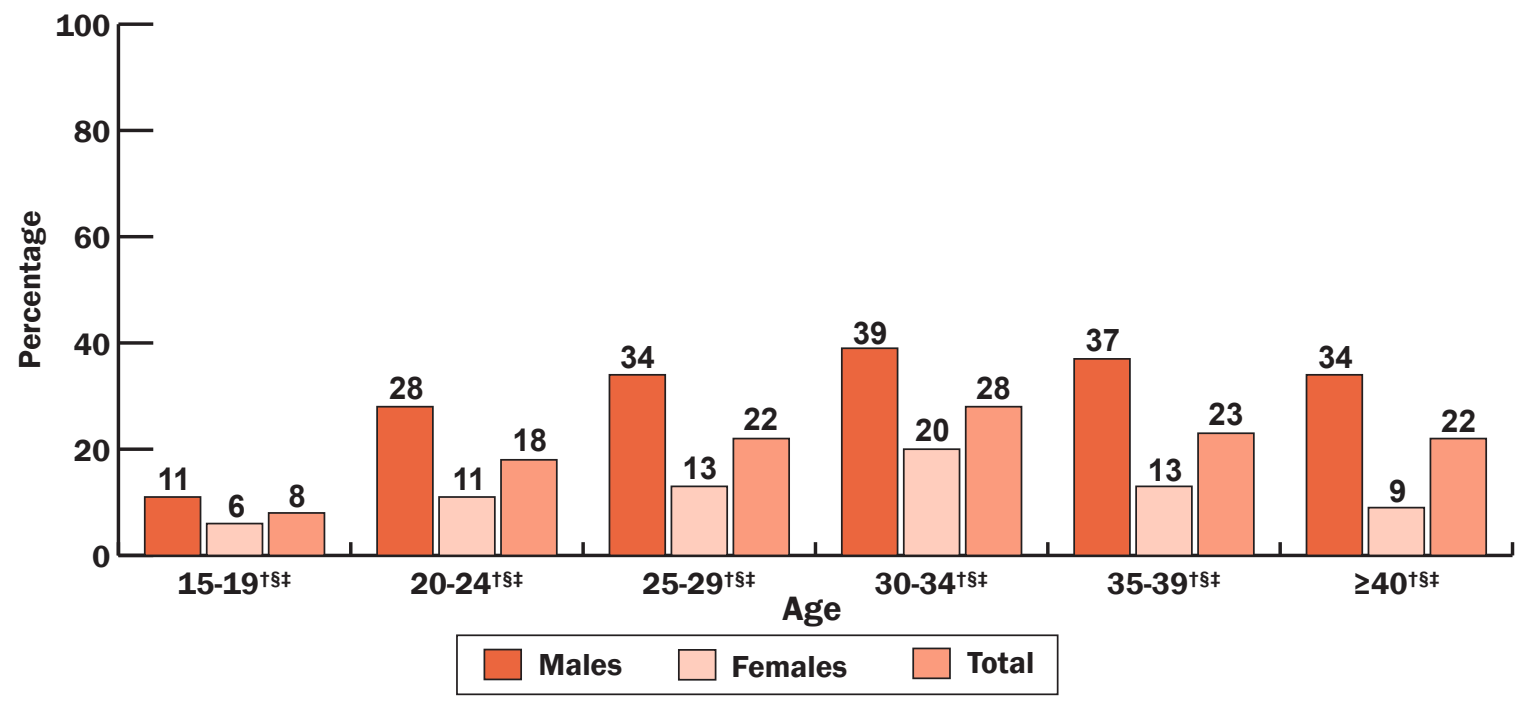

†Statistically different across age groups for males $(p<0.05)$.

sStatistically different across age groups for females $(p<0.05)$.

‡Statistically different between males and females $(p<0.05)$. 
When examining experience of abuse among women with alcohol problems, we found that those with clinically significant alcohol problem were twice as likely to have ever been physically or sexually abused (52 percent versus 28 percent; $p<0.05$ ) (Figure 29).

Figure 29 Percent of female respondents who reported having ever been physically or sexually abused by alcohol abuse status ${ }^{a}(n=1,708)$

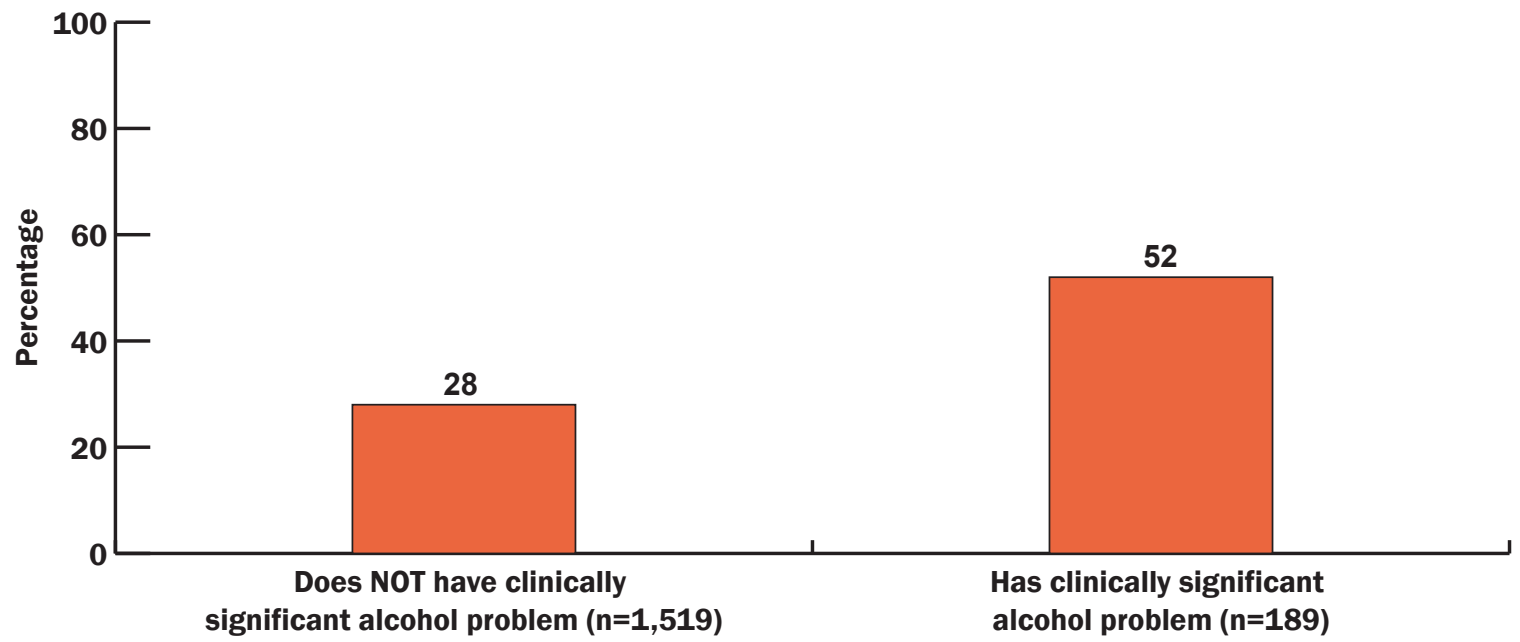

aA person is considered to have a clinically significant alcohol problem based on the CAGE questionnaire (Ewing 1984). Statistically significant by alcohol problem $(p<0.05)$.

\section{HIV Seroprevalence}

The overall HIV seroprevalence was 14 percent (Figure 30). While the prevalence did not vary significantly across communities for men and women, there was a significant difference by sex. Women were significantly more likely to be HIV infected than men (17 percent versus 10 percent; $p<0.05)$. The difference in HIV seroprevalence between women and men was most pronounced in Kaniki (16 percent versus 9 percent; $p<0.05$ ) and Kawama $(21$ percent versus 12 percent; $p$ $<0.05)$. These figures are similar to the HIV prevalence from the 2007 ZDHS. 
Figure 30 HIV seroprevalence among males and females by community (Male =1,221;

Female $=1,498$ )

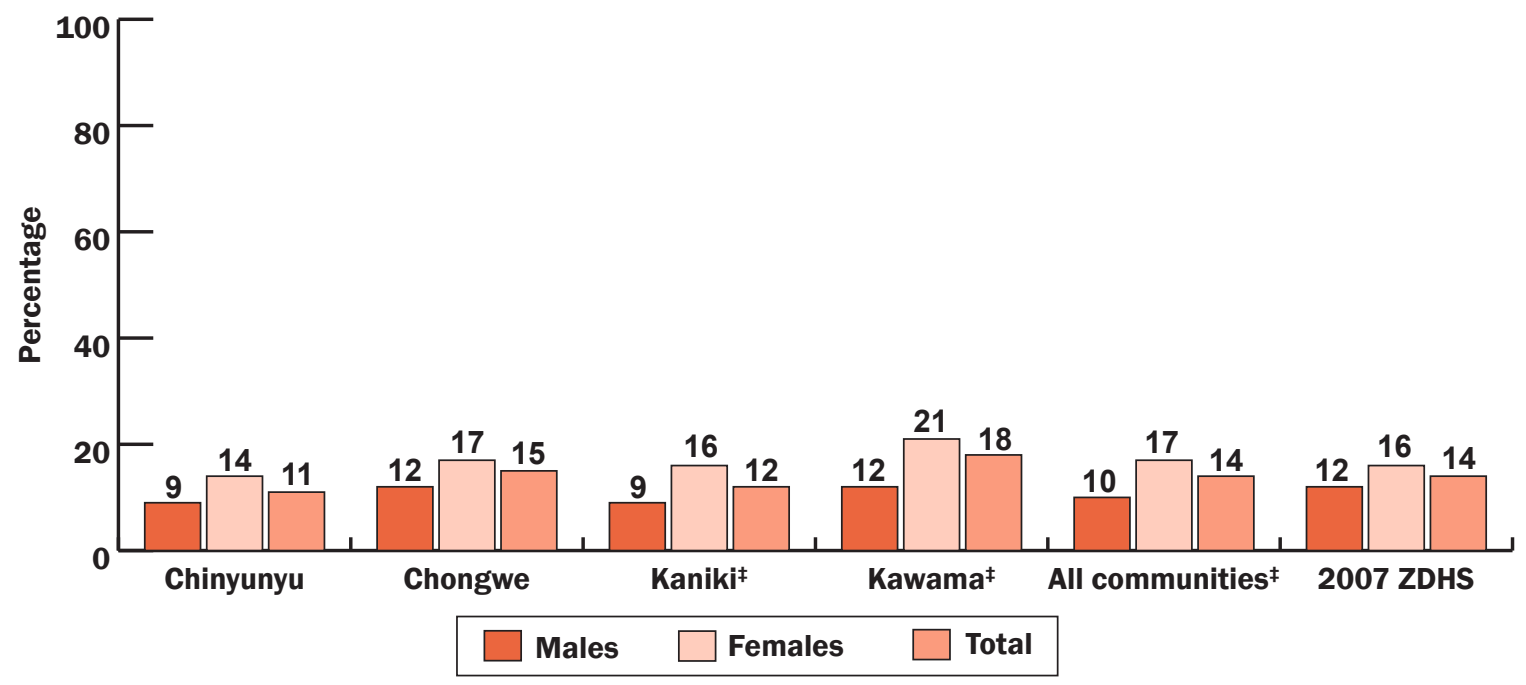

₹Statistically different between males and females $(p<0.05)$.

Similar to the 2007 ZDHS, HIV seroprevalence in this study peaked at 40 years or older for men (21 percent) and 30-34 years of age for women (30 percent). HIV prevalence was highest among those aged 25-29 years (24 percent) and 30-34 years (22 percent) and lower among those 18-24 years old (13 percent) and 35 or older (16 percent) (Figure 31). The difference in HIV seroprevalence is particularly striking among 20-24 year olds where young women were six times more likely to be HIV infected than young men $(p<0.05)$. The difference is again striking among 30-39 year olds, where women were twice as likely to be HIV infected (males: 14 percent and females: $29-30$ percent; $p<0.05$ ).

Figure 31 HIV seroprevalence among males and females by age $(n=2,718)$

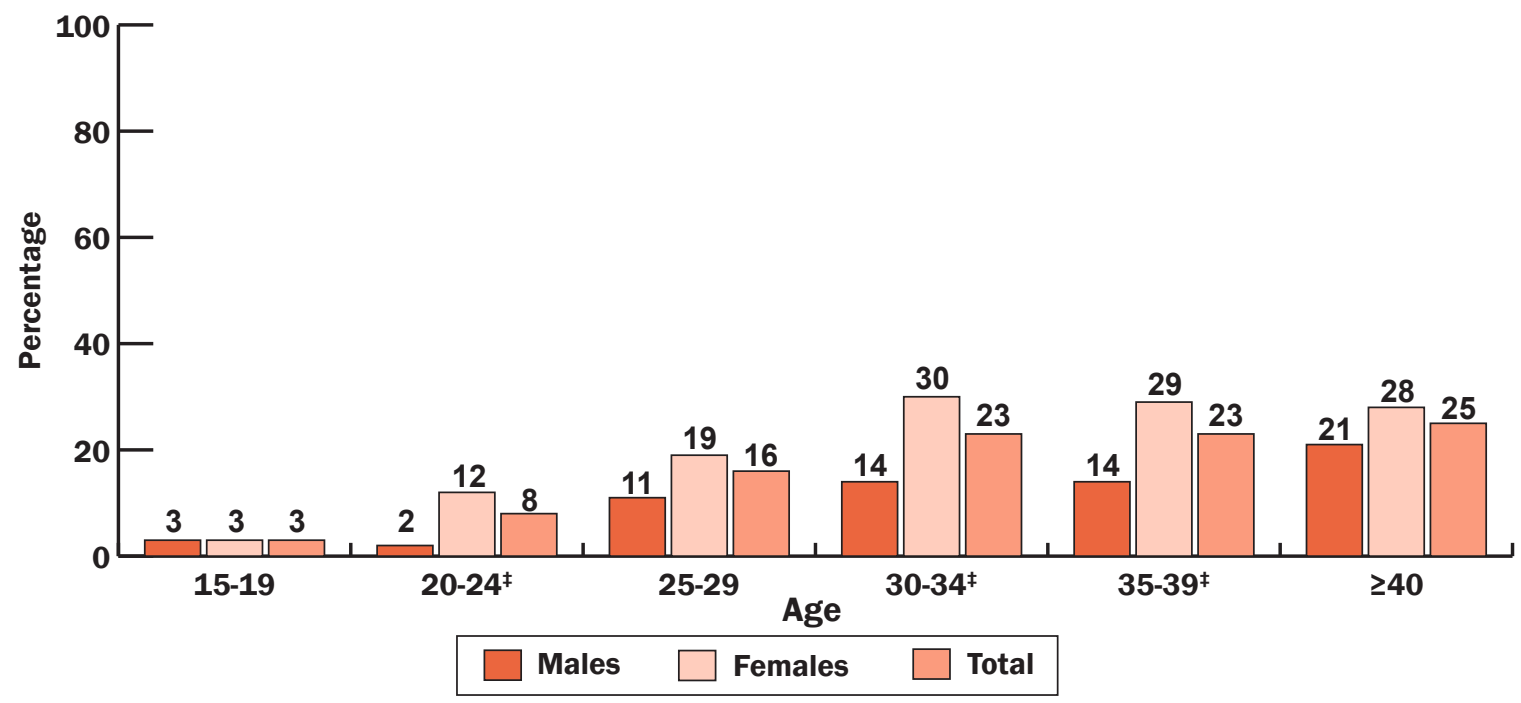

FStatistically different between males and females $(p<0.05)$. 


\section{HIV seroprevalence by demographics}

HIV seroprevalence was significantly higher among urban compared to rural residents (17 percent versus 13 percent); however, HIV prevalence did not vary by wealth status in either urban or rural settings (Figure 32).

Those who were married/cohabiting (17 percent) or divorced/separated (34 percent) were significantly more likely to be HIV infected compared to those never married (6 percent) (Table 9). There was no difference in HIV seroprevalence by education level.

Figure 32 HIV seroprevalence by wealth in urban and rural settings

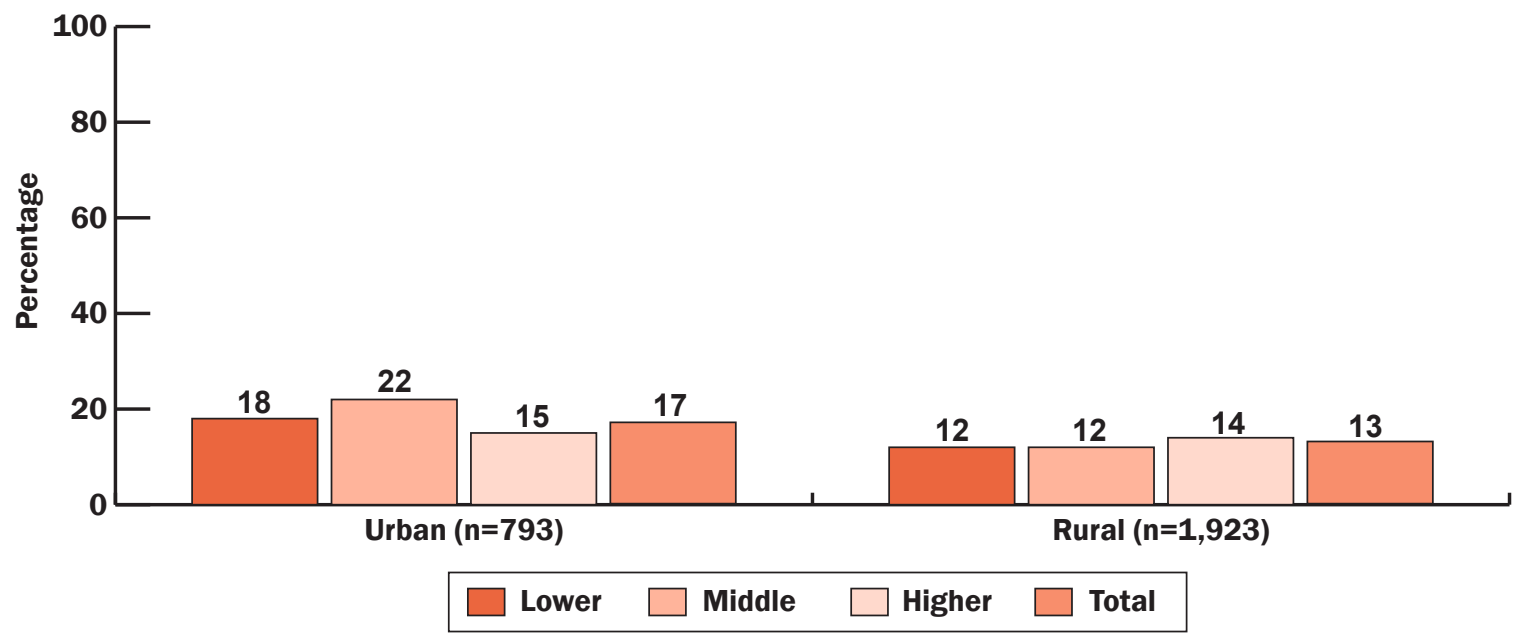

†Statistically significant by urban and rural area $(p<0.05)$.

Table 9 HIV seroprevalence by education and marital status $(n=2,719)$

\begin{tabular}{|lrc|}
\hline & $\%$ & p-value \\
\hline Marital status & & \\
$\quad$ Never married & 6.1 & $<0.001$ \\
Married/Living with partner & 17.3 & \\
Divorced/Wid'd/Separated & 34.2 & \\
Education level & & \\
None/Primary & 15.1 & 0.162 \\
Secondary or higher & 13.2 & \\
\hline
\end{tabular}

\section{Factors associated with HIV infection}

We also examined some risk factors for HIV infection. Among males, HIV infection was associated with higher number of lifetime partners, having sex in the last 12 months, and having a clinical alcohol problem. There was a marginal association with early sexual debut for males, with those who initiated sex before age 15 being less likely to be infected than those who initiated sex after age 15 ( 7 percent versus 13 percent; $p=0.051$ ). There was also no association with number of sex partners in the past 12 months or having paid for sex in the past 12 months for males. For 
females, HIV infection was associated with higher lifetime number of partners, lifetime experience of sexual or physical abuse, and having a clinical alcohol problem. There was no association with age of sexual debut for women.

Table 10 HIV infection by risk behaviors

\begin{tabular}{|c|c|c|c|c|}
\hline & \multicolumn{2}{|c|}{ Males } & \multicolumn{2}{|c|}{ Females } \\
\hline & $\%$ & p-value & $\%$ & p-value \\
\hline Sexual debut & $(n=965)$ & & $(n=1,260)$ & \\
\hline Before age 15 & 7 & 0.051 & 21 & 0.784 \\
\hline At age 15 or greater & 13 & & 20 & \\
\hline Lifetime number of sex partners & $(n=1,079)$ & & $(n=1,183)$ & \\
\hline None & 4 & $<0.001$ & 2 & $<0.001$ \\
\hline One & 6 & & 14 & \\
\hline $2-4$ & 14 & & 21 & \\
\hline 5 or more & 11 & & 49 & \\
\hline Sex in the last 12 months & $(n=1,191)$ & & $(n=1,433)$ & \\
\hline Yes & 12 & $<0.001$ & 18 & 0.131 \\
\hline No & 5 & & 15 & \\
\hline $\begin{array}{l}\text { Number of sex partners in past } 12 \text { months (among } \\
\text { those who had sex) }\end{array}$ & $(n=755)$ & & $(n=959)$ & \\
\hline One & 13 & 0.551 & 18 & 0.330 \\
\hline 2 or more & 11 & & 23 & \\
\hline Paid for sex in past 12 months (Males only) & $(n=785)$ & & & \\
\hline Yes & 16 & 0.238 & - & \\
\hline No & 12 & & & \\
\hline Ever been abused physically or sexually (Females only) & & & $(n=1,461)$ & \\
\hline Yes & & & 21 & $<0.05$ \\
\hline No & - & & 16 & \\
\hline \multicolumn{5}{|l|}{ Has clinical alcohol problem (per CAGE) } \\
\hline Yes & 16 & $<0.001$ & 28 & $<0.001$ \\
\hline No & 8 & & 16 & \\
\hline
\end{tabular}

\section{Unrecognized HIV infection}

Among those who tested positive in this study, we examined whether they had ever previously tested. An individual who was "unaware"' of his/her HIV infection was defined as someone who tested HIV positive at the time of this study and reported no lifetime HIV test or did not receive the results of their most recent HIV test. Unrecognized HIV infection has implications for ongoing HIV transmission as well as obtaining timely care and treatment. There was a high percentage of respondents who tested positive for HIV during this study and were unaware of their HIV infection (males: 41 percent; females: 17 percent; $p<0.001$ ) (Figure 33). There were no significant differences in the proportion unaware of their HIV infection across communities. It should be noted 
that the percentage that is unaware of their HIV infection is the minimum number of unrecognized infections since those who have previously tested and got results may have actually tested negative at their last test and may not know when they became HIV positive.

Figure 33 HIV testing history of persons found to be HIV infected in this study (Males: 122; Females: 256)

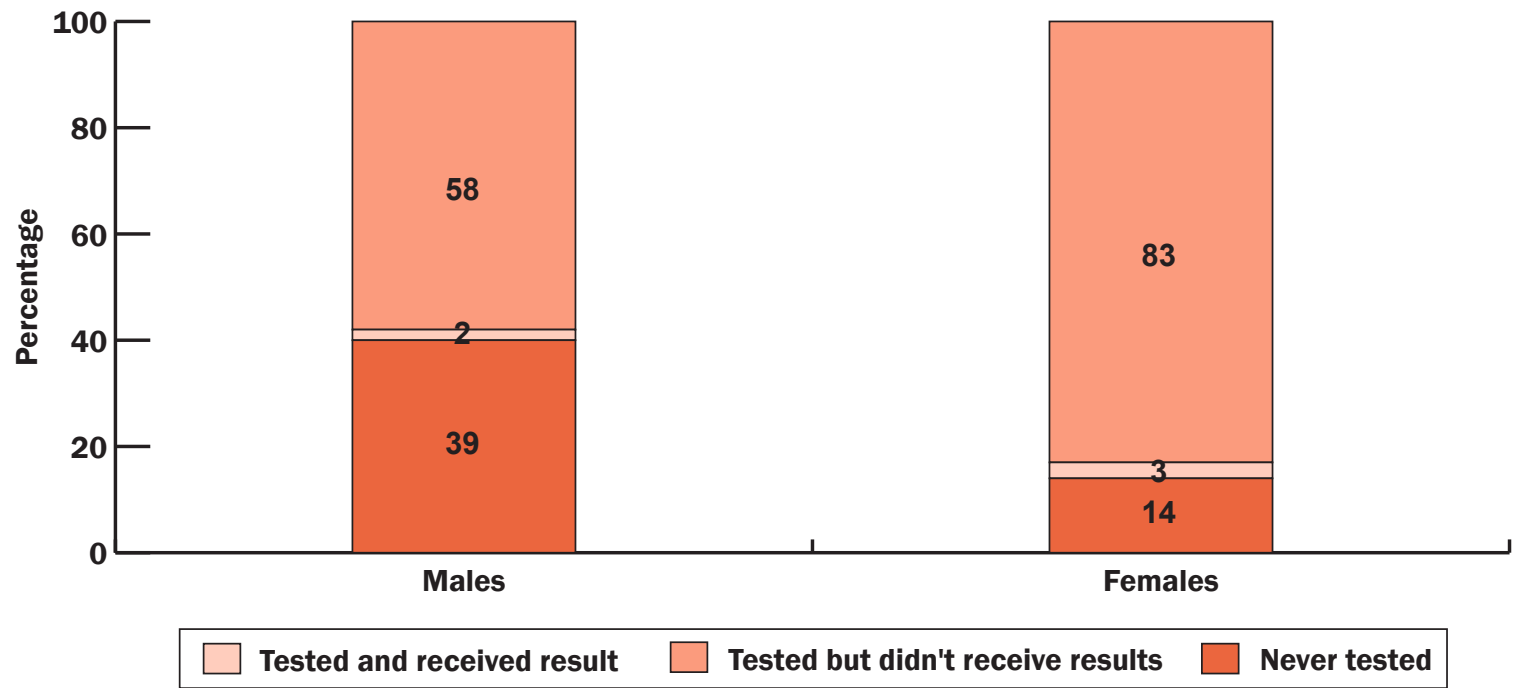

‡Statistically different between males and females $(p<0.05)$.

\section{Focus on Adolescent Girls}

One of the key interventions in the community compacts is the implementation of Safe Spaces for adolescent girls aged 12 to 19 years. The core of the Safe Spaces model is to enable girls to demand and enjoy their human rights, protect themselves from bodily harm, including sexual abuse and preventable diseases, and learn financial and economic skills that will contribute to a more self-reliant adulthood. This section of the report focuses on selected indicators for adolescent girls (aged 15-19 years).

\section{Sexual behaviors of adolescent girls}

Overall, 17 percent of adolescent girls were married or cohabiting (Table 11). Although not significant, Chongwe had the highest percentage of married or cohabiting girls (24 percent) compared to other communities (13-17 percent). Approximately one-half of adolescent girls have had sex in their lifetime. There were no variations by community. Of those who had ever had sex, nearly one out of five (19 percent) indicated they had sex before the age of 15. This is a significantly higher proportion than the older cohort, of which only 10 percent indicated they had sex before the age of 15 (data not shown). Hence, girls today have a younger sexual debut than previous generations. Overall, only 63 percent used condoms at first sex.

Overall, 36 percent of girls reported having sex in the past 12 months. Girls in Chinyunyu (42 percent) and Chongwe (42 percent) were slightly more likely to have had sex in the last 12 months than in Kaniki (31 percent) and Kawama (29 percent) ( $p=0.054)$. Of those who were sexually active, the majority had sex with only one partner in the last 12 months. 
Table 11 Marital status and sexual behaviors of adolescent girls aged 15-19 years

\begin{tabular}{|c|c|c|c|c|c|c|}
\hline & $\begin{array}{c}\text { Total } \\
(n=467) \\
\%\end{array}$ & $\begin{array}{c}\text { Chinyunyu } \\
(\mathrm{n}=93) \\
\%\end{array}$ & $\begin{array}{c}\text { Chongwe } \\
(n=132) \\
\%\end{array}$ & $\begin{array}{c}\text { Kaniki } \\
(n=120) \\
\%\end{array}$ & $\begin{array}{c}\text { Kawama } \\
(n=122) \\
\%\end{array}$ & p-value \\
\hline \multicolumn{7}{|l|}{ Marital status } \\
\hline Never married & 81 & 84 & 74 & 85 & 80 & 0.227 \\
\hline Married or cohabiting & 17 & 13 & 24 & 13 & 17 & \\
\hline $\begin{array}{l}\text { Divorced/Separated/ } \\
\text { Widowed }\end{array}$ & 2 & 3 & 2 & 2 & 3 & \\
\hline Ever had sex & 51 & 58 & 55 & 45 & 47 & 0.141 \\
\hline \multirow[t]{2}{*}{ Had sex before age 15} & $(n=238)$ & $(n=54)$ & $(n=73)$ & $(n=54)$ & $(n=57)$ & 0.078 \\
\hline & 19 & 24 & 10 & 26 & 19 & \\
\hline \multirow[t]{2}{*}{ Condom use at first sex } & $(n=232)$ & $(n=51)$ & $(n=72)$ & $(n=54)$ & $(n=55)$ & 0.599 \\
\hline & 63 & 67 & 57 & 67 & 65 & \\
\hline $\begin{array}{l}\text { Had sex in the last } 12 \\
\text { months }\end{array}$ & 36 & 42 & 42 & 31 & 29 & 0.054 \\
\hline $\begin{array}{l}\text { Number of sex partners in } \\
\text { past } 12 \text { months (among } \\
\text { those who had sex last } 12 \\
\text { months) }\end{array}$ & $(n=165)$ & $(n=39)$ & $(n=56)$ & $(n=36)$ & $(n=34)$ & \\
\hline One & 92 & 87 & 93 & 100 & 85 & 0.107 \\
\hline 2 or more & 8 & 13 & 7 & 0 & 15 & \\
\hline
\end{tabular}

\section{Pregnancy and pregnancy care among adolescent girls}

Among those who were sexually active, only one-half had heard of ways to avoid or delay pregnancy. Those in Chinyunyu (38 percent) and Kaniki (47 percent) were less likely to have heard of them compared to those in Chongwe (70 percent) and Kawama (65 percent). Only 19 percent of sexually active girls were currently using any method to avoid or delay pregnancy. There were no differences by community. The most commonly used forms of methods used to avoid or delay pregnancy were the contraceptive pill (53 percent), injectables (45 percent), and male condoms (37 percent) (data not shown).

One-quarter of adolescent girls reported having given birth and 74 percent of them indicated that their last pregnancy was unintended. 
Table 12 Pregnancy-related characteristics of adolescent girls aged 15-19 years

\begin{tabular}{|c|c|c|c|c|c|c|}
\hline & $\begin{array}{c}\text { Total } \\
(n=467) \\
\%\end{array}$ & $\begin{array}{c}\text { Chinyunyu } \\
\left(\begin{array}{c}n=93) \\
\%\end{array}\right.\end{array}$ & $\begin{array}{c}\text { Chongwe } \\
(n=132) \\
\%\end{array}$ & $\begin{array}{c}\text { Kaniki } \\
(n=120) \\
\%\end{array}$ & $\begin{array}{c}\text { Kawama } \\
(n=122) \\
\%\end{array}$ & p-value \\
\hline $\begin{array}{l}\text { Heard of ways to avoid } \\
\text { pregnancy }\end{array}$ & 41 & 30 & 55 & 33 & 42 & $<0.001$ \\
\hline $\begin{array}{l}\text { Heard of ways to avoid } \\
\text { pregnancy (among sexually } \\
\text { active) }\end{array}$ & $\begin{array}{c}(n=166) \\
56\end{array}$ & $\begin{array}{c}(n=39) \\
38\end{array}$ & $\begin{array}{c}(n=56) \\
70\end{array}$ & $\begin{array}{c}(n=36) \\
47\end{array}$ & $\begin{array}{c}(n=34) \\
65\end{array}$ & $<0.05$ \\
\hline $\begin{array}{l}\text { Ever used any methods } \\
\text { to avoid/delay pregnancy } \\
\text { among those who ever had } \\
\text { sex }\end{array}$ & $\begin{array}{c}(n=238) \\
23.1\end{array}$ & $\begin{array}{c}(n=54) \\
14.8\end{array}$ & $\begin{array}{c}(n=73) \\
21.9\end{array}$ & $\begin{array}{c}(n=54) \\
22.2\end{array}$ & $\begin{array}{c}(n=57) \\
33.3\end{array}$ & 0.137 \\
\hline $\begin{array}{l}\text { Currently using method } \\
\text { to avoid/delay pregnancy } \\
\text { among those who had sex } \\
\text { in last } 12 \text { months }\end{array}$ & $\begin{array}{c}(n=165) \\
18.8\end{array}$ & $\begin{array}{c}(n=39) \\
10.3\end{array}$ & $\begin{array}{c}(n=56) \\
21.4\end{array}$ & $\begin{array}{c}(n=36) \\
19.4\end{array}$ & $\begin{array}{c}(n=34) \\
23.5\end{array}$ & 0.453 \\
\hline Ever given birth & 23 & 19 & 26 & 19 & 26 & 0.369 \\
\hline $\begin{array}{l}\text { Unintended pregnancy (at } \\
\text { last birth) }\end{array}$ & 74 & 83 & 67 & 74 & 77 & 0.570 \\
\hline $\begin{array}{l}\text { Saw anyone for ANC at last } \\
\text { birth }\end{array}$ & 83 & $\mathrm{n} / \mathrm{a}$ & $\mathrm{n} / \mathrm{a}$ & $\mathrm{n} / \mathrm{a}$ & $\mathrm{n} / \mathrm{a}$ & $\mathrm{n} / \mathrm{a}$ \\
\hline $\begin{array}{l}\text { Had }<4 \text { ANC visits (among } \\
\text { those who attended ANC for } \\
\text { last pregnancy) }\end{array}$ & 47 & $\mathrm{n} / \mathrm{a}$ & $\mathrm{n} / \mathrm{a}$ & $\mathrm{n} / \mathrm{a}$ & $\mathrm{n} / \mathrm{a}$ & $\mathrm{n} / \mathrm{a}$ \\
\hline Ever had an abortion & 4 & 2 & 3 & 5 & 6 & 0.508 \\
\hline
\end{tabular}

\section{Physical and sexual abuse among adolescent girls}

Overall, 16 percent of adolescent girls had experienced physical or sexual abuse. It was highest among girls in Kawama (25 percent) compared to other communities (9-15 percent). Abuse in the past 12 months was low. Among those who had ever been abused, only 17 percent sought help (Table 13). 
Table 13 Experience of physical and sexual abuse among adolescent girls aged 15-19 years

\begin{tabular}{|c|c|c|c|c|c|c|}
\hline & $\begin{array}{c}\text { Total } \\
(n=467) \\
\%\end{array}$ & $\begin{array}{c}\text { Chinyunyu } \\
(\mathrm{n}=93) \\
\%\end{array}$ & $\begin{array}{c}\text { Chongwe } \\
(n=132) \\
\%\end{array}$ & $\begin{array}{c}\text { Kaniki } \\
(n=120) \\
\%\end{array}$ & $\begin{array}{c}\text { Kawama } \\
(n=122) \\
\%\end{array}$ & p-value \\
\hline Ever physically abused & 14 & 6 & 14 & 12 & 20 & $<0.05$ \\
\hline Ever sexually abused & 4 & 3 & 2 & 3 & 7 & 0.075 \\
\hline $\begin{array}{l}\text { Ever physically or sexually } \\
\text { abused }\end{array}$ & 16.2 & 8.6 & 15.3 & 13.7 & 25.4 & $<0.01$ \\
\hline $\begin{array}{l}\text { Physically abused last } 12 \\
\text { months }\end{array}$ & 2 & 1 & 3 & 1 & 3 & 0.444 \\
\hline $\begin{array}{l}\text { Sexually abused last } 12 \\
\text { months }\end{array}$ & 1 & 1 & 1 & 0 & 2 & 0.585 \\
\hline $\begin{array}{l}\text { Sought help among those } \\
\text { ever physically or sexually } \\
\text { abused }\end{array}$ & 17 & $\mathrm{n} / \mathrm{a}$ & $\mathrm{n} / \mathrm{a}$ & $\mathrm{n} / \mathrm{a}$ & $\mathrm{n} / \mathrm{a}$ & $\mathrm{n} / \mathrm{a}$ \\
\hline
\end{tabular}




\section{DISCUSSION}

\section{HIV awareness-raising campaigns need to reach rural populations}

The overall comprehensive knowledge results from this baseline survey appear to be better than the results from the 2007 ZDHS. However, Chinyunyu appears to be more in line with the 2007 ZDHS. Perhaps these results reflect that awareness raising campaigns have indeed increased knowledge about HIV since 2007; however, the campaigns may not have reached the more rural areas like Chinyunyu.

Greater coverage of HIV testing is needed for men; high proportion of men unaware of their HIV positive status

While there is great awareness of where one can get tested for HIV, there is a need to increase actual HIV testing, particularly among men. The HIV testing rates in these communities appear to be much better than the national HIV testing rate found in the 2007 ZDHS. This is likely due to recent intensified HIV testing campaigns throughout the country, especially given that a high proportion of those who had ever tested were in fact tested in the last 12 months (approximately two-thirds). This is an encouraging sign of reaching greater numbers of people with HIV testing. However, there is a need to intensify efforts to reach both men and women, particularly women outside of the ANC setting.

In all communities, men were significantly less likely to have tested. Further, a high proportion of those who tested positive in this study were unaware of their HIV positive status (39 percent). For men, there is nothing equivalent to routine opt-out testing within ANC. As such, communities should consider conducting male-focused information and testing campaigns. Further, testing services should be evaluated to determine whether they are meeting the unique needs of men for HIV testing and sexual health. Male-centered/sensitive counseling and testing promotional campaigns should be considered. In addition to communication strategies, collaborating with clinics and clinical technical assistance partners in HIV testing outreach events, special Male Testing Days, or the like should be considered, especially in light of our finding that men are more likely to have been tested at stand-alone centers and mobile clinics. Perhaps efforts should focus on further increasing the utilization of these stand-alone and mobile clinics by making them more male-friendly to increase coverage to the men who are not currently being reached.

\section{Need focus on HIV testing for women outside of ANC}

A high proportion of women are tested through ANC, which explains the higher HIV testing prevalence among women. In fact, HIV testing in ANC is quite high-over 80 percent of all women who attended ANC for their last birth did receive HIV testing and results. While HIV testing within ANC appears to be happening on a fairly consistent basis, there is a need to reach women outside of ANC, particularly in light of the finding that only about three-quarters of women attended ANC at their last pregnancy. Therefore, HIV testing efforts need to focus on improving HIV testing outside of the ANC setting, since HIV testing is indeed occurring within ANC. However, HIV testing within ANC must continue with equal or stronger intensity, as it is the best option for reaching a large proportion of women with HIV testing. 


\section{HIV testing efforts need to be intensified for those with lower income}

We did not find HIV testing to be correlated with urban/rural residency or education, but rather with wealth. Those with greater wealth were more likely to have tested for HIV. While HIV testing is free of charge, perhaps a further exploration of socio-economic and structural barriers to HIV testing may be warranted to tease out the effects of wealth on HIV testing.

\section{Men are more likely to engage in risky sex}

Risky sex (having multiple partners, having a non-regular sex partner, and not using condoms) was more common among males than females, indicating an imminent need for male-centered programs that reduce sexual risk behaviors. About two out of five men had sex with non-regular sex partners in the last 12 months; it was particularly high in Chinyunyu and Kawama, where approximately one-half of men had non-regular sex partners. Of note is that condom use was extremely low with their last non-regular sex partner (only 8 percent). Further, approximately one-quarter of men had two or more sex partners in the last 12 months. Again, Kawama had the highest prevalence of men who had multiple partners in the past year.

Programs must be designed to meet the sexual health needs of men, with messaging specifically tailored to high-risk men. Chinyunyu and Kawama in particular may need intensified efforts to change sexual behavior norms among men.

\section{Improving gender norms must be part of any HIV prevention program}

Inequitable gender norms were prevalent in all communities, but were particularly high in Kaniki and Kawama, where approximately 40-50 percent of men and women supported inequitable gender norms. Programs need to promote gender-equitable norms to both men and women. There is evidence that inequitable gender norms are associated with risky behaviors such as more partner violence and less condom use (Pulerwitz, Michaelis et al. 2010). This study in particular found that inequitable norms were associated with having multiple sex partners. Indeed, it is difficult to tease out whether individuals with poor gender attitudes were more prone to risky behaviors or whether poor gender attitudes are a result of the risky behaviors. However, it is clear that gender inequitable attitudes and risky behaviors are intertwined and must be addressed together in any HIV prevention program. Behavior change programs improving gender norms have been shown to improve HIV and STI risk outcomes (Pulerwitz, Barker et al. 2006, Pulerwitz, Michaelis et al. 2010).

\section{Very high levels of abuse; abused women more likely to be HIV infected}

Our findings show that it was common for women in all provinces to have experienced physical or sexual abuse, with the highest prevalence in Kawama (42 percent). The majority of abuse was physical abuse. Kawama also had the highest proportion of men who believed that wife beating is justified for a variety of reasons (i.e., neglecting children, arguing with husband, or refusing sex with husband). This study found that those who had ever been abused were more likely to be HIV infected, which has been reported in other studies (Campbell, Baty et al. 2008).

Interestingly, in the rural areas, we found that those in the wealthier group were more likely to have been abused compared to those in the lower wealth groups. This is similar to findings from 
2007 ZDHS, where women in the lowest wealth group were the least likely to have ever experienced physical or sexual violence, and there was an increase of abuse with increasing wealth index (ZDHS 2007). This may be because men feel less masculine when women are economically empowered, which results in abuse of the woman. Programs that work to increase women's economic empowerment and equality need to be mindful of this association between greater wealth and violence.

It should be noted that experience of abuse in the last 12 months was lower than what was reported in the 2007 ZDHS. This might indicate that GBV has decreased from 2007 to the present. Zambia passed an anti-gender based violence law in April 2011. Although the data collection for this study started only six months after the law was signed, it is possible that there was a lot of publicity and awareness of GBV leading up to the passage of the law. It will be interesting to see the impact the law has had on GBV in Zambia.

Despite the high levels of abuse experienced by women, very few sought help after the abuse. Of those who did seek help, they were more likely to seek help from family members. This might suggest that COMPACT will need to focus on improving family response to abuse. However, it will also be important to help women know where else they can turn for help. There is a need to strengthen health and psychosocial services for survivors of gender-based violence. Providers at health facilities must be sensitized, and doctors and nurses need to be trained to provide services for survivors (Elson and Keesbury 2010).

Additionally, interventions must promote cooperation between the police victim support unit and health services to improve physical and psychosocial support and care for survivors of gender-based violence. Interventions have been successfully implemented at police stations to provide appropriate, timely, and sensitive services and care for victims, including in Zambia (Keesbury, Zama et al. 2009, Raifman, Askew et al. 2011). Linkages must be developed between local hospitals/health centers and the police and other NGOs or CBOs dealing with GBV in order to facilitate referrals for victims. Services for survivors of GBV should include emergency contraceptive, psychosocial counseling, STI testing and treatment, and post-exposure prophylaxis to prevent HIV. Working with the police and health services may improve the supply side of services for rape victims; however, the survivors must also be willing to report incidents and seek help from police and hospitals. Community sensitization strategies must be conducted through various channels in order to facilitate help-seeking behaviors so that survivors obtain medical attention in a timely manner.

In addition to support for victims, programs also need to focus on the prevention of GBV. Programs need to work with men to change social norms and perceptions related to GBV.

\section{Fairly high level of acceptance of people with HIV though there is perception that stigma may be high}

While the majority of respondents (over 84 percent) were fine with interactions with persons infected with HIV (i.e., buying vegetables from an infected person, allowing female HIV-infected teacher to teach, and taking care of HIV infected family member), a high proportion were not fine with others knowing if a family member was infected (59 percent). It is interesting to note that while the respondents themselves did not hold stigmatizing attitudes towards people with HIV, there seems to be the perception (or misperception) that there is a high level of stigma in the community and hence they would want to keep it a secret if a family member had HIV. Stigma 
reduction campaigns perhaps also need to address this misconception that people are not accepting of people with HIV.

\section{Unintended pregnancies were high}

The use of contraceptives was low among sexually active women in all communities and unintended pregnancies were high (ranging from 56-63 percent of last pregnancies being unintended). Given that the majority of women did not report having challenges in obtaining contraceptives and that the approximately three-quarters of sexually active women knew about methods to avoid/delay pregnancy, perhaps the challenge is in the actual use of the contraceptives, such as negotiating for the use of it in a relationship. Unintended pregnancies were the most common among younger and unmarried women. One-quarter of adolescent girls had previously given birth, and their unintended pregnancy prevalence was extremely high at 74 percent. It is possible that adolescent girls are unlikely to access family planning services for fear of judgment by health care providers. Unintended pregnancies were also the highest among the urban poor. It will be important for programs to create youth friendly centers where younger people feel comfortable accessing family planning services, particularly targeting the poor in urban areas.

Lastly, awareness of and access to emergency contraceptive need to be improved. The majority of respondents had never heard of emergency contraception, which is a key component of the Zambia national family planning method mix. Emergency contraceptive use could lower the rates of unintended pregnancies.

\section{Need for improvement in ANC coverage}

Attendance of at least one ANC visit for a pregnancy was low, particularly in the rural community of Chinyunyu (only 63 percent). Further, of those who attended ANC, only two out of five completed at least the four recommended ANC visits. There is an urgent need to increase ANC coverage in all communities and ensure that women attend at least four ANC visits. Additionally, Kaniki and Kawama had a high proportion of women who gave birth to a live child that later diedit was as high as 25 percent in Kaniki. Unfortunately we do not have information on the age and causes of death. The high proportion of deaths urgently needs further investigation in these two communities.

\section{Alcohol risk reduction is needed}

The data in this report show that having a clinically significant alcohol problem was highly prevalent among men (approximately one-third), particularly among men over 20 years of age. Alcohol inhibits judgment and is a risk factor for sexual transmission of HIV. People under the influence are less likely to use a condom during sex and are more likely to engage in sex with a casual partner, whose status is unknown to them (Cook and Clark 2005, Kalichman, Simbayi et al. 2007). Indeed, in this study, we found that those with clinically significant alcohol problems (both male and female) were more likely to be HIV infected. As part of a comprehensive risk reduction strategy during HIV counseling and testing, counselors should be given the appropriate tools to evaluate alcohol use such as the CAGE tool (Ewing 1984), and to recommend strategies for reducing risk related to alcohol abuse.

Women also had clinically significant alcohol problems particularly among those 30-34 years of age (20 percent). Of note, we found that women who abused alcohol were twice as likely to 
have ever experienced physical or sexual abuse. The direction of this association is unknown (i.e., whether women turn to alcohol because of their abuse or whether the abuse is a result of their alcohol problem). Regardless of the causal pathway, it is important to address both of these issues simultaneously.

\section{HIV prevalence remains high and reflects gender disparities}

The HIV seroprevalence was high in this study (10 percent in men and 17 percent in women) but is similar to the seroprevalence found in the 2007 ZDHS. The difference in HIV seroprevalence between women and men is particularly striking among 20-24 year olds; young women are six times more likely to be HIV infected than young men (12 percent versus 2 percent). This may reflect earlier sexual debut by girls, often with partners who on average are at least five years older and may already have had multiple sexual partners. (Kandala, Ji et al. 2008) The difference is again striking among those who are 30-39 years of age, where women are twice as likely to be HIV infected (males: 14 percent and females: 29-30 percent). This may reflect gender inequalities in relationships where the woman is unable to negotiate safer sex or refuse sex to her husband.

\section{Girls are initiating sex at an earlier age than older generations}

We found that approximately 20 percent of girls aged 15-19 years in this study had sex before the age of 15, and this was significantly higher than the older cohorts, in which 10 percent had sex before the age of 15 . Therefore, it seems that adolescent girls today are engaging in sex at an earlier age than older cohorts. We also found that those who engaged in sex before age 15 were also significantly more likely to have ever been physically and sexually abused. Because early sexual debut is significantly associated with risky sex, pregnancy, and increased HIV and STI risk (Duncan, Tibaux et al. 1990, Greenberg, Magder et al. 1992, Laga, Schwartlander et al. 2001, Pettifor, van der Straten et al. 2004, Kaestle, Halpern et al. 2005), interventions should include life skills and HIV prevention programs in schools and out of school. Programs should also promote positive communication with children on sexuality and HIV, and improve/provide youthfriendly sexual health services.

\section{Concluding Remarks}

This study determined baseline levels of key indicators related to HIV, sexual behaviors, gender-based violence, alcohol abuse, and reproductive health. These baseline levels will be used as part of the evaluation in measuring the effect of the COMPACT program. These baseline measures will be compared with midline and endline levels to assess COMPACT's programmatic success. Additionally, the baseline findings provided critical insights into key areas for interventions in these four communities and highlighted variability in the populations across the communities and between males and females that provide valuable guidance for programming. 


\section{APPENDIX 1: EXAMPLES OF EVIDENCE-BASED INTER- VENTIONS UTILIZED BY COMPACT}

\begin{tabular}{|ll|}
\hline Clinical/Biomedical Interventions & Structural Interventions \\
\hline Increasing HIV testing and counseling (HTC) & Promoting income generating activities \\
Increasing condom promotion and supply & Reducing vulnerability of adolescent girls \\
Promoting voluntary male medical circumcision & Preventing and responding to sexual violence \\
$\begin{array}{l}\text { Prevention of mother-to-child transmission } \\
\text { Family planning counseling }\end{array}$ & Addressing alcohol abuse \\
$\begin{array}{l}\text { Behavior change communication or information, } \\
\text { education, communication interventions }\end{array}$ & Fostering gender equality \\
$\begin{array}{l}\text { Positive living interventions, including prevention } \\
\text { with positives }\end{array}$ & \\
\hline
\end{tabular}




\section{APPENDIX 2: ILLUSTRATIVE BENCHMARKS FOR A COM- MUNITY COMPACT}

\begin{tabular}{|c|c|c|c|}
\hline \multirow[t]{2}{*}{ Benchmark categories } & \multicolumn{3}{|c|}{ Illustrative Intervention and Benchmarks } \\
\hline & $\begin{array}{l}\text { Intervention } 1 \\
\text { Men-to-men alcohol use } \\
\text { reduction program }\end{array}$ & $\begin{array}{l}\text { Intervention } 2 \\
\text { Peer promotion of } \\
\text { positive living } \\
\text { strategies }\end{array}$ & $\begin{array}{l}\text { Intervention } 3 \\
\text { Establishment of safe } \\
\text { spaces groups for } \\
\text { adolescent girls }\end{array}$ \\
\hline $\begin{array}{l}\text { Benchmark 1: Community } \\
\text { mobilization activities } \\
\text { achieved }\end{array}$ & $\begin{array}{l}500 \text { men attend informa- } \\
\text { tional "campfires" }\end{array}$ & $\begin{array}{l}3 \text { new PLHA/post-test } \\
\text { clubs established }\end{array}$ & $\begin{array}{l}200 \text { girls enrolled in } \\
\text { safe spaces groups }\end{array}$ \\
\hline $\begin{array}{l}\text { Benchmark } 2 \text { : Community } \\
\text { mobilization activities } \\
\text { achieved }\end{array}$ & $\begin{array}{l}100 \text { men sign pledge } \\
\text { to end drunkenness }\end{array}$ & $\begin{array}{l}100 \text { PLHA trained to } \\
\text { promote ABC }\end{array}$ & $\begin{array}{l}95 \% \text { of girls attend } \\
3+\text { sessions }\end{array}$ \\
\hline $\begin{array}{l}\text { Benchmark 3: Service- } \\
\text { seeking behavior targets } \\
\text { achieved }\end{array}$ & $\begin{array}{l}95 \% \text { of men signing } \\
\text { pledge receive HCT }\end{array}$ & $\begin{array}{l}\text { 1,000 PLHA reached by } \\
\text { peer promoters }\end{array}$ & $\begin{array}{l}\text { 95\% of girls receive } \\
\text { HCT }\end{array}$ \\
\hline $\begin{array}{l}\text { Benchmark 4: Intermediate } \\
\text { outcomes }\end{array}$ & $\begin{array}{l}90 \% \text { of men's partners } \\
\text { receive HCT }\end{array}$ & $\begin{array}{l}\text { 95\% of trained PLHA } \\
\text { receive HCT }\end{array}$ & $\begin{array}{l}90 \% \text { of girls complet- } \\
\text { ing current grade }\end{array}$ \\
\hline $\begin{array}{l}\text { Benchmark 5: Ultimate } \\
\text { community-wide outcome }\end{array}$ & \multicolumn{3}{|c|}{ Reduction in high risk intercourse } \\
\hline
\end{tabular}




\section{APPENDIX 3: SOCIO-DEMOGRAPHIC CHARACTERISTICS BY COMMUNITY AND SEX}

\begin{tabular}{|c|c|c|c|c|c|c|c|}
\hline 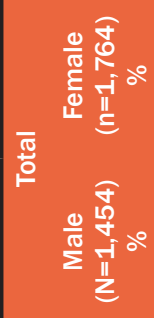 & 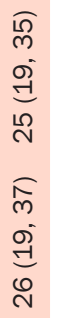 & 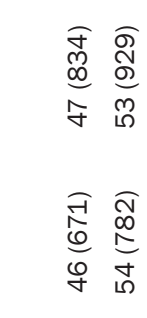 & 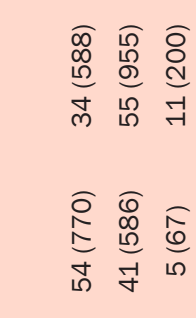 & 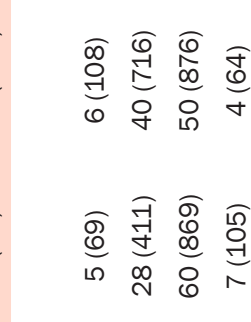 & 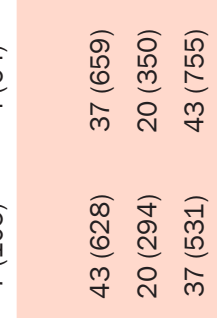 & 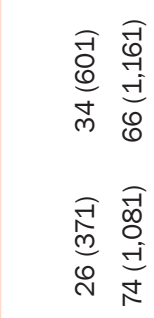 & 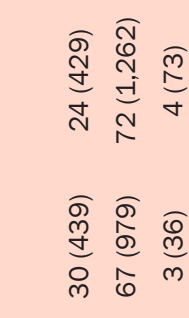 \\
\hline 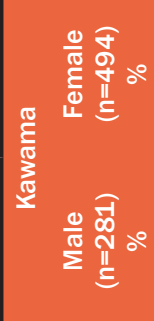 & 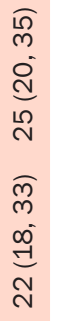 & 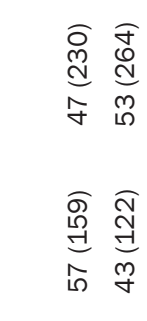 & 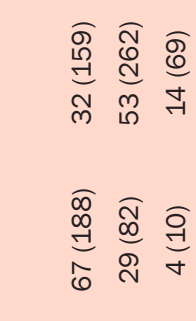 & 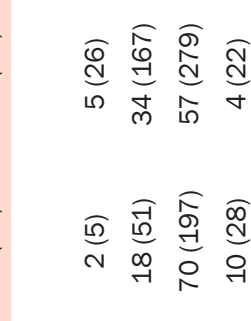 & 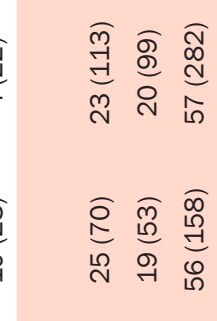 & 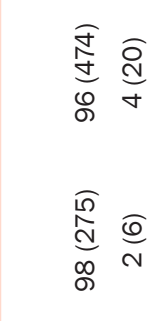 & 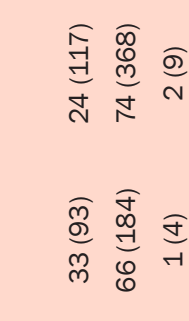 \\
\hline 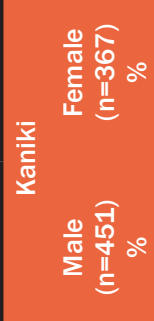 & 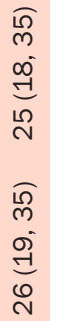 & 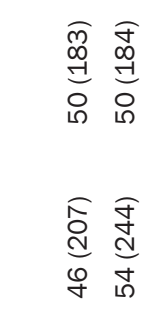 & 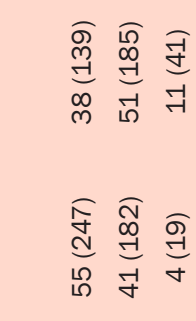 & 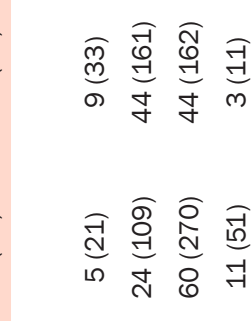 & 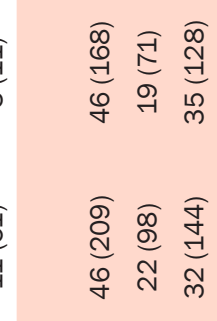 & 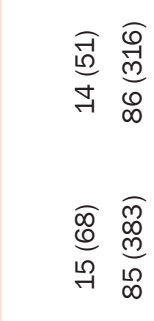 & 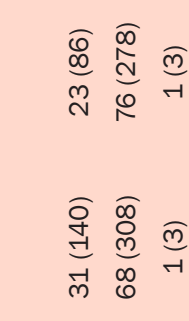 \\
\hline 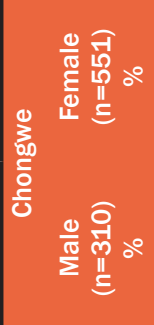 & 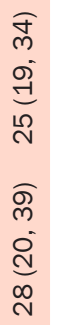 & 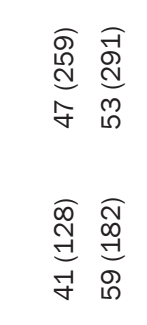 & 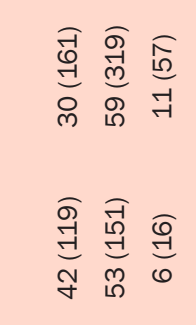 & 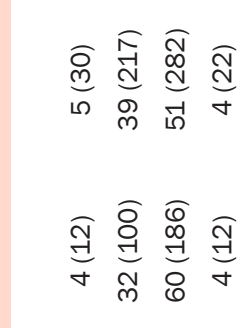 & 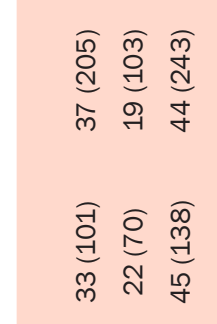 & 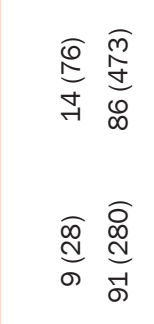 & 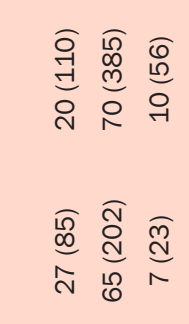 \\
\hline 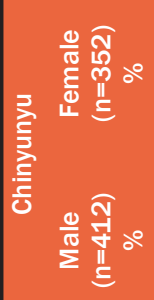 & 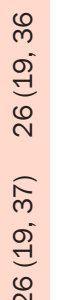 & 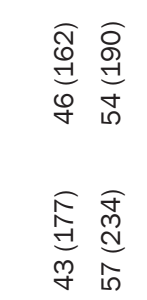 & 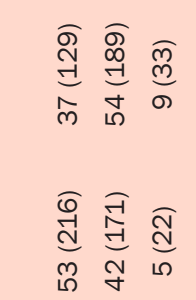 & 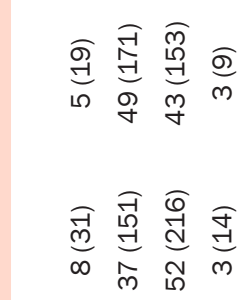 & 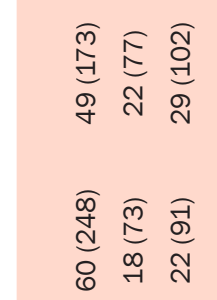 & 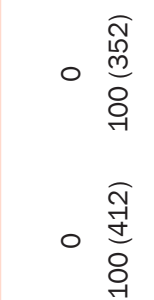 & 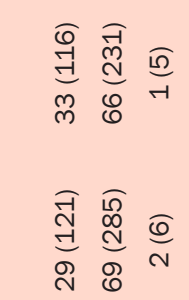 \\
\hline 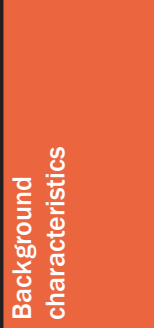 & 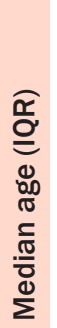 & 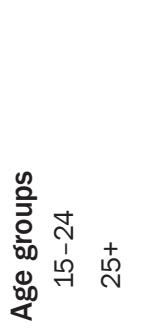 & 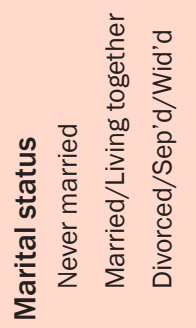 & 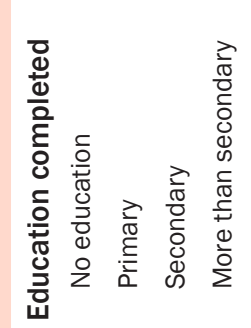 & 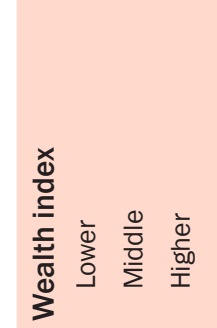 & 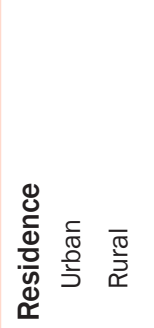 & 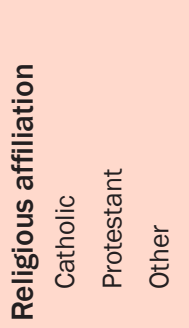 \\
\hline
\end{tabular}




\section{APPENDIX 4: KNOWLEDGE ABOUT HIV AND AIDS}

\begin{tabular}{|c|c|c|c|c|c|c|c|c|}
\hline 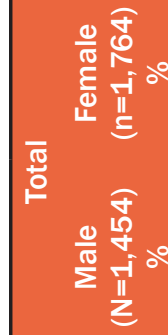 & 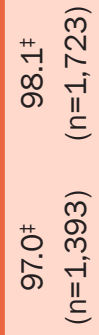 & & 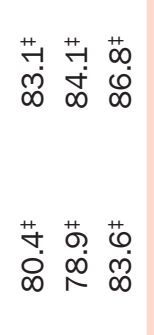 & $\begin{array}{l}m \\
\dot{\infty}\end{array}$ & & $\begin{array}{ll}0 & \\
0 & 0 \\
\infty & 0 \\
\sim & \infty\end{array}$ & $\begin{array}{l}\stackrel{+}{-} \\
0 \\
\infty\end{array}$ & \\
\hline 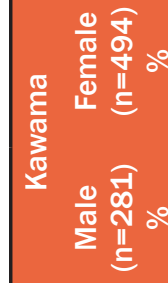 & 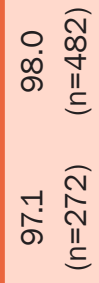 & & 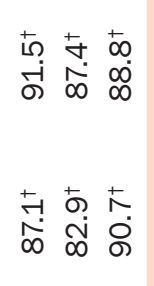 & $\begin{array}{l}\dot{0} \\
\dot{\square}\end{array}$ & & 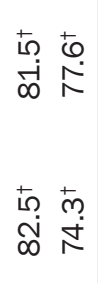 & 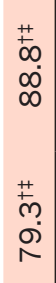 & \\
\hline 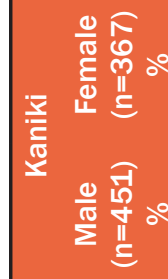 & 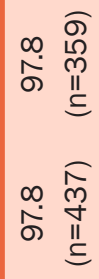 & & 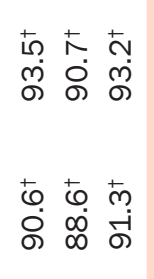 & $\begin{array}{l}+ \\
\infty \\
\infty \\
\infty \\
\\
+ \\
+ \\
\infty \\
\infty\end{array}$ & & 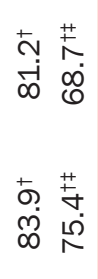 & $\begin{array}{l}+ \\
m \\
\infty \\
\infty \\
\infty\end{array}$ & 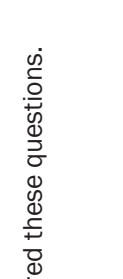 \\
\hline 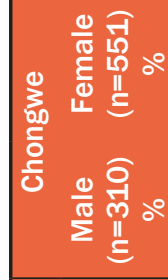 & 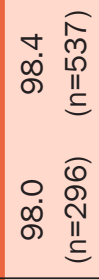 & & 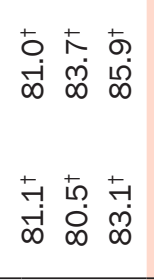 & $\begin{array}{l}+ \\
\infty \\
\infty \\
\infty \\
\infty\end{array}$ & & $\begin{array}{ll}+ & + \\
\infty & 0 \\
\stackrel{1}{\sim} & \infty \\
& \infty \\
& \\
+\infty & \\
\infty & \infty \\
\infty & 0 \\
\sim & \infty\end{array}$ & 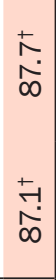 & 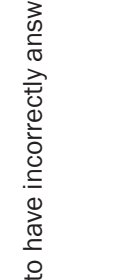 \\
\hline 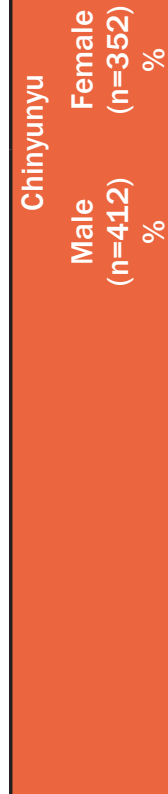 & 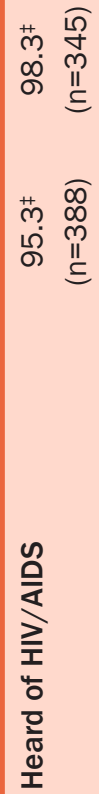 & 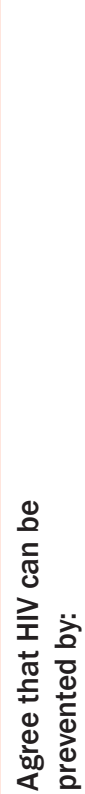 & 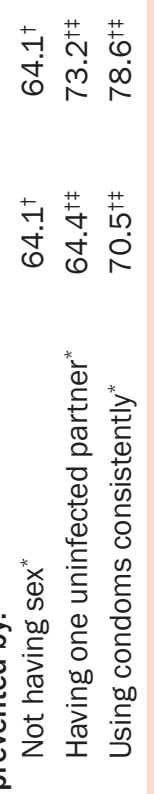 & 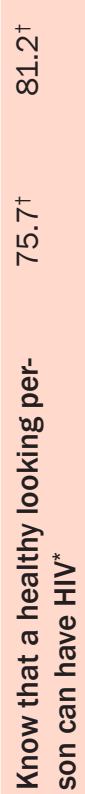 & 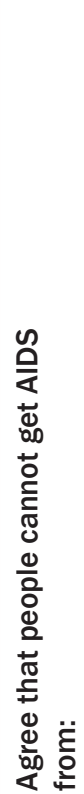 & 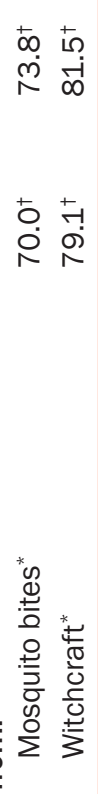 & 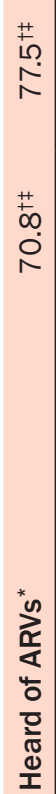 & 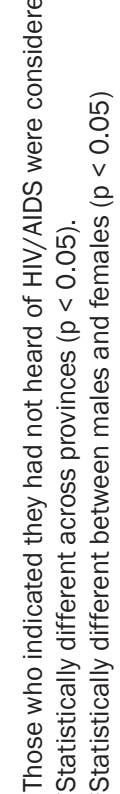 \\
\hline
\end{tabular}




\section{APPENDIX 5: HIV TESTING}

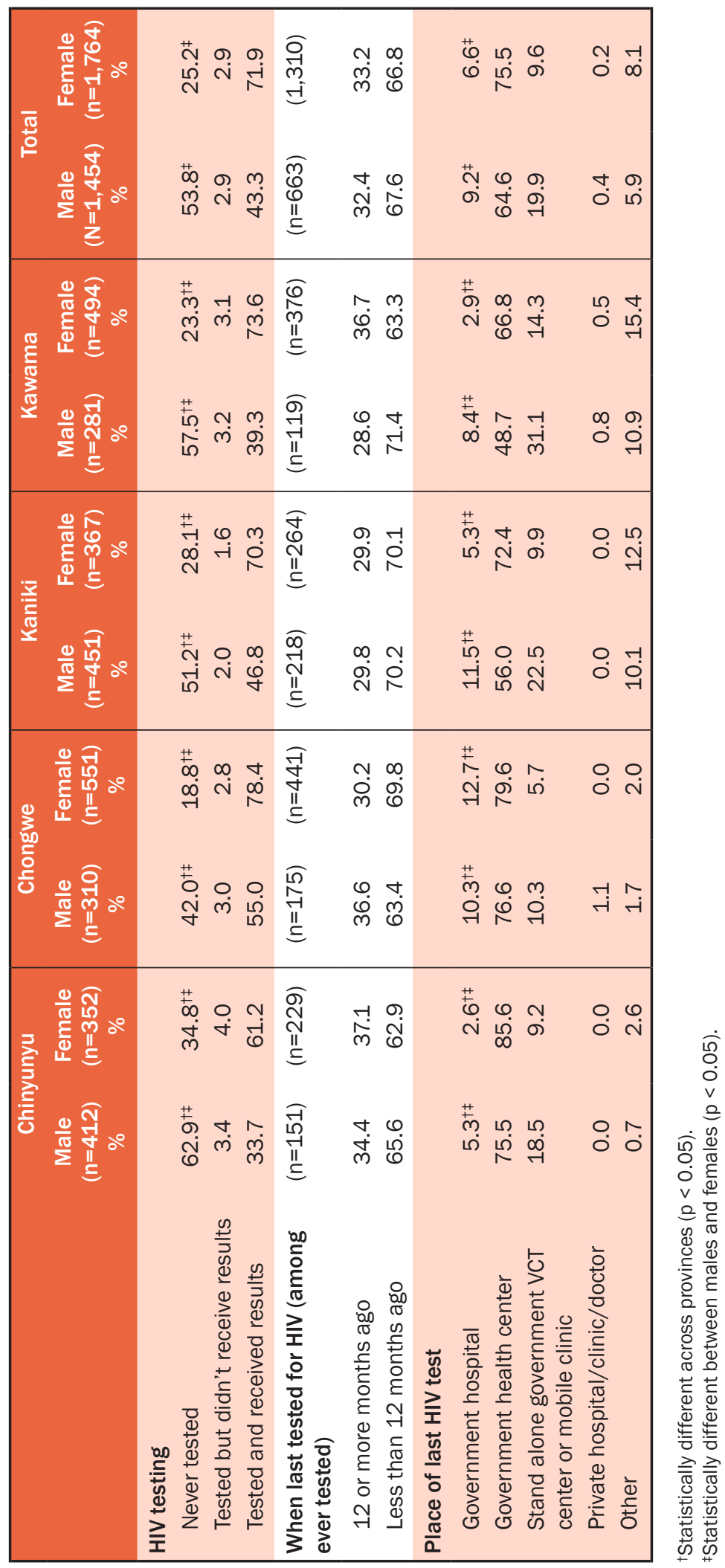




\section{REFERENCES}

Campbell, J. C. et al. 2008. "The intersection of intimate partner violence against women and HIV/ AIDS: a review," Int J Inj Contr Saf Promot 15(4): 221-231.

Central Statistical Office, Ministry of Health, Zambia. 2007. Zambia Demographic and Health Survey 2007. Calverton, Maryland: Tropical Diseases Research Centre, University of Zambia and Macro International Inc.

Cook, R. L. and D. B. Clark. 2005. "Is there an association between alcohol consumption and sexually transmitted diseases? A systematic review," Sex Transm Dis 32(3): 156-164.

Duncan, M. E. et al. 1990. "First coitus before menarche and risk of sexually transmitted disease," Lancet 335(8685): 338-340.

Elson, L. and J. Keesbury. 2010. :PEPFAR special initiative on sexual and gender-based violence: Baseline report." Lusaka: Population Council.

Ewing, J. A. 1984. “Detecting alcoholism. The CAGE questionnaire," JAMA 252(14): 1905-1907.

Greenberg, J., L. Magder and S. Aral. 1992. "Age at first coitus. A marker for risky sexual behavior in women," Sex Transm Dis 19(6): 331-334.

Kaestle, C. E. et al. 2005. "Young age at first sexual intercourse and sexually transmitted infections in adolescents and young adults," Am J Epidemiol 161(8): 774-780.

Kalichman, S. C. et al. 2007. "Alcohol use and sexual risks for HIV/AIDS in sub-Saharan Africa: systematic review of empirical findings," Prev Sci 8(2): 141-151.

Kandala, N. B. et al. 2008. "The epidemiology of HIV infection in Zambia," AIDS Care 20(7): 812-819.

Kayeyi, N. et al. 2012. "Decline in HIV prevalence among young women in Zambia: National-level estimates of trends mask geographical and socio-demographic differences," PLOS One 7(4): e33652.

Keesbury, J., M. Zama, and S. Shreeniwas. 2009. "The Copperbelt Model of Integrated Care for Survivors of Rape and Defilement: Testing the feasibility of police provision of emergency contraceptive pills." Lusaka: Population Council.

Laga, M. et al. 2001. "To stem HIV in Africa, prevent transmission to young women," AIDS 15(7): 931-934.

National AIDS Council, Ministry of Health, Zambia. 2009. "Zambia: HIV prevention response and modes of transmission analysis." Geneva: UNAIDS and World Bank Global HIV/AIDS Program.

Pettifor, A. E. et al. 2004. "Early age of first sex: a risk factor for HIV infection among women in Zimbabwe," AIDS 18(10): 1435-1442.

Pulerwitz, J. and G. Barker. 2008. "Measuring attitudes toward gender norms among young men in Brazil: Development and psychometric evaluation of the GEM scale," Men \& Maculinities 10: 322-338.

Pulerwitz, J. et al. 2006. "Promoting more gender-equitable norms and behaviors among young men as an HIV/AIDS prevention strategy," Horizons Final Report. Washington, DC: Population Council.

Pulerwitz, J. et al. 2010. "Addressing gender dynamics and engaging men in HIV programs: lessons learned from Horizons research," Public Health Rep 125(2): 282-292.

Raifman, S. et al. 2011. "The prevention and management of HIV and sexual and gender-based violence: Responding to the needs of survivors and those-at-risk.: Washington, DC: Population Council.

WHO. 2000. Violence Against Women Instrument from the WHO Multi-country Study on Women's Health and Domestic Violence Against Women. Geneva: World Health Organization. 
Baseline Evaluation Report a 57 
Population Council/Zambia

P/Bag RW 319, Lusaka, 10101

Plot 4108, Mwinilunga Road,

Sunningdale, Kabulonga

Lusaka, Zambia

www.popcouncil.org 